Universidade de Brasília

Faculdade de Tecnologia

Departamento de Engenharia Mecânica

\title{
ESTUDO DO FATOR DE INDUÇÃO AXIAL EM TURBINAS DE EIXO HORIZONTAL
}

Rafael Castilho Faria Mendes

Orientador: Taygoara Felamingo de Oliveira

Dissertação de Mestrado em Ciências Mecânicas

Publicação: ENM.DM-230 A/2015

Brasília-DF: 07/2015 
Universidade de Brasília

Faculdade de Tecnologia

Departamento de Engenharia Mecânica

\title{
ESTUDO DO FATOR DE INDUÇÃO AXIAL EM TURBINAS DE EIXO HORIZONTAL
}

\author{
Rafael Castilho Faria Mendes
}

DISSERTAÇÃO SUBMETIDA AO DEPARTAMENTO DE ENGENHARIA MECÂNICA DA FACULDADE DE TECNOLOGIA DA UNIVERSIDADE DE BRASÍLIA COMO PARTE DOS REQUISITOS NECESSÁRIOS PARA OBTENÇÃO DO GRAU DE MESTRE EM CIÊNCIAS MECÂNICAS.

Aprovada por:

Taygoara Felamingo de Oliveira, Prof. Dr., UnB (Orientador)

Antonio Cesar Pinho Brasil Junior, Prof. Dr., UnB (Examinador interno)

André Luiz Amarante Mesquista, Prof. Dr., UFPA (Examinador externo)

Marcus Vinicius Girão de Morais, Prof. Dr., UnB (Examinador suplente)

Brasília, 9 de julho de 2015. 
FICHA CATALOGRÁFICA

\author{
Rafael Castilho Faria Mendes \\ ESTUDO DO FATOR DE INDUÇÃO AXIAL EM TURBINAS DE EIXO \\ HORIZONTAL/ Rafael Castilho Faria Mendes. - Brasil, 2015- \\ 62 p. : il. (algumas color.) ; $30 \mathrm{~cm}$. \\ Orientador: Taygoara Felamingo de Oliveira \\ Dissertação (mestrado) - Universidade de Brasília - UnB \\ Faculdade de Tecnologia \\ Programa de Pós-Graduação em Ciências Mecânicas, 2015. \\ 1. fator de indução axial. 2. velocidade de ponta de pá critica. I. Orientador. II. \\ Universidade de Brasília. III. Faculdade de Tecnologia. IV. Estudo do fator de \\ indução axil em turbinas de eixo horizontal
}

\title{
REFERÊNCIA BIBLIOGRÁFICA
}

Mendes, R. C. F. (2015). ESTUDO DO FATOR DE INDUÇÃO AXIAL EM TURBINAS DE EIXO HORIZONTAL. Dissertação de Mestrado em Ciências Mecânicas, Publicação ENM.DM-230 A/2015, Departamento de Engenharia Mecânica, Universidade de Brasília, Brasília, DF, 62p.

\section{CESSÃO DE DIREITOS}

NOME DO AUTOR: Rafael Castilho Faria Mendes.

TÍTULO DA DISSERTAÇÃO DE MESTRADO: ESTUDO DO FATOR DE INDUÇÃO AXIAL EM TURBINAS DE EIXO HORIZONTAL.

GRAU/ANO: Mestre/2015.

É concedida à Universidade de Brasília permissão para reproduzir cópias desta dissertação de mestrado e para emprestar ou vender tais cópias somente para propósitos acadêmicos e científicos. O autor reserva outros direitos de publicação e nenhuma parte desta dissertação de mestrado pode ser reproduzida sem a autorização por escrito do autor.

Rafael Castilho Faria Mendes

SQSW 103 bloco E, apt 111 - Sudoeste

70670-305, Brasília, DF, Brasil

rafael.cfmendes@gmail.com 
Dedico este trabalho ao meu pai, Francisco, que continua olhando por mim lá de cima. 


\section{Agradecimentos}

À minha e Mãe e meus irmãos pelo carinho e apoio incondicional em minhas escolhas.

À minha namorada, Luiza, pelo amor e companheirismo em toda minha jornada.

Ao meu orientador, professor Taygoara, pela disponibilidade, paciência e deveras empolgação pela ciência.

Ao professor Brasil pela sua atenção e colaboração em meu trabalho.

Aos meus colegas de laboratório Nela, Paulo, Aramis, Ramsay, Francis, Vinícius, Eugênia e Miguel pelo agradável convívio diário, me proporcionando ótimas discussões acadêmicas.

Ao Conselho Nacional de Desenvolvimento Científico e Tecnológico (CNPQ) e ELETRONORTE pelo suporte financeiro dado durante a execução do trabalho. 


\section{Resumo}

O principal objetivo deste trabalho é investigar o comportamento do fator de indução axial, ao longo do escoamento de uma turbina de eixo horizontal, utilizando a teoria clássica de aerodinâmica de rotores e simulações numéricas do tipo RANS com o modelo de turbulência $S S T$. O estudo foi realizado para uma turbina eólica de $500 \mathrm{~W}$. As simulações foram validadas utilizando dados experimentais do coeficiente de potência $(C p)$ obtidos em ensaios em túnel de vento aberto. Foi observado que fator de indução não é uma variável integral do escoamento, sendo ele uma função das coordenadas espaciais do sistema. Assumiu-se uma equação linear como modelo o fator de indução em cada plano a montante da turbina. Uma curva do coeficiente de potência máximo para essa turbina foi calculada aplicando o modelo do fator de indução proposto e teoria de Glauert para máximo valor de $C p$. Por meio dessa curva, foi introduzido o conceito de velocidade de ponta de pá crítica, sendo descrita como uma condição operacional em que existe um ponto de operação que a turbina está girando sem nenhuma potência.

Palavras-chaves: fator de indução axial. velocidade de ponta de pá critica. turbinas de eixo horizontal. estol. 


\section{Abstract}

The main objective of this work is to investigate the axial induction factor behavior, along the flow of a horizontal axis turbine, using the classical theory of aerodynamics rotors and numerical simulations RANS and turbulence model SST. The study was conducted for a $500 \mathrm{~W}$ wind turbine. The simulations were validated using experimental data of power coefficient that was obtained in open wind tunnel tests. It was observed that induction factor is not an integral flow variable, it is a space coordinates function. It was assumed a linear equation to model the induction factor in each plane upstream of the turbine. A curve of the maximum power coefficient, for this turbine, was calculated by applying the induction factor model proposed and Glauert theory to $C p$ maximum . By this curve, it was introduced the concept of critical tip speed ratio, which is described as an operating condition point that there is some rotation, but the power coefficient is null.

Key-words: axial induction factor. critical tip speed ratio . horizontal axis turbines. stall. 


\section{Lista de ilustrações}

Figura 1 - Fotos da turbina hidrocinética Geração 1, desenvolvida pela UnB e instalada na cidade de Correntina BA. . . . . . . . . . . . 2

Figura 2 - Foto da turbina hidrocinética Geração 2. . . . . . . . . . . . . . 3

Figura 3 - Modelo geométrio da turbina hidrocinética Geração 3 . . . . . . . . . . . 3

Figura 4 - Ilustração do escoamento através do disco atuador. . . . . . . . . . . . 6

Figura 5 - Representação da velocidade tangencial induzida a jusante da turbina. 9

Figura 6 - Representação do dico utilizado para o cálculo da potência. . . . . . . . 10

Figura 7 - Representação dos triângulos de velocidade na pá na condição de antes do estol. Os ângulos presentes são: $\alpha=$ ângulo de ataque; $\theta_{p}=$ ângulo de passo; $\varphi=$ ângulo relativo do vento. . . . . . . . . . . 12

Figura 8 - Coeficiente de potência em função do $\lambda$, considerando efeitos de rotação no escoamento. Curva pontilhada: limite de Betz; curva cheia: metodologia proposta por Glauert. . . . . . . . . . . . . . 13

Figura 9 - Turbina utilizada nos ensaios de túnel de vento. Marca: IstaBreeze i-500. 15

Figura 10 - Sistemas de colmeias utilizadas para homogenizar o escoamento. . . . . 16

Figura 11 - Planos e coordenadas utilizados para medir os perfis de velocidade do escoamento. ......................... 17

Figura 12 - Sistema de posicionamento do tubo de pitot. . . . . . . . . . . . . . 18

Figura 13 - Projeto da bancada de calibração do gerador. . . . . . . . . . . . . . . 19

Figura 14 - Foto da bancada de calibração do gerador elétrico. . . . . . . . . . . . . 19

Figura 15 - Circuito utilizado na calibração do gerador. . . . . . . . . . . . . . . 20

Figura 16 - Modulação por largura de pulso (PWM) . . . . . . . . . . . . . . . 21

Figura 17 - Esquemático de controle e aquisição de dados utilizando o microprocessador Arduino. . . . . . . . . . . . . . . . . . 22

Figura 18 - Montagem experimental do ensaio da turbina em túnel de vento. . . . . 24

Figura 19 - Esquema elétrico do controle da turbina . . . . . . . . . . . . . . . 24

Figura 20 - Diagrama de bloco do controle PID da turbina . . . . . . . . . . 25

Figura 21 - Metodologia experimental para medição da geometria da pá. . . . . . . 28

Figura 22 - Modelo da pá desenhado em SolidWorks. . . . . . . . . . . . . . . . . 29

Figura 23 - Modelo completo da turbina. . . . . . . . . . . . . . . . . . . . . 29

Figura 24 - Domínios utilizados para geração da malha. A região cilíndrica representa o domínio rotativo e o prisma externo representa a região sem rotação. . . . . . . . . . . . . . . . . . . .

Figura 25 - Condições de contorno aplicadas na simulação numérica, sendo a região inlet a seção de entrada do escoamento e a outlet a seção saída. ... . 30

Figura 26 - Refinamento da malha ao longo dos domínios. . . . . . . . . . . . . . . 32 
Figura 27 - Representação da malha na parede do rotor. . . . . . . . . . . . . . . . 32

Figura 28 - Coordenadas utilizadas no cálculo do fator de indução axial. ..... 34

Figura 29 - Velocidade nas seções de ensaio do túnel de vento aberto. . . . . . . . . 36

Figura 30 - Distribuição dos perfis de velocidade no espaço a jusante do túnel de

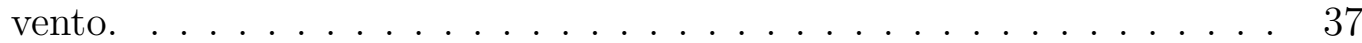

Figura 31 - Áreas utilizadas na análise do perfil de velocidade. . . . . . . . . . . . 37

Figura 32 - Análise da velocidade em função da área da seção. Cada linha representa um plano. $\mathbf{\square}: 1$ metro; $\boldsymbol{\Delta}: 2$ metros; $\bullet$ : 3 metros; $\bullet 4$ metros. . . . . . . .

Figura 33 - Curvas de eficiência do gerador. Os pontos foram obtidos por meio de ensaios experimentais e as curvas calculadas utilizando o ajuste descrito pela Equação 5.1. Cada curva representa um ensaio utilizando uma porcentagem diferente da carga. . . . . . . . . . . . . . . . .

Figura 34 - Curva de ensaio experimental da turbina. Curva cheia: velocidade $\omega$; curva pontilhada: \% da carga aplicada no gerador. . . . . . . . . . . .

Figura 35 - Comparação das curvas numéricas e experimental de $C p \times \lambda$. ‥ : BEM; + : CFX; •: pontos experimentais. . . . . . . . . . . . . . 42

Figura 36 - Representação das linhas de corrente no extradorso da pá. . . . . . . . . 43

Figura 37 - Escoamento em torno do aerofólio $\mathrm{r}=1 / 2 \mathrm{R}$. a: $\lambda=3,14$; b: $\lambda=4,18$; $\mathrm{c}: \lambda=5,23 ; \mathrm{d}: \lambda=6,28$.

Figura 38 - Distribuição da velocidade a montante da turbina para $\lambda=5,23 \ldots$. . . 45

Figura 39 - Velocidade ao longo do escoamento para $\lambda=5,23 \ldots \ldots$. . . . . . . 45

Figura 40 - Fator de indução no disco de raio $r$ em função da largura do disco. $0.2 m ; \boldsymbol{\nabla}: 0.4 m ; \circ: 0.6 m \ldots \ldots \ldots$

Figura 41 - Fator de indução local no plano $z$ em função do raio. $\mathbf{\nabla}: 0.2 m ;+$ : $0.4 m$; o: $0.6 m ; \mathbf{\square}: 0.8 m ; \times: 1.0 m \ldots \ldots \ldots \ldots \ldots$

Figura 42 - Coeficiente angular das retas ajustas aos pontos do gráfico da Figura 41. A função $\xi(z)=\xi_{0} \exp \left(-z / L_{x} i\right)$, com $\xi_{0}=-0,69$ e $L_{x} i=0,27$ ajusta-se aos pontos com $R^{2}=1$, dentro de uma tolerância compatível com os erros de ponto flutuante do computador empregado no tratamento dos dados.

Figura 43 - Fator de indução no centro do escoamento $(r=0)$ A função $a_{0}(z)=$ $a_{00} e^{-z / L_{a 0}}$., com $a_{00}=0,43$ e $L_{a 0}=0,33$ ajusta-se aos pontos com $R^{2}=1.48$

Figura 44 - Cuvas do coeficiente de potência em função da velocidade de ponta de pá. As curvas pretas são resultados da resolução numérica da Equação 2.25 utilizando a fator de indução descrito neste trabalho; as curvas de CFX, BEM e EXP são as mesmas utilizadas na Figura 35 ; a de $C p_{\max }$ é o ajuste parabólico dos pontos da Tabela $9 \ldots \ldots$. . . . . . . . . 51

Figura 45 - Aerofólio da turbina . . . . . . . . . . . . . . . . . . . 58

Figura 46 - Sensor de corrente $y=0.025 x-12.95 \ldots \ldots \ldots \ldots$. . . . . . . 59 
Figura 47 - Sensor de Tensão $y=0.0234 x+0.0654 \ldots \ldots \ldots \ldots \ldots$. . . . . . . 60

Figura 48 - Calibração da célula de carga $y=1.0026 x-0.0909 \ldots \ldots$. . . . . . . 60 


\section{Lista de tabelas}

Tabela 1 - Tabela de especificações IstaBreeze i-500 . . . . . . . . . . . . . 15

Tabela 2 - Especificações do sensores utilizados para a medir a potência elétrica . 22

Tabela 3 - Especificações do sensor de proximidade e célula de carga . . . . . . . . 23

Tabela 4 - Especificações computacionais. . . . . . . . . . . . . . . . 27

Tabela 5 - Pontos de operação utilizado nas simulações numérica. . . . . . . . . . . 31

Tabela 6 - Estudo de convergência de malhas. . . . . . . . . . . . . . . . . 33

Tabela 7 - Comparação do $C p$ máximo obtido pelo BEM, CFX e experimento. . . 41

Tabela 8 - Parâmetros do modelo para o fator de indução axial, dado pelas Equações $(5.4),(5.4)$ e $(5.5) . \ldots \ldots$. . . . . . . . . . . . . . . . . . . . . . . . 48

Tabela 9 - Resolução da Equação 2.25 para $\lambda$ simulados. . . . . . . . . . . . . . . 52

Tabela 10 - Dados da geometria da pá. . . . . . . . . . . . . . . 58

Tabela 11 - Coeficientes das equações de ajuste de curvas utilizados na calibração do gerador. . . . . . . . . . . . . . . . . . 59 


\section{Lista de símbolos}

\section{Símbolos latinos}

\begin{tabular}{|c|c|c|}
\hline$A$ & Área & {$\left[m^{2}\right]$} \\
\hline$a$ & Fator de indução axial & \\
\hline$a^{\prime}$ & Fatoro de indução tangencial & \\
\hline$C p$ & Coeficiente de potência & \\
\hline$D$ & Diâmetro do rotor & \\
\hline$g$ & Aceleração da gravidade & {$\left[\mathrm{m} / \mathrm{s}^{2}\right]$} \\
\hline$I$ & Corrente & \\
\hline$M$ & Momento angular & {$\left[\mathrm{kgm}^{2} / \mathrm{s}\right]$} \\
\hline$p$ & Pressão & {$[P$} \\
\hline$P$ & Potência & {$[W]$} \\
\hline$r$ & Raio & \\
\hline$T$ & Torque & {$[\mathrm{kgm}]$} \\
\hline$U$ & Velocidade do escoamento & {$[\mathrm{m} / \mathrm{s}]$} \\
\hline$V$ & Tensão & $\lceil l$ \\
\hline
\end{tabular}

Símbolos gregos

$\lambda \quad$ Velocidade de ponta de pá

$\rho \quad$ Densidade

$\left[\mathrm{kg} / \mathrm{m}^{3}\right]$

$\omega \quad$ Velocidade angular

$[\mathrm{rad} / \mathrm{s}]$

$\eta \quad$ Rendimento

$[-]$

$\sigma \quad$ Erro experimental 
Sobrescritos

Grandeza local

Medida experimental

\section{Subscritos}

$\infty \quad$ Ecoamento não perturbado

d Escoamento no disco atuador

$w \quad$ Escoamento a jusante da turbina

ele Elétrica

mec Mecânica

crit crítico

Siglas

BEM Blade element methodolog

CFD Compute fluid dinamics

NREL National Renewable Energy Laboratory

PWM Pulse width modulation

RANS Reynolds-averaged Navier-Stokes

RMS Root mean square

UnB Universidade de Brasília 


\section{Sumário}

INTRODUÇÃO $\ldots \ldots \ldots \ldots \ldots \ldots \ldots \ldots \ldots$

$1.1 \quad$ Contextualização $\ldots \ldots \ldots \ldots \ldots \ldots \ldots \ldots$

1.1.1 Evolução da turbina hidrocinética na Universidade de Brasília . . . . . . . 1

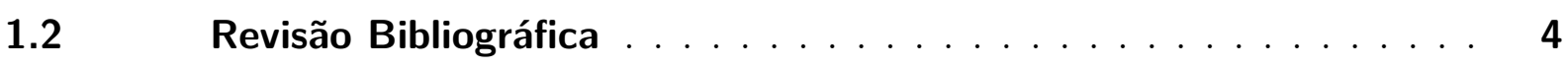

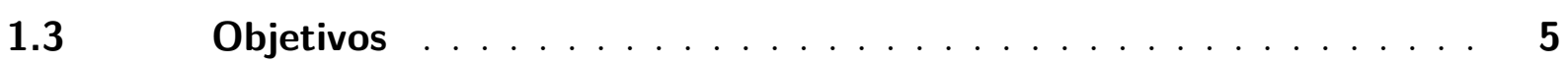

1.3.1 Objetivos Específicos $\ldots \ldots \ldots \ldots \ldots \ldots \ldots \ldots$

2 AERODINÂMICA DE TURBINAS DE EIXO HORIZONTAL ... 6

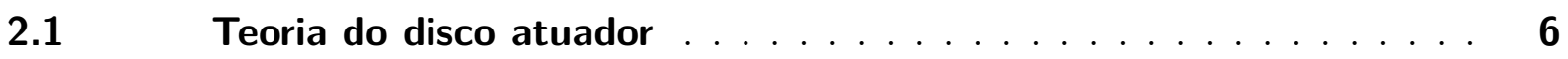

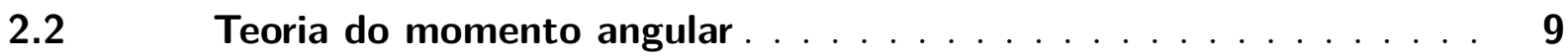

$2.3 \quad$ Blade element moment (BEM) $\ldots \ldots \ldots \ldots \ldots$

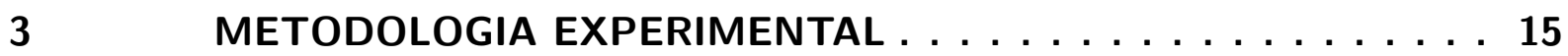

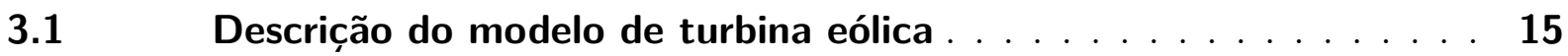

$3.2 \quad$ Túnel de vento aberto $\ldots \ldots \ldots \ldots \ldots \ldots \ldots$

3.2.1 Medição do campo de velocidade médio . . . . . . . . . . . 17

$3.3 \quad$ Calibração do gerador da turbina $\ldots \ldots \ldots \ldots \ldots \ldots$

3.3.1 Descrição do ensaio do gerador . . . . . . . . . . . . . . . . . . 19

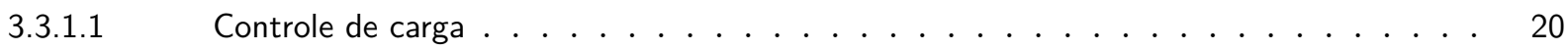

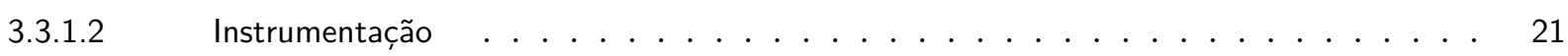

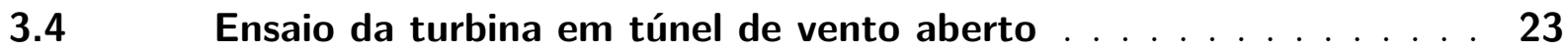

3.4.1 Controle de velocidade da turbina . . . . . . . . . . . . . . . . . 24

3.4.2 Procedimentos dos ensaios de potência da turbina . . . . . . . . . . 25

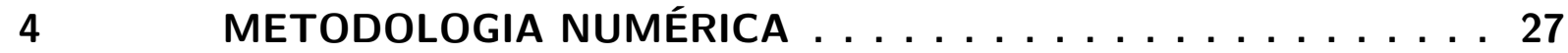

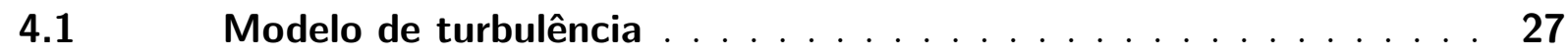

$4.2 \quad$ Modelo geométrico $\ldots \ldots \ldots \ldots \ldots \ldots \ldots \ldots$

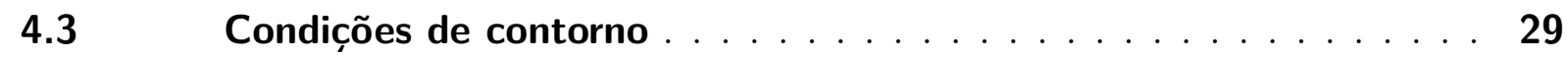

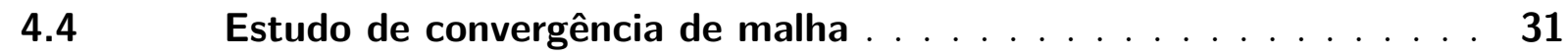

$4.5 \quad$ Investigação do fator de indução axial . . . . . . . . . . . 33

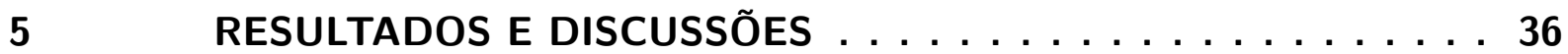

5.1 Determinação do perfil de velocidades no túnel aberto . . . . . 36

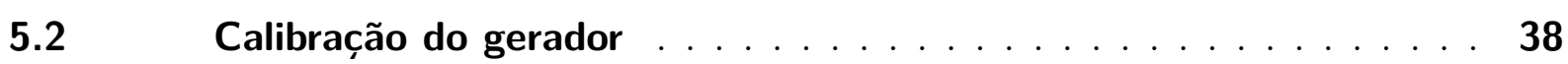

$5.3 \quad$ Controle de velocidade de rotação da turbina . . . . . . . . 40

$5.4 \quad$ Validação de resultados numéricos . . . . . . . . . . . 40 


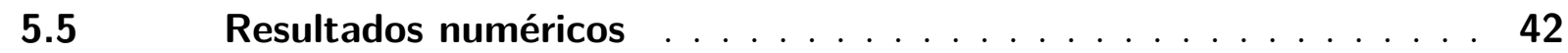

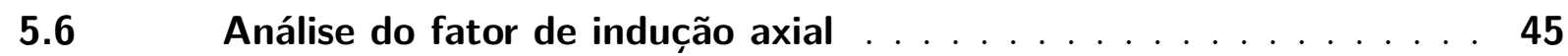

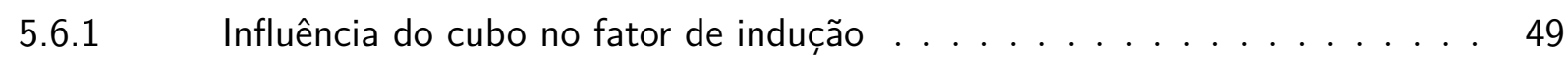

$5.6 .2 \quad$ Cálculo do máximo coeficiente de potência . . . . . . . . . . 50

$6 \quad$ CONCLUSÕES $\ldots \ldots \ldots \ldots \ldots \ldots \ldots \ldots \ldots \ldots \ldots \ldots$

REFERÊNCIAS $\ldots \ldots \ldots \ldots \ldots \ldots \ldots \ldots$

APÊNDICE A - ELEMENTOS GEOMÉTRICOS DA PÁ . . . . . 58

APÊNDICE B - CALIBRAÇÃO DOS SENSORES . . . . . . 59

APÊNDICE C - PROPAGAÇÃO DE INCERTEZAS . . . . 61 


\section{Introdução}

\subsection{Contextualização}

A produção de energia sempre foi uma temática muito importante, visto que deis dos primórdios da humanidade existe a necessidade da utilização de fontes de energia para sobrevivência do homem. A busca por novas maneiras de produzir energia é um dos maiores incentivadores para o desenvolvimento de novas tecnologias.

Nos últimos anos, em virtude das várias crises energéticas ocorridas na história e ao impacto ambiental causado pelo uso de combustíveis fósseis, o perfil da produção energética tem mudado bastante, aumentando assim a importância ao uso de fontes de energia renováveis, tais como solar, eólica e biomassa.

Do ponto de vista da produção eólica, o crescimento tem sido muito acelerado, devido à grandes avanços na tecnologia aplicada no desenvolvimento das turbinas. Desde a década de 1980, avanços aerodinâmicos e estruturais vêm fazendo com que a produção de energia elétrica, proveniente da eólica, cresça em torno de $5 \%$ ao ano, número esse bastante significativo para o mercado energético. (HERBERT et al., 2007)

O avanço do mercado eólico tem acelerado também o crescimento da utilização da energia hidrocinética, tendo em vista que o funcionamento dessa fonte pode ser explicado pelos mesmos princípios aerodinâmicos da energia eólica. A principal diferença entre as duas fontes é o fluido de trabalho utilizado, sendo o vento para energia eólica e água para energia hidrocinética.

Entre as energias renováveis, a hidrocinética é umas das tecnologias mais recentes e que vêm apresentando um dos maiores fatores de crescimento. Entretanto, em comparação as outras fontes, a energia hidrocinética ainda não tem uma produção expressiva, a maioria de seus projetos encontram-se em fase de pesquisa e desenvolvimento (YUCE; MURATOGLU, 2015).

\subsubsection{Evolução da turbina hidrocinética na Universidade de Brasília}

No ano de 1986 iniciou-se o estudo do primeiro projeto hidrocinético da Universidade de Brasília (UnB) para construção de uma turbina hidrocinética, projeto realizado pelo Departamento de Engenharia Mecânica. O projeto tinha como principal objetivo construir uma máquina capaz de gerar energia utilizando o potencial da corrente do rio, para manter um posto médico e uma residência em uma comunidade próxima à cidade de Correntina localizada no estado da Bahia, Brasil. 
A primeira máquina foi instalada em julho de 1995 e foi chamada de Geração 1. As fotos da turbina são mostradas na Figura 1. A primeira geração da turbina hidrocinética é composta por: um rotor axial de 2 pás; uma grade de proteção, para que nenhum grande corpo sólido entre em contato com o rotor, evitando danos nas pás; uma braço de sustentação pivotado; e um gerador. A Geração 1 obteve um $C p$ de aproximadamente 0,3.
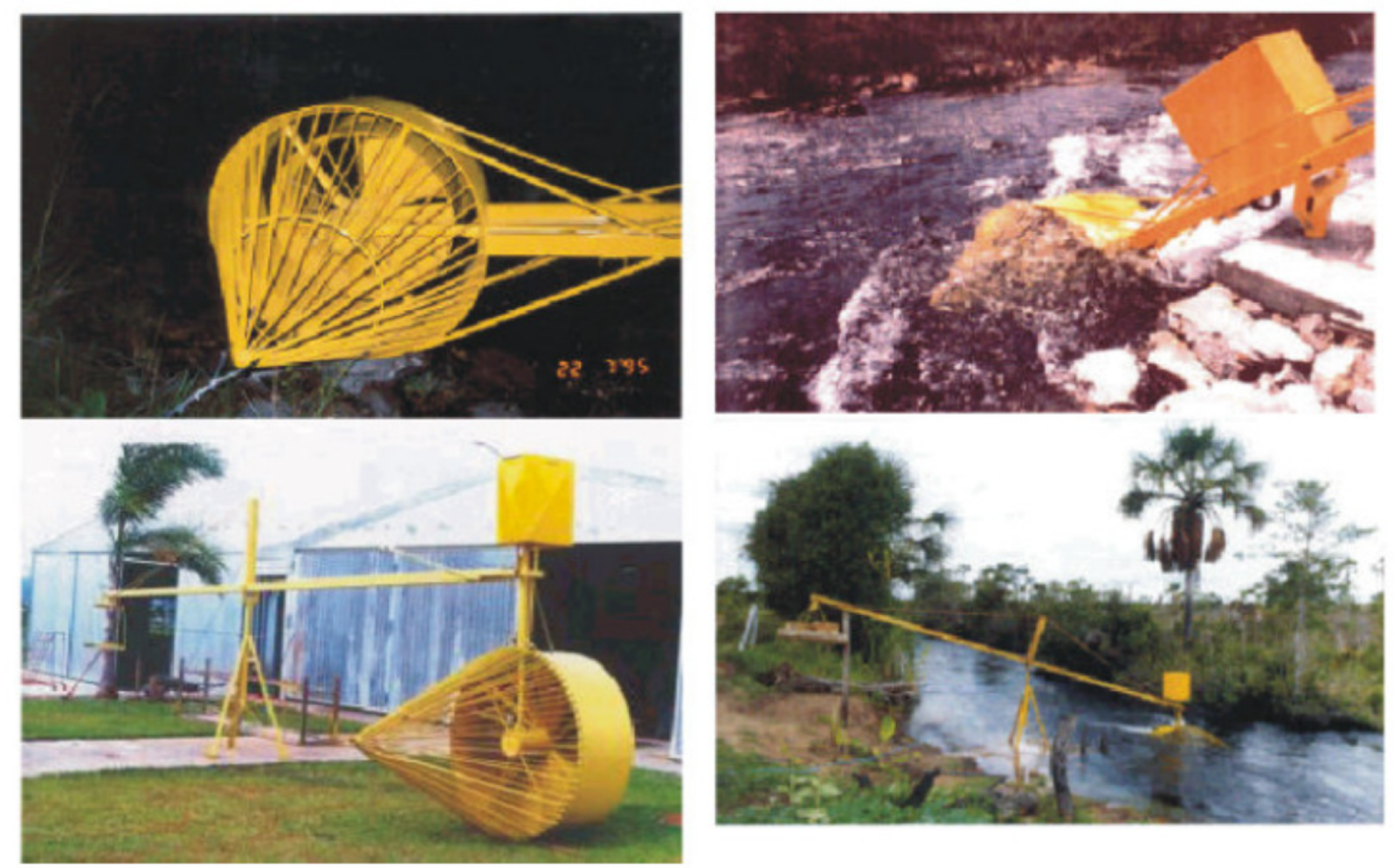

Figura 1 - Fotos da turbina hidrocinética Geração 1, desenvolvida pela UnB e instalada na cidade de Correntina BA.

Fonte: Brasil et al. (2007)

Após estudos, alguns aprimoramentos na Geração 1 foram realizados. Foram instalados: um estator na entrada da turbina, com o intuito de direcionar o fluxo do rio diretamente ao rotor, melhorando com isso a eficiência da conversão hidráulica; e um difusor, colocado na saída da máquina aumentando assim a velocidade que o escoamento atinge o rotor e consequentemente o rendimento da turbina. A Geração 2, mostrada na Figura 2, foi desenvolvida no ano de 2005 e conseguiu um $C p$ de aproximadamente 0,5.

Continuando a evolução das turbinas hidrocinética, a Geração 3, Figura 3, foi criada pelo Departamento de Engenharia Mecânica em parceria com a ELETRONORTE e com a Éscole Nationale d' et Metiers (ENSAM) de Paris, França (Brasil Jr, Lula, Maruzewski-Gaud, Nogera, \& Salomon, 2006).

As principais alterações na Geração 3 foram: uma nova geometria, reduzindo o seu tamanho; o gerador integrado ao núcleo da turbina, fazendo com que as perdas na 


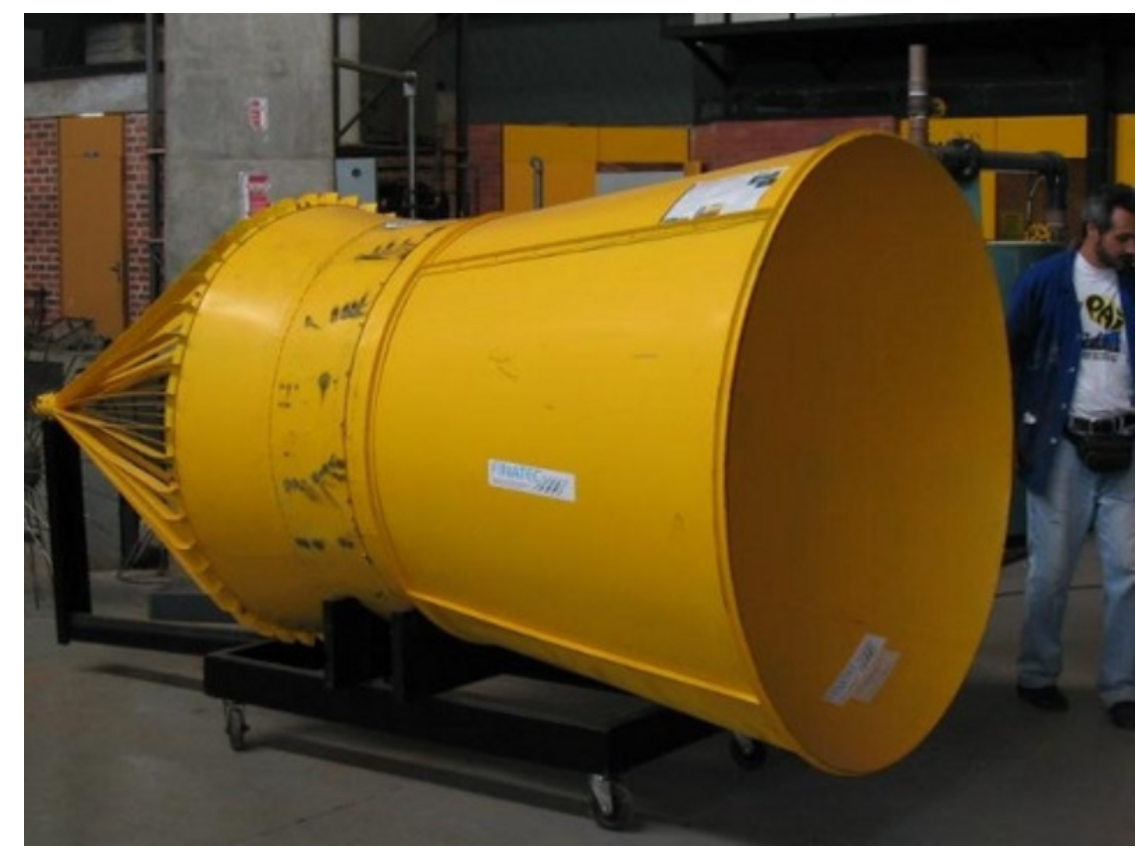

Figura 2 - Foto da turbina hidrocinética Geração 2.

Fonte: Brasil et al. (2007)

transmissão entre o rotor e o gerador diminuam; um novo difusor. A geometria desse difusor era inovadora, pois ele não era um difusor cônico e sim achatado. Essa característica foi dada pensando no posicionamento da turbina no rio, sendo que essa nova geometria exige um rio menos profundo. Outra inovação no difusor, foi uma abertura, após a turbina, que permitia que o escoamento externo passe dentro do difusor, contribuindo para evitar descolamentos de camada limite na parede do difusor e diminuindo efeitos de recirculação. A Geração 3 obteve um $C p$ de aproximadamente 1,0 em suas simulações numéricas e em ensaio de modelo reduzido na escala de 1:10 (SOUZA; OLIVEIRA; JUNIOR, 2006; BRASIL et al., 2007).

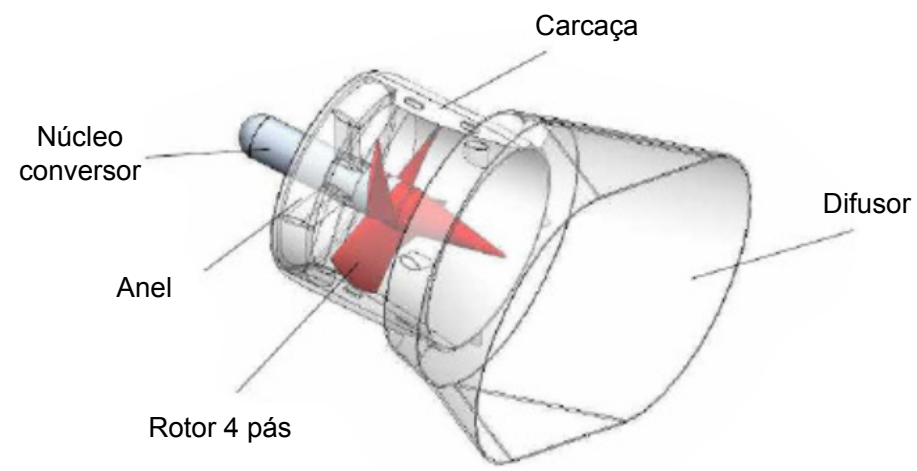

Figura 3 - Modelo geométrio da turbina hidrocinética Geração 3.

Fonte: Souza, Oliveira e Junior (2006, p. 32) 


\subsection{Revisão Bibliográfica}

A teoria do disco atuador de Rankine (1865) foi uma das primeiras propostas de abordagem para o funcionamento de uma turbina de eixo horizontal. Essa teoria propõe um modelo que explica a extração de energia realizada por uma turbina, considerando um escoamento uniforme em uma única direção e desconsiderando todos os efeitos de rotação. Uma observação muito importante dessa teoria foi a conclusão de que a velocidade que o escoamento chega à turbina é diferente da velocidade do escoamento livre. Esse diferença acontece, pois a turbina realiza um bloqueio no escoamento, induzindo assim a velocidade a um valor menor que do escoamento original. Na teoria do disco atuador, chama-se de fator de indução axial a razão entre a velocidade induzida pela turbina e a velocidade não perturbada, sendo o comportamento dessa variável muito importante para o desempenho da turbina.

Acrescentando efeitos de rotação e a conservação angular, Froude (1889) conseguiu melhorar o modelo da disco atuador. Durante seu trabalho, ele introduziu o conceito do fator de indução tangencial, que diz respeito ao momento angular gerado no escoamento após passar pela turbina. Utilizando a teoria do disco atuador, Betz (1920) deduziu que o valor para limite máximo de eficiência que uma turbina de escoamento livre poderia chegar é de aproximadamente 59,6\%, esse limite é conhecido como o limite de Betz.

Glauert (1963) desenvolveu a metodologia do BEM (Blade Elementy Momentum). O objetivo desse método é prever o desempenho de uma turbina por meio da análise de elementos radiais da pá, sendo os cálculos realizados separadamente, sem interferência de elementos vizinhos. Segundo Lanzafame e Messina (2007), o BEM é, até hoje, a metodologia mais utilizada para projetar pás e avaliar o rendimento da turbina em várias condições de operação, devido a sua confiabilidade e a o tempo de processamento. Para melhorar a resposta obtida pelo BEM, algumas otimização podem ser aplicadas. Nos trabalho de Wilson e Lissaman (1974), Vries (1979) podem ser observados a introdução de modelos para otimização da metodologia, como a correção de ponta de pá baseada no trabalho de Prandtl (1926) e a aplicação do modelo do vórtice de Rankine.

Com o crescimento computacional, metodologias baseadas em dinâmica dos fluidos computacional (CFD) como abordagens do tipo RANS (Reynolds-averaged Navier-Stokes) têm sido aplicadas para prever o funcionamento de turbinas. Sagol, Reggio e Ilinca (2012) testaram a acurácia de diferentes modelos de turbulência utilizando a metodologia RANS para calcular a potência de uma turbina eólica. Utilizando resultados experimentais, ele chegou a conclusão que o melhor modelo para esse caso é o $S S T$.

Para obter boas ferramentas de previsão do funcionamento de uma turbina, é necessário ter dados experimentais para realizar comparações e ajustar as metodologias de predição. Um dos principais ensaios efetuados em turbinas de eixo horizontal, foi realizado 
no ano 2000 utilizando a turbina NREL phase VI de 10 metros de diâmetro. Os testes foram efetuados no túnel de vento NASA Ames com seção de testes de $24.4 \times 36.6 m$ e foram investigadas mais de 1700 condições de operação da turbina.

Os trabalho de Sørensen, Michelsen e Schreck (2002), Pape e Lecanu (2004), GomezIradi, Steijl e Barakos (2009), Lee et al. (2012), Li et al. (2012) aplicaram RANS utilizando os modelos de turbulência $\kappa-\omega$ ou $S S T$ para simular o complexo campo do escoamento ao redor da turbina NREL phase VI. Nessas investigações, as previsões para a potência gerada pela turbina conseguiram reproduzir os resultados experimentais para os de pré estol. Entretanto, os resultados obtidos para o regime pós estol da turbina são discrepantes com a realidade.

\subsection{Objetivos}

O principal objetivo desse trabalho é investigar o comportamento do fator de indução axial ao longo do escoamento em uma turbina de eixo horizontal. Pretende-se apresentar uma metodologia capaz de modelar o fator de indução utilizando dados de simulações numéricas, do tipo RANS, previamente validadas em ensaios de túnel de vento.

\subsubsection{Objetivos Específicos}

- Concepção e construção do túnel de vento aberto.

- Medições dos perfis de velocidade do túnel de vento para caracterizar o escoamento e assim localizar a melhor posição para o ensaio da turbina.

- Calibração gerador da turbina, visando encontrar curvas de rendimento em função da rotação do gerador.

- Ensaio da turbina em túnel de vento aberto;

- Simulação da turbina utilizando o software ANSYS CFX,

- Validação da metodologia numérica utilizando dados experimentais obtidos no ensaio em túnel de vento.

- Desenvolvimento de uma metodologia para o cálculo do fator de indução axial usando resultados da simulação numérica. Um modelo matemático será elaborado utilizando médias de velocidades em planos a montante da turbina. Pretende-se encontrar uma equação que represente o fator de indução ao longo do escoamento a montante da turbina. 


\section{Aerodinâmica de turbinas de eixo horizon-}

\section{tal}

\subsection{Teoria do disco atuador}

A teoria do disco atuador trata de aspectos da conversão de energia cinética em energia mecânica pela ação de turbinas de eixo horizontal. Nessa teoria, o rotor é tomado por um disco permeável (denominado disco atuador) através do qual o escoamento experimenta uma queda de pressão. A Figura 4 é a representação do escoamento de velocidade $U_{\infty}$ passando por uma turbina de eixo horizontal. Considerando que o escoamento linear e livre de todos os efeitos de rotação causados pela turbina.

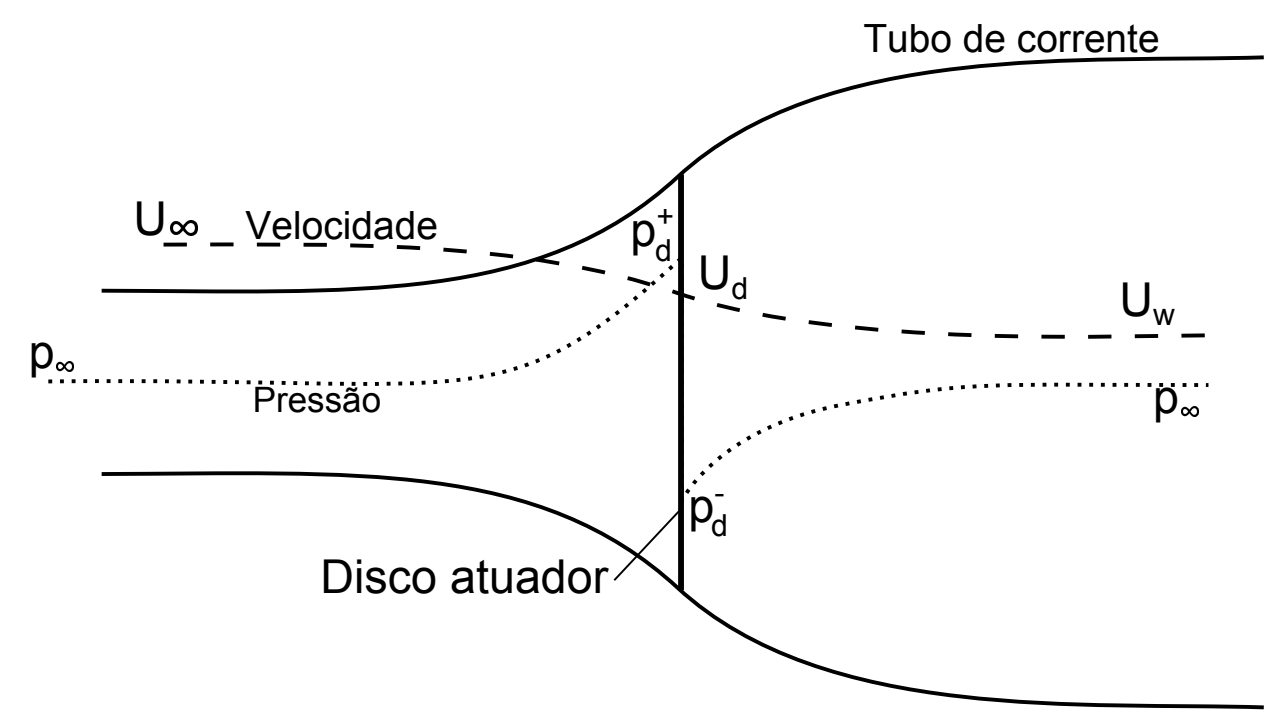

Figura 4 - Ilustração do escoamento através do disco atuador.

Fonte: Burton et al. (2001, p. 43)

O rotor provoca uma elevação da pressão a montante da turbina (disco), causando a diminuição da velocidade do escoamento e afastando as linhas de corrente. No momento que o escoamento passa pelo rotor, a pressão cai, para um valor menor que a pressão atmosférica, devido a efeitos relacionados a geometria das pás. A região a jusante em que o escoamento se encontra com a velocidade e a pressão baixas é chamada de esteira aerodinâmica da turbina. Em uma região distante, a jusante da turbina, a pressão estática da esteira irá subir, para poder ser equilibrar novamente com a pressão atmosférica, porém a velocidade não voltara a ser a mesma, devido a extração da energia cinética pela turbina.

Pode-se representar todo o escoamento que passa através da turbina por um tubo de corrente, considerando que não exista troca de massa entre o escoamento dentro e fora 
desse tubo, sabe-se, pela equação da continuidade que

$$
\rho A_{\infty} U_{\infty}=\rho A_{d} U_{d}=\rho A_{w} U_{w}
$$

sendo o índice $\infty$ indica que a grandeza é medida no escoamento não perturbado, o índice $d$ indica que a grandeza é medida na entrada do disco atuador e o índice $w$ é referente a grandeza medida a jusante da turbina.

Como $U_{\infty}>U_{d}>U_{w}$, chega-se a uma relação entre as áreas $A_{\infty}<A_{d}<A_{w}$, ou seja, o escoamento sofre uma expansão durante seu percurso, ilustrado na Figura 4.

Seguindo essas premissas, define-se o fator de indução axial do como

$$
a=\frac{U_{\infty}-U_{d}}{U_{\infty}}
$$

O fator de indução é uma variável adimensional que pode ser interpretada como uma razão de vazões entre escoamento não perturbado e o escoamento que sofre interferência da turbina. A magnitude do fator de indução pode variar no intervalo $(0,1)$, sendo que $a=1$ implica que $U_{\infty}=U_{d}$, sendo esta uma condição a turbina não gera nenhuma alteração no escoamento. Já para $a=0$ implica que $U_{d}=0$, significando um total bloqueio do escoamento causado pela turbina.

Pela segunda lei de Newton, sabe-se que uma força de superfície (pressão) é igual a taxa de variação de quantidade de movimento. Aplicando essa lei no volume de controle do fluido que envolve o rotor e sabendo que a variação da quantidade de movimento é descrita como $\left(U_{\infty}-U_{w}\right) \rho A_{d} U_{d}$, tem-se

$$
\left(p_{d}^{+}-p_{d}^{-}\right) A_{d}=\left(U_{\infty}-U_{w}\right) \rho A_{d} U_{d}
$$

Substituindo (2.2) em (2.3),

$$
\left(p_{d}^{+}-p_{d}^{-}\right) A_{d}=\left(U_{\infty}-U_{w}\right) \rho A_{d} U_{\infty}(1-a)
$$

O cálculo das pressões na entrada e saída do disco atuador é realizado considerando que o escoamento a montante é invíscido e irrotacional, de forma que a equação de Bernoulli possa ser aplicada. É importante observar que o total de energia a jusante da turbina é diferente da energia a montante, tendo em vista que a turbina extrai energia do sistema. Portanto, é necessário aplicar a equação a montante e a jusante separadamente.

A equação de Bernoulli a montante pode ser descrita como

$$
\frac{1}{2} \rho_{\infty} U_{\infty}^{2}+\rho_{\infty} g h_{\infty}+p_{\infty}=\frac{1}{2} \rho_{d} U_{d}^{2}+\rho_{d} g h_{d}+p_{d}^{+}
$$


como o escoamento é horizontal, $h_{\infty}=h_{d}$, e incompressível, $\rho_{\infty}=\rho_{d}=\rho$, tem-se que

$$
\frac{1}{2} \rho U_{\infty}^{2}+p_{\infty}=\frac{1}{2} \rho U_{d}^{2}+p_{d}^{+}
$$

Similarmente, a jusante a equação de Bernoulli é

$$
\frac{1}{2} \rho U_{w}^{2}+p_{\infty}=\frac{1}{2} \rho U_{d}^{2}+p_{d}^{-}
$$

Subtraindo (2.7) de (2.6),

$$
\left(p_{d}^{+}-p_{d}^{-}\right)=\frac{1}{2} \rho\left(U_{\infty}^{2}-U_{w}^{2}\right)
$$

e substituindo (2.8) em (2.4),

$$
\frac{1}{2} \rho\left(U_{\infty}^{2}-U_{w}^{2}\right)=\left(U_{\infty}-U_{w}\right) \rho A_{d} U_{\infty}(1-a)
$$

Simplificando, tem-se que a velocidade do escoamento a jusante da turbina é dado por

$$
U_{w}=(1-2 a) U_{\infty}
$$

A potência da turbina é dada pelo produto da velocidade no disco $\left(U_{d}=U_{\infty}(1-a)\right)$ e a força axial. Como já foi visto anteriormente, a força axial foi definida pela Equação 2.4, portanto a potência $P$ é expressa como,

$$
P=2 \rho A_{d} U_{\infty}^{3} a(1-a)^{2} .
$$

Por definição, chama-se coeficiente de potência $(C p)$ a razão da potência produzida pela turbina pela potência disponível no vento $\left(P_{\text {vento }}\right)$, sendo

$$
P_{\text {vento }}=\frac{1}{2} \rho U_{\infty}^{3} A_{d}
$$

portanto,

$$
C p=\frac{2 \rho A_{d} U_{\infty}^{3} a(1-a)^{2}}{\frac{1}{2} \rho U_{\infty}^{3} A_{d}}
$$

obtendo assim,

$$
C p=4 a(1-a)^{2}
$$


Por uma simples regra de cálculo, sabe-se que o valor máximo da função de $C p$ acontece quando sua derivada é nula, portanto,

$$
\begin{gathered}
\frac{d C p}{d a}=0, \\
4(1-a)(1-3 a)=0 .
\end{gathered}
$$

Resolvendo Equação 2.16, obtêm-se

$$
C p_{\text {máx }}=\frac{16}{27} \approx 0,593
$$

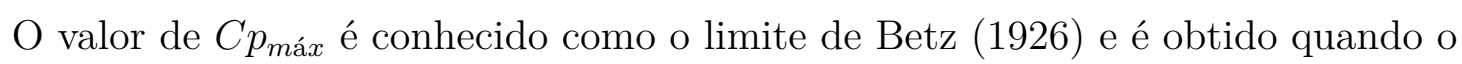
valor do fator de indução é igual a $1 / 3$. Esse resultado representa o máximo de eficiência que qualquer turbina de eixo horizontal de fluxo livre poderá chegar.

\subsection{Teoria do momento angular}

Como explicado anteriormente, a teoria do disco atuador não considera os efeitos de rotação do escoamento, sendo assim ela não é capaz de explicar completamente o comportamento da turbina. Para se aproximar da realidade, os efeitos de rotação devem ser levados em consideração. A jusante da turbina, o campo de velocidade precisa ter uma componente tangencial para que a conservação do momento angular ocorra. A aceleração (taxa de variação do momento) necessária para alterar o sentido do vetor velocidade consome energia, diminuindo a potência aproveitada pela turbina.

O escoamento entra na turbina com o momento angular nulo, pois a montante da turbina não existe nenhum movimento de rotação. Após passar pela turbina, o momento angular do escoamento deixa de ser nulo, devido a uma velocidade tangencial induzida pelas pás, como mostrado na Figura 5.

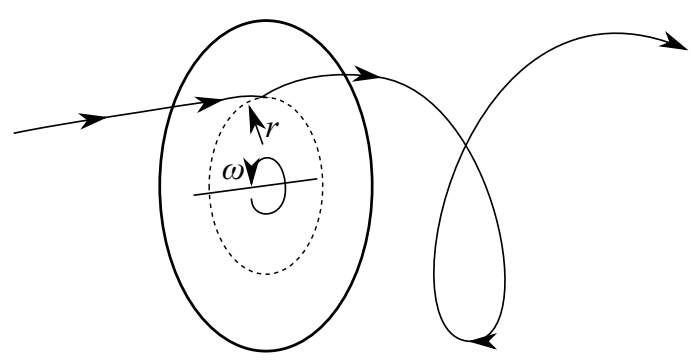

Figura 5 - Representação da velocidade tangencial induzida a jusante da turbina.

Fonte: Burton et al. (2001, p. 47) 
Por definição, a velocidade tangencial do escoamento $\left(u_{\theta}\right)$ induzida a jusante da turbina é expressa por

$$
u_{\theta}=2 a^{\prime} \omega r
$$

em que $r$ é a distância ao centro de giro da turbina, como mostrado Figura 5, $\omega$ é a velocidade de rotação da máquina e $a^{\prime}$ é o fator indutivo tangencial. A definição do fator de indução tangencial pressupõe que existe um escorregamento (ou defasagem) entre a velocidade local de rotação do rotor e a componente tangencial do vetor velocidade do escoamento.

A potência da turbina pode ser calculada como a soma da potências de todos elementos $d r$, representados Figura 6. Como a turbina é uma máquina rotativa, a potência do disco de espessura $d r$ é calculada pelo produto do torque $(\mathrm{T})$ e velocidade angular $(\omega)$.

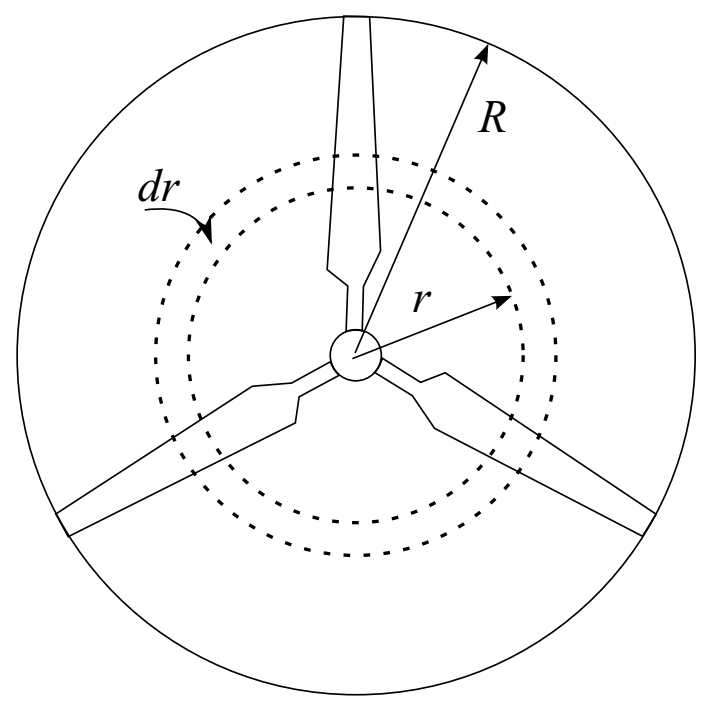

Figura 6 - Representação do dico utilizado para o cálculo da potência.

Fonte: Hansen (2008, p. 24)

Pela segunda lei de Newton, pode-se dizer que o torque é a variação igual a variação do momento angular $(d M)$, portanto a potência do disco $d r$ pode-se ser expressa como

$$
d P=\omega d M
$$

entretanto, a variação no momento angular pode ser expressa como o fluxo de massa $\left(A_{d} \rho u_{d}\right)$ multiplicado pela velocidade tangencial $\left(u_{\theta}\right)$ e raio $(r)$, portanto

$$
d P=\omega A_{d} \rho u_{d} u_{\theta} r d r
$$


Substituindo a área em função do $r$

$$
d P=\omega 2 \pi \rho u_{d} u_{\theta} r^{2} d r
$$

deixando as velocidades em função dos fatores de indução axial (2.2) e tangencial (2.18) e integrando ao longo da coordenada radial ou ao longo do raio do rotor.

$$
P=\omega^{2} 4 \pi \rho U_{\infty} \int_{0}^{R}(1-a) a^{\prime} r^{3} d r .
$$

Assim, o coeficiente de potência pode ser descrito como

$$
C p=\frac{8 \omega^{2}}{R^{2} U_{\infty}^{2}} \int_{0}^{R}(1-a) a^{\prime} r^{3} d r
$$

É comum no estudo de turbinas de eixo horizontal o uso da velocidade de ponta de pá $(\lambda)$, que uma velocidade adimensional para o rotor e correlaciona a velocidade na ponta da pá $(\omega R)$ com a velocidade do escoamento não perturbado, sendo

$$
\lambda=\frac{\omega R}{U_{\infty}}
$$

colocando a Equação 2.23 em função do $\lambda$ local, tal que $\lambda_{r}=\frac{\omega r}{U_{\infty}}$, tem-se que

$$
C p=\frac{8}{\lambda^{2}} \int_{0}^{\lambda}(1-a) a^{\prime} \lambda_{r}^{3} d r .
$$

Para se encontrar o valor máximo de $C p$, a função $(1-a) a^{\prime}$ da equação anterior tem que ser maximizada, portanto

$$
\begin{array}{r}
\frac{d}{d a}(1-a) a^{\prime}=0 \\
\frac{d a^{\prime}}{d a}=\frac{a^{\prime}}{1-a}
\end{array}
$$

O próximo passo para encontrar o valor máximo de $C p$ é descobrir uma relação entre os fatores de indução $a, a^{\prime}$ e o $\lambda_{r}$. A Figura 7 representa o triângulo de velocidade na pá de um turbina. Os eixos apresentados representam o plano axial e o plano radial da turbina. Como é possível notar, existem dois componentes na velocidade relativa de entrada $\left(U_{r e l}\right)$, o primeiro está relacionado a velocidade do escoamento $\left(U_{\infty}\right)$ e o segundo está relacionado com a velocidade de rotação da turbina( $\omega r)$. Essa relação só é possível realizar em condições em que a pá não esteja estolada.

Na Figura 7, pode-se tirar duas relações para o angulo $\varphi$, sendo 


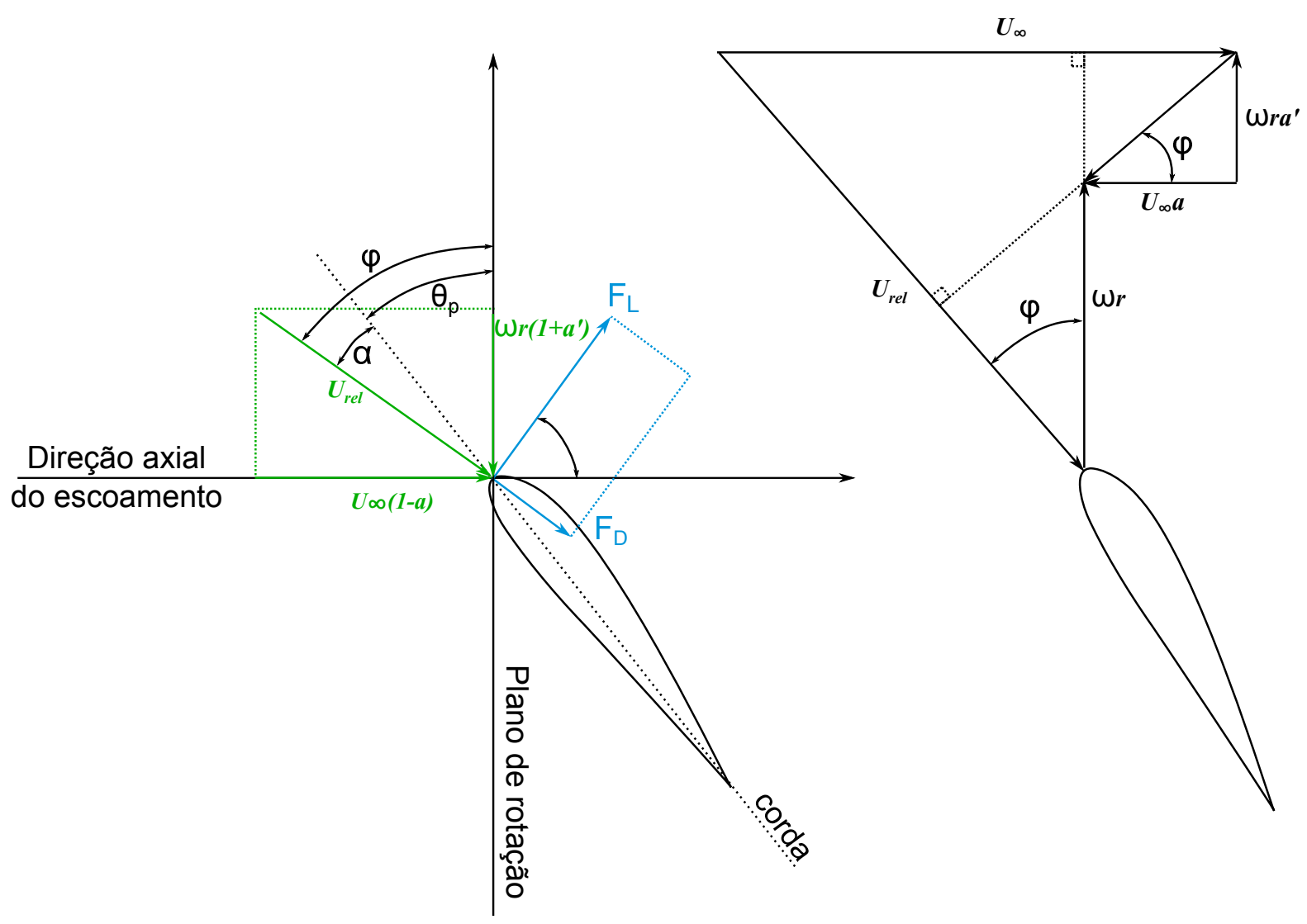

Figura 7 - Representação dos triângulos de velocidade na pá na condição de antes do estol. Os ângulos presentes são: $\alpha=$ ângulo de ataque; $\theta_{p}=$ ângulo de passo; $\varphi=$ ângulo relativo do vento.

Fonte: Nilsson (2012, p. 20)

$$
\begin{array}{r}
\operatorname{tg}(\varphi)=\frac{(1-a) U_{\infty}}{\left(1+a^{\prime}\right) \omega r}, \\
\operatorname{tg}(\varphi)=\frac{a^{\prime} \omega r}{a U_{\infty}} .
\end{array}
$$

Igualando as duas equações e isolando $\lambda_{r}$ tem-se que

$$
\lambda_{r}^{2}=\frac{a(1-a)}{a^{\prime}\left(1+a^{\prime}\right)} .
$$

Derivando a equação anterior em função de $a$, tem-se que

$$
1-2 a=\lambda_{r}^{2} \frac{d a^{\prime}}{d a}\left(1+2 a^{\prime}\right) .
$$

Subsistindo (2.27) e (2.30) em (2.31), encontra-se $a^{\prime}$ em função de $a$ para o ponto de $C p$ 
máximo,

$$
a^{\prime}=\frac{1-3 a}{4 a-1}
$$

A equação acima for descrita pela primeira vez por Glauert e faz uma relação entre os valores de indução axial e tangencial para o maior valor de $C p$ que uma turbina pode chegar. Substituindo o valor de $a^{\prime}$ na Equação 2.25 é possível resolver a integral e encontrar $C p$ em função de $\lambda$. O gráfico mostrado Figura 8, mostra o $C p$ em função de $\lambda$ encontrado pela resolução da integral da Equação 2.25.

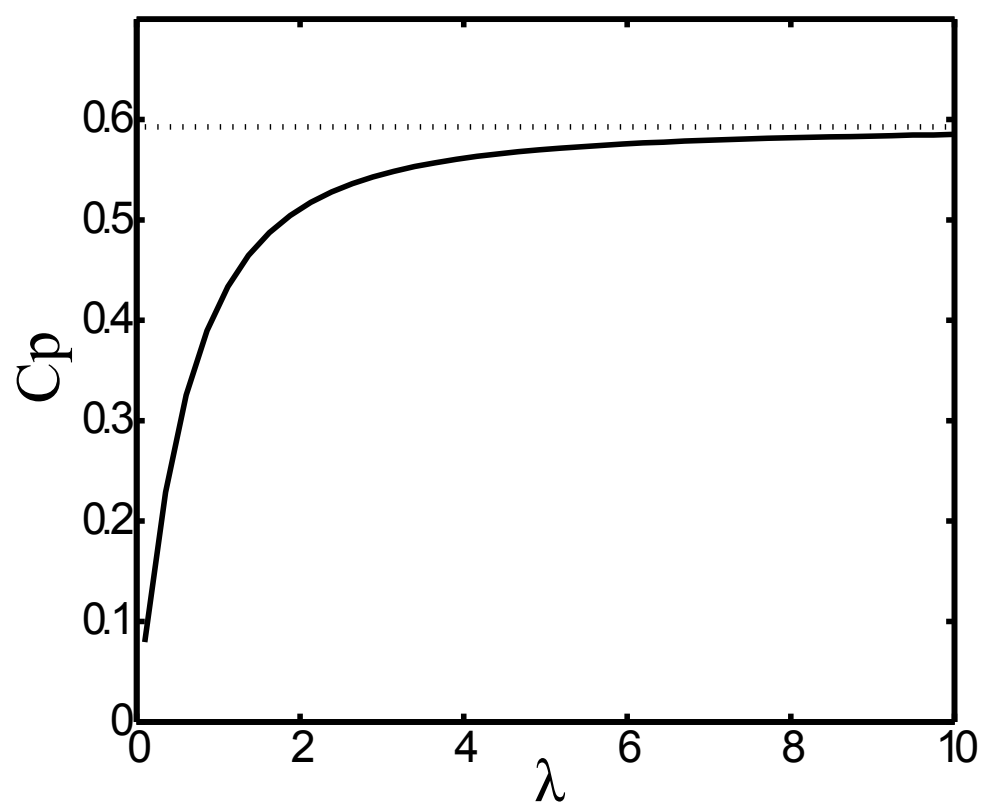

Figura 8 - Coeficiente de potência em função do $\lambda$, considerando efeitos de rotação no escoamento. Curva pontilhada: limite de Betz; curva cheia: metodologia proposta por Glauert.

A principal diferença entre a metodologia de Glauert e o limite de Betz é a consideração de fenômenos rotativos no escoamento da turbina. Por esse motivo, observa-se uma influência da velocidade de rotação adimensional $(\lambda)$ no comportamento do coeficiente de potência $(C p)$. Segundo a função de Glauert, quando a velocidade de rotação for nula $(\lambda=0)$ a turbina não irá produzir potência $(C p=0)$. No momento que $\lambda$ passa ser diferente de zero, o coeficiente de potência começa a crescer, atingindo o limite de Betz para velocidade altas.

\subsection{Blade element moment (BEM)}

Essa metodologia é uma extensão das teorias do disco atuador e momento angular. O BEM assume que as pás do rotor podem ser divididas em pequenos elementos, que 
Capítulo 2. Aerodinâmica de turbinas de eixo horizontal 29 atuam de forma independentes e operam como aerofólios bidimensionais cujas as forças aerodinâmicas podem ser calculadas com base nas condições de escoamento local (LANZAFAME; MESSINA, 2012). A potência de cada elemento é calculada através dos coeficientes de arrasto e sustentação do aerofólio utilizado no elemento e a potência total da turbina é obtida através da integração de todos elemento ao longo das pás.

A metodologia BEM é baseada somente na geometria da pá, deixando de lado os efeitos presentes no escoamento, sendo que para prever a potência, o BEM precisa utilizar de dados de sustentação e arrasto dos perfis aerodinâmicos da pá. Para obter bons resultados com o BEM é necessário ter uma boa qualidade informações do perfil da pá. 


\section{Metodologia experimental}

O ensaio em túnel de vento foi realizado com o intuito de obter resultados experimentais do coeficiente de potência para validar a simulação numérica de uma turbina eólica. Pretende-se encontrar uma curva do coeficiente em função da velocidade de ponta de pá $(\lambda)$. No ensaio, foram realizados medidas de velocidade e torque da turbina, sendo que a medida do torque é feita de maneira indireta, utilizando dados elétricos da potência de saída do gerador, previamente calibrado. Esse capítulo apresenta toda a metologia aplicada para obter a curva experimental de $C p \times \lambda$.

\subsection{Descrição do modelo de turbina eólica}

Utilizou-se uma turbina eólica de pequeno porte da marca InstaBreeze modelo i-500, mostrada na Figura 9. A Tabela 1 apresenta as especificações da turbina fornecidas pelo fabricante.

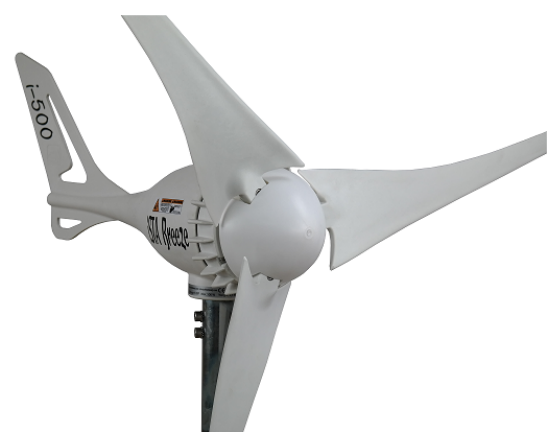

Figura 9 - Turbina utilizada nos ensaios de túnel de vento. Marca: IstaBreeze i-500.

Tabela 1 - Tabela de especificações IstaBreeze i-500.

\begin{tabular}{cc}
\hline Potência nominal & $400 \mathrm{~W}$ \\
Potência máxima & $600 \mathrm{~W}$ \\
Mínima velocidade do escoamento & $3 \mathrm{~m} / \mathrm{s}$ \\
Máxima velocidade do escoamento & $45 \mathrm{~m} / \mathrm{s}$ \\
Velocidade ideal do escoamento & $12,5 \mathrm{~m} / \mathrm{s}$ \\
Número de pás & 3 \\
Diâmetro & $102 \mathrm{~cm}$ \\
Gerador & Imãs permanentes de corrente alternada \\
Voltagem Nominal & $12 \mathrm{~V} \mathrm{AC}$ \\
Peso da turbina & $4,5 \mathrm{Kg}$ \\
\hline
\end{tabular}




\subsection{Túnel de vento aberto}

Um túnel de vento aberto é caracterizado quando o escoamento de ar é feito de maneira livre, sem nenhuma parede realizando bloqueio lateral ao longo do caminho. Esse tipo de túnel foi utilizado nesse trabalho com a intensão de eliminar efeitos de parede presentes em túneis de vento tradicionais e com isso deixar o experimento mais próximo do funcionamento em campo desse tipo de turbina. O túnel utilizado é formado por quatro ventiladores, de $3 \mathrm{hp}$, ligados em paralelo e com seção transversal de $4 \mathrm{~m}^{2}$.

Para melhores resultados experimentais a turbulência do túnel de vento deve ser minimizada e o perfil de velocidade na seção de testes deve ser o mais constante possível. Sendo assim, foram selecionadas algumas estruturas (telas) para diminuir os efeitos da turbulência no escoamento do túnel. A Figura 10 mostra os sistemas aplicados para melhorar o escoamento.

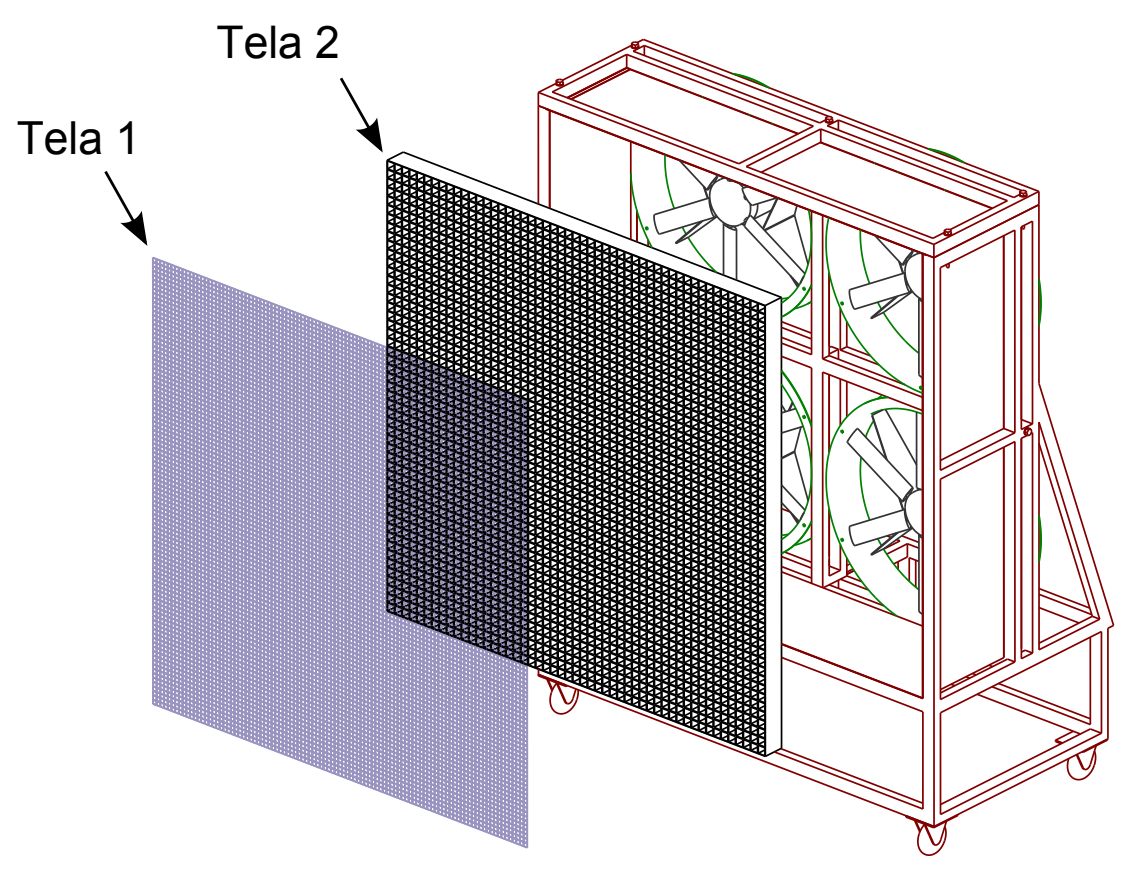

Figura 10 - Sistemas de colmeias utilizadas para homogenizar o escoamento.

As telas selecionadas são placas permeáveis formadas por pequenos tubos alinhados que permitem a passagem do ar com a finalidade de alinhar o escoamento suprimindo os componentes de velocidade perpendiculares ao sentido do jato do ventilador (Kulkarni, Sahoo e Chavan (2011)). A Tela 1 tem espessura de $10 \mathrm{~mm}$ e uma malha de $10 \times 10 \mathrm{~mm}$ localizada a $300 \mathrm{~mm}$ dos ventiladores. Já a Tela 2 tem espessura de $1 \mathrm{~mm}$ e células de $2 \times 2 \mathrm{~mm}$ e está localizada a $100 \mathrm{~mm}$ da Tela 1 , estabilizando estruturas de vórtices menores. 


\subsubsection{Medição do campo de velocidade médio}

Como se trata de um túnel aberto, a seção de testes não é bem definida, portanto a medição dos perfis de velocidade se faz necessária para o conhecer do escoamento a jusante do túnel e assim se determinar um local apropriado para o ensaio da turbina eólica.

A metodologia de medição foi baseada no sistema de pitometria, em que o tubo de Pitot é posicionado em um conjunto de pontos referenciados por um sistema de coordenadas cartesianas de três dimensões. O tubo de Pitot foi ligado a um manômetro diferencial com resolução de 0.1 mmca e fundo de escala de 12.5 mmca.

A Figura 11 é a representação gráfica dos pontos de tomada de velocidade. Pretendese definir uma região no espaço (volume de medida) na qual o campo de velocidade seja aproximadamente uniforme, dentro da qual serão realizados os ensaios do presente trabalho. As medidas foram realizadas nos quatros planos representado pelas linhas tracejadas, sendo a distância entre eles de 1 metro. Em cada plano, foram realizadas medidas em uma com 10 posições no eixo $x$ e 9 no eixo $z$, totalizando 90 pontos.
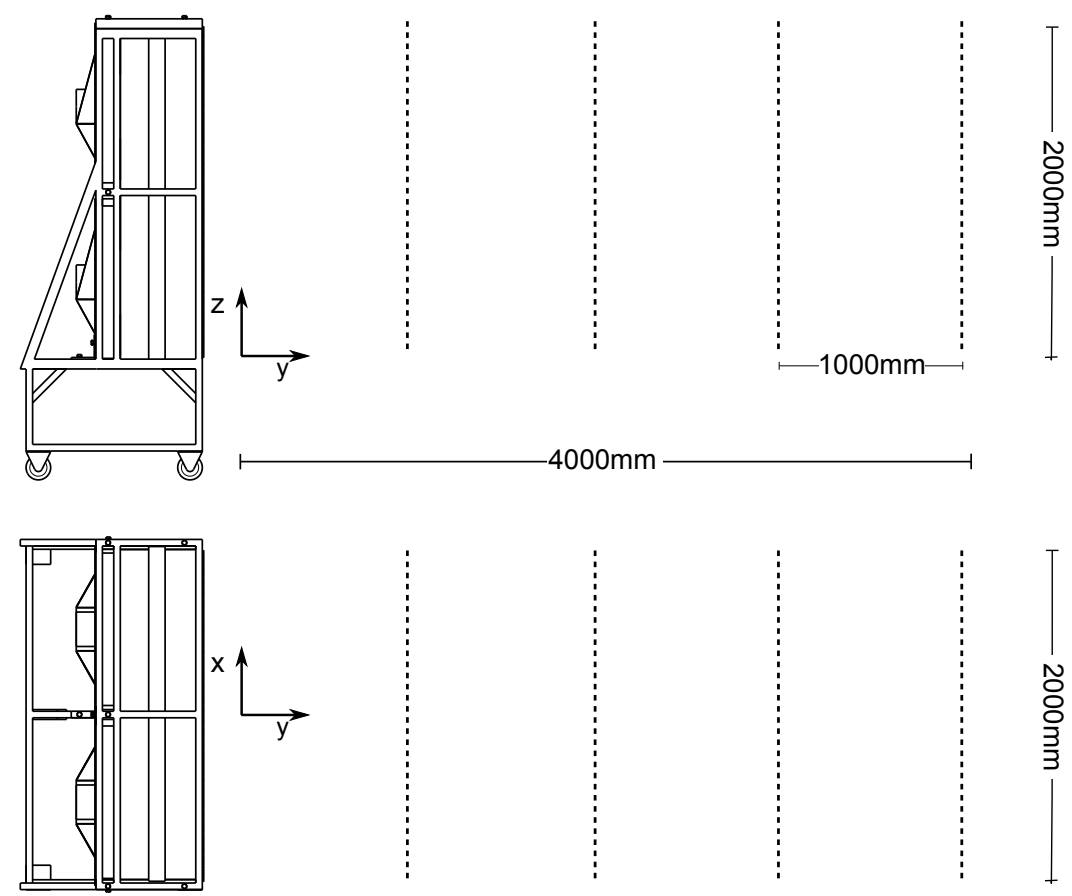

Figura 11 - Planos e coordenadas utilizados para medir os perfis de velocidade do escoamento.

A Figura 12 mostra fotos do aparato experimental utilizado medição dos perfis de velocidade. A Figura 12(a) é uma foto do sistema de suporte do tubo de Pitot. O suporte é formado por uma base móvel, que é posicionada na marcação das coordenadas, e por um tubo vertical para fixação do tubo de Pitot em várias alturas. A Figura 12(b) é a foto 
dos planos que foram realizadas as medições de velocidade do escoamento.

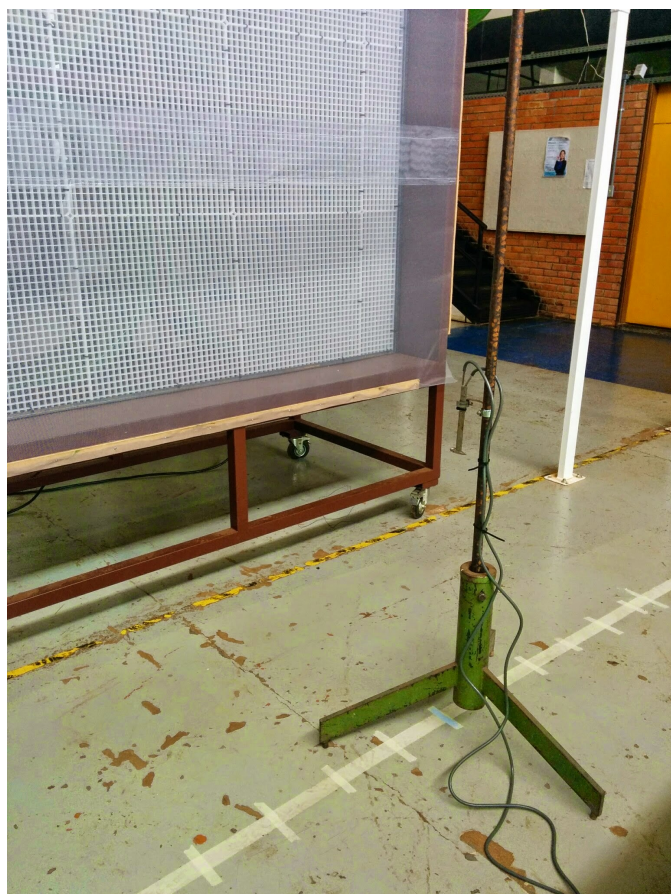

(a) Suporte tubo de pitot

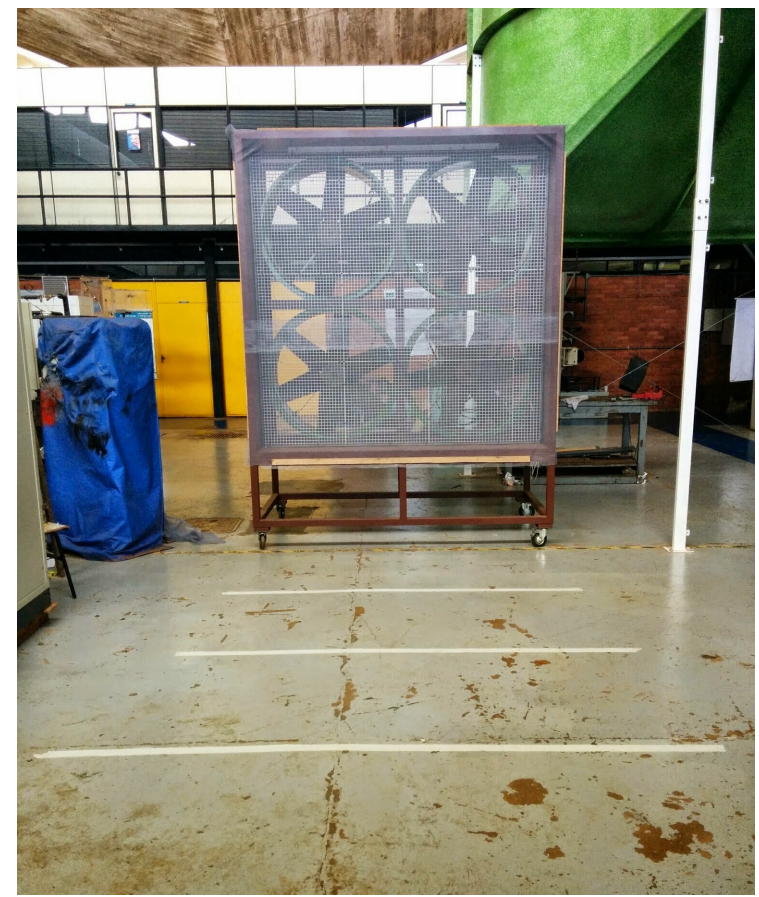

(b) Marcações dos planos de medição

Figura 12 - Sistema de posicionamento do tubo de pitot.

\subsection{Calibração do gerador da turbina}

A calibração do gerador da turbina é feita para obter a potência mecânica por meio da medição da potência elétrica. A calibração realizada é similar a um ensaio de eficiência do gerador, sendo a eficiência a razão entre potência elétrica produzida, calculada pelo produto da corrente $(i)$ e tensão $(V)$, e a potência mecânica no eixo, descrita pelo produto da velocidade angular $(\omega)$ e torque $(T)$.

$$
\eta=\frac{P_{\text {ele }}}{P_{\text {mec }}}=\frac{i V}{\omega T}
$$

O conceito básico do ensaio de eficiência é excitar o eixo do gerador com uma potência mecânica conhecida e depois medir a potência elétrica produzida. Neste trabalho, utilizou-se um motor para acionamento mecânico do gerador. O motor elétrico deve ser montado entre rolamentos de forma que possa girar livremente ao redor do próprio eixo (montagem em balanço). Um braço mecânico é fixado na carcaça do motor, de forma que a força necessária para manter o motor parado (sem girar) é aplicada por este braço. Dessa forma, é possível determinar o torque mecânico (força aplicada multiplicada pelo comprimento do braço), a menos do torque necessário para vencer os atritos nos rolamentos. 
A Figura 13 mostra o projeto desenvolvido para o ensaio de eficiência do gerador. Pode-se observar que o motor está conectado à turbina por meio de um acoplamento e que o eixo do motor está apoiado somente por dois acoplamentos, o que permite que o motor fique em balanço. Pode-se observar também o braço mecânico fixado ao motor, transmitindo o torque da carcaça do motor à célula de carga.

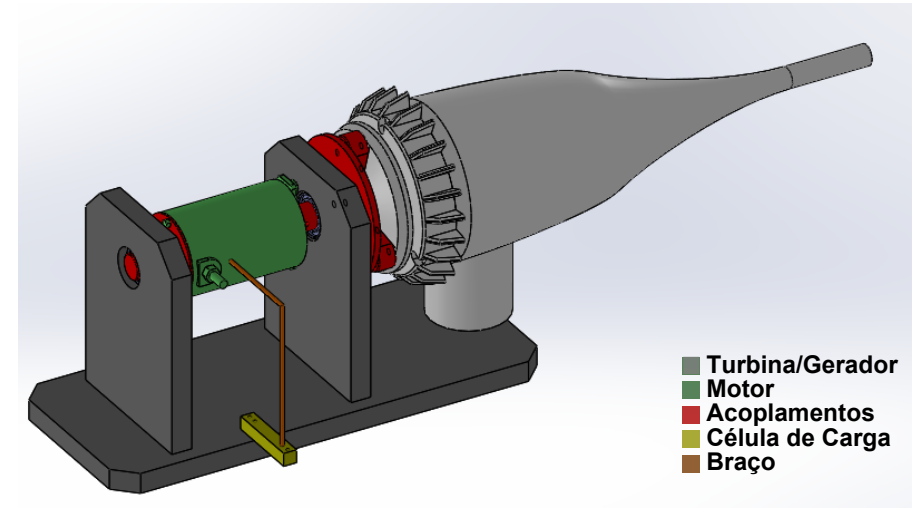

Figura 13 - Projeto da bancada de calibração do gerador.

A Figura 14 apresenta fotos do sistema de calibração do gerador. A Figura 14(a) mostra o sistema completo: motor e gerador. É possível observar o sensor de velocidade angular apontado para o rotor da turbina. Já a Figura 14(b) mostra o braço conectado na carcaça do motor e o posicionamento da célula de carga. Um elemento elástico foi empregado como pré-tensionador, para estabilizar a haste mecânica sobre a célula de carga, evitando que durante os ensaios, principalmente em baixas velocidades de rotação, o braço mecânico vibrasse sobre a célula de carga.

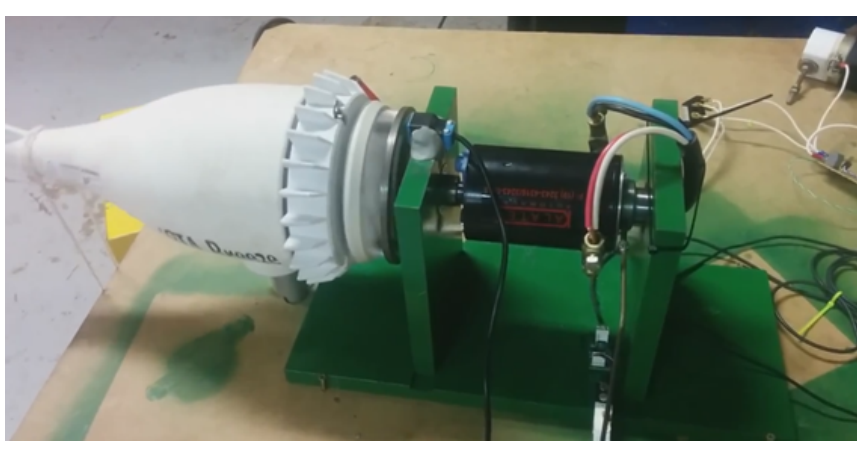

(a) Sistema de calibração do gerador.

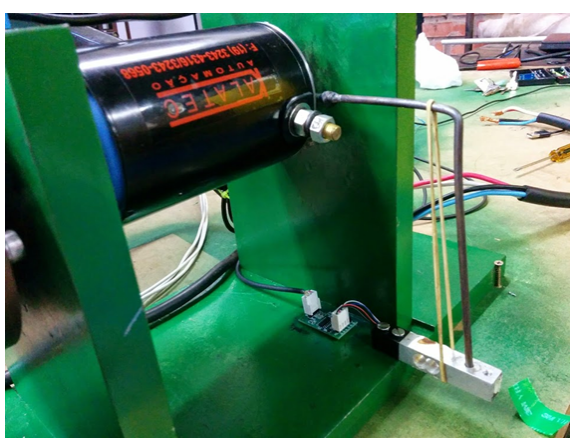

(b) Detalhe da célula de carga.

Figura 14 - Foto da bancada de calibração do gerador elétrico.

\subsubsection{Descrição do ensaio do gerador}

O ensaio do gerador é realizado para simular seu comportamento em diversas condições de operação, sendo assim o princípio básico do ensaio é utilizar o motor para acionar o gerador em diferentes condições de operação. Durante o ensaio, o gerador funciona 
como um freio para o motor, pois quando se coloca uma carga resistiva no circuito do gerador um torque contrário ao movimento surge no eixo, freando assim o sistema. A magnitude do torque de frenagem varia de acordo com a carga aplicada, sendo que quanto menor a resistência inserida no sistema maior será a força de frenagem causado pelo gerador.

O rendimento do gerador é função da carga aplicada e da velocidade de rotação, sendo assim o ensaio deve varrer todas as possibilidades de operação. A variação da velocidade é obtida por meio da variação da tensão do motor elétrico que aciona o gerador. Já a variação da carga é realizada por meio da resistência conectada no circuito do gerador.

\subsubsection{Controle de carga}

Um sistema de modulação foi utilizado para realizar a variação da carga no ensaio do gerador. Esse sistema é formado por um circuito com uma resistência fixa e um aparato para controlar a abertura e fechamento do circuito, controlando assim o instante em que a resistência é conectada ao gerador. Por meio do ajuste do tempo de modulação do sistema, é possível o obter um valor de resistência resultante médio equivalente a uma resistência fixa, sobre a qual se tem controle.

A Figura 15 apresenta o esquema eletrônico do circuito modulador de carga, utilizado nos ensaios. O sistema é composto por um motor de corrente continua utilizado para acionar um gerador elétrico de corrente alternada. No circuito, a turbina está ligado uma ponte retificadora, para transformar o circuito em corrente continua, uma resistência e um transistor (IRFZ44N). O transistor serve para abrir e fechar o circuito da resistência e com isso dar diferentes cargas no sistema. A modulação do transistor é feita por um sistema de modulação por largura de pulso, mais conhecida como PWM (pulse width modulation).

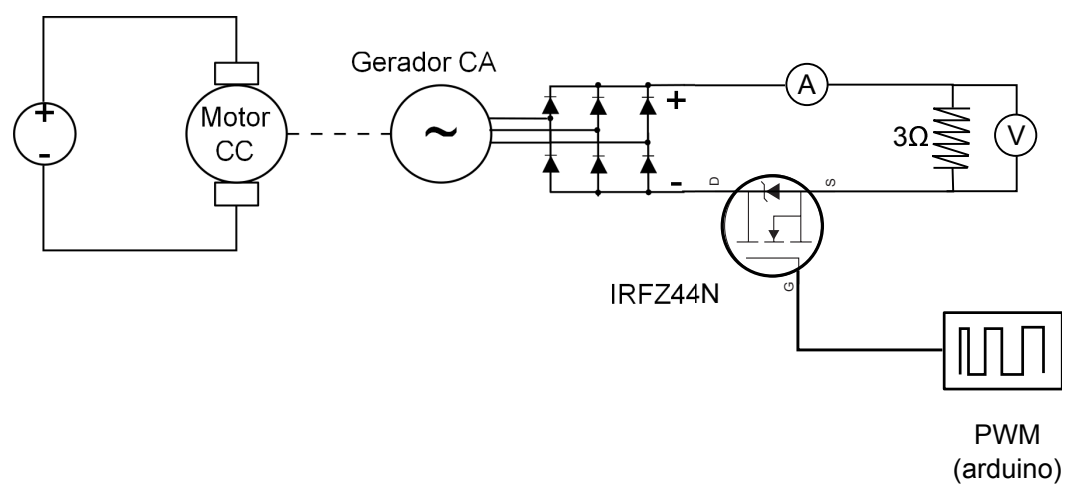

Figura 15 - Circuito utilizado na calibração do gerador.

O PWM é um sistema de modulação digital cíclica que controla o tempo que a onda permanece em sua amplitude máxima. A Figura 16 é a representação da modulação PWM, 
nesse sistema o controle é feito pela porcentagem do tempo de trabalho (dutyCycle), que representa a porcentagem do tempo que a onda permanece em seu valor máximo (HIRZEL, 2006).

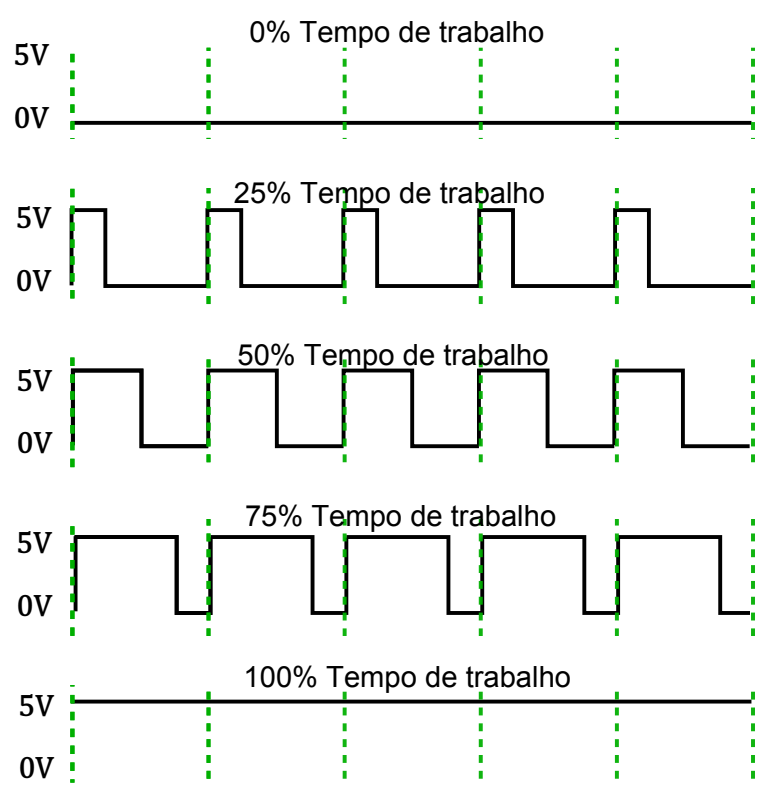

Figura 16 - Modulação por largura de pulso (PWM).

No sistema de controle da carga, Figura 15, quando a onda do PWM tem seu valor máximo significa que o transistor, IRF44N, estará fechado fazendo com que a resistência se conecte ao gerador e assim freando o eixo. Quando o PWM é mínimo, o transistor estará aberto deixando o gerador sem carga. O PWM aplicado é criado por um microcontrolador do tipo Arduino, sendo que frequência da onda nesse dispositivo é fixa em 500hz.

\subsubsection{Instrumentação}

Os sistemas de aquisição de dados, controle e monitoramento dos ensaios deste trabalho foram construídos utilizando o microcontrolador Arduino. A Figura 17 ilustra o esquema da ligação entre eles. Os sensores enviam um sinal, analógico ou digital, para o Arduino que os processa e envia, via comunicação serial. O Arduino também é responsável por controlar o sistema de controle para variação da carga utilizando uma saída PWM. O monitoramento dos ensaios foi realizado pelo software LabView. A Tabela 2 apresenta os sensores utilizados para a medir a potência elétrica na saída do gerador. 


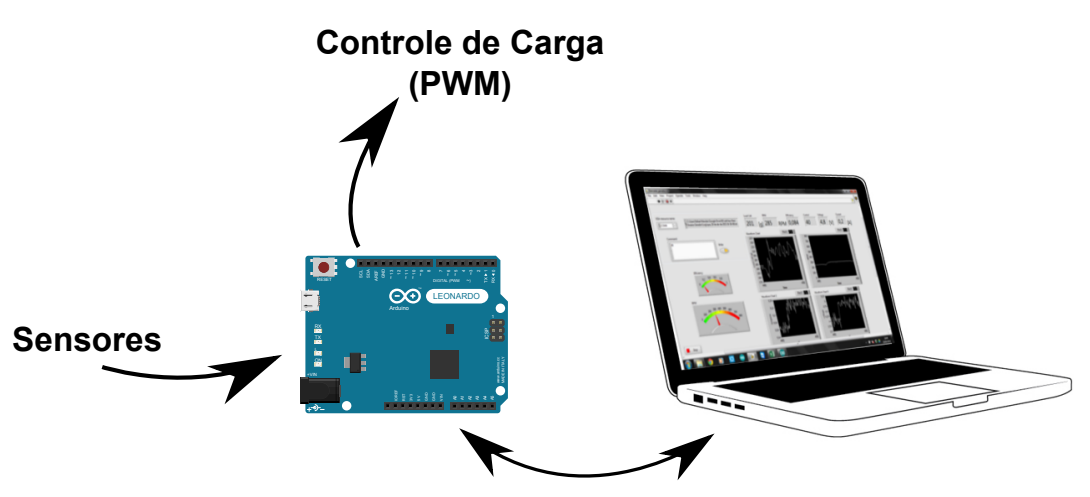

Figura 17 - Esquemático de controle e aquisição de dados utilizando o microprocessador Arduino.

Tabela 2 - Especificações do sensores utilizados para a medir a potência elétrica

\begin{tabular}{clc}
\hline & Corrente & \multicolumn{1}{l}{ Tensão } \\
\hline Fabricante: & \multicolumn{2}{l}{ Allegro Microsystems } \\
Modelo: & ACS712 & FZ0430 \\
Range: & $0-15[\mathrm{~A}]$ & $0-25[\mathrm{~V}]$ \\
Resolução: & $0.01[\mathrm{~A}]$ & $0.02[\mathrm{~V}]$ \\
\hline
\end{tabular}

Os sensores apresentados na Tabela 2 podem ser usados em circuitos de corrente continua ou alternada. Nos ensaios do gerador, a corrente produzida é continua, mas o controle da carga é feito por um transistor que abre e fecha o circuito, transformando um circuito novamente em corrente alternada. A frequência de modulação do transistor é de $500 \mathrm{~Hz}$ e para conseguir medir nessa faixa de frequência os sensores foram programados para $10 k H z$. Sendo assim, o sistema de medição elétrica realiza 20 medidas em um ciclo de modulação do PWM (2 milissegundos).

Para simplificar a quantidade de dados, uma média temporal do tipo RMS (root mean square) foi utilizada nos dados adquiridos pelos sensores elétricos. Em termos físicos, o valor RMS de uma corrente alternada é o valor equivalente a uma corrente corrente contínua que transmite a mesma potência, sendo assim

$$
P_{\text {ele }}=R I_{r m s}^{2}
$$

e pela definição

$$
I_{r m s}=\sqrt{\frac{1}{T^{\prime}} \int_{0}^{T^{\prime}} i(t)^{2} d t},
$$

sendo $T^{\prime}$ o período em que as medições foram realizadas. 
Para medir a rotação utilizou-se um sensor de proximidade indutivo. Esse sensor é um dispositivo eletrônico capaz de detectar a presença ou aproximação de elementos metálicos diversos. Com a finalidade de produzir um sinal facilmente detectável pelo sensor de rotação, um pequeno elemento metálico foi soldado ao eixo do gerador. Dessa forma, a cada passagem do elemento metálico pelo sensor, este envia um pulso de voltagem. A frequência de tais pulsos fornece uma medida direta da velocidade angular eixo do gerador.

O resultado da frequência entre os pulsos é a medida da velocidade angular. A Tabela 3 apresenta as especificações do sensor de proximidade e célula de carga utilizada nos ensaios.

Tabela 3 - Especificações do sensor de proximidade e célula de carga

\begin{tabular}{ccc}
\hline & Sensor de proximidade & Célula de carga \\
\hline Fabricante: & Telemecanique & AVIA \\
Modelo: & XS4P18AB110 & Hx771 \\
Range: & $5000 \mathrm{RPM}$ & $0-5000[\mathrm{~g}]$ \\
Resolução: & $1[\mathrm{RPM}]$ & $1[\mathrm{~g}]$ \\
\hline
\end{tabular}

O Apêndice B apresenta as curvas de calibração de todos os sensores utilizados nesse trabalho.

\subsection{Ensaio da turbina em túnel de vento aberto}

O objetivo do ensaio da turbina é obter a curva de do coeficiente de potência $(C p)$ em função da velocidade de ponta de pá $(\lambda)$.

Como já visto anteriormente, a razão de velocidade de ponta de pá, $\lambda$, é função do raio, velocidade do escoamento e velocidade angular. Portanto, para variar o valor de $\lambda$ é necessário alterar a velocidade do vento ou a velocidade de rotação da turbina. No presente trabalho a metodologia utilizada foi variar o $\lambda$ por meio da variação da velocidade de rotação da turbina, mantendo-se a velocidade do escoamento constante em todos os ensaios. A variação da velocidade da turbina é obtida através da aplicação de uma carga do gerador. Toda vez que a carga do gerador é acionada a velocidade turbina diminui, logo o gerador tem o comportamento similar a um freio.

A Figura 18 apresenta fotos da montagem experimental da turbina localizada a jusante do túnel de vento aberto. É importante escolher um local em que o escoamento apresente perfil de velocidade média uniforme, pois assim é possível medir corretamente a velocidade que o escoamento chega no rotor. A posição escolhida para o ensaio foi determinada por meio da análise das medidas de velocidade do escoamento. 

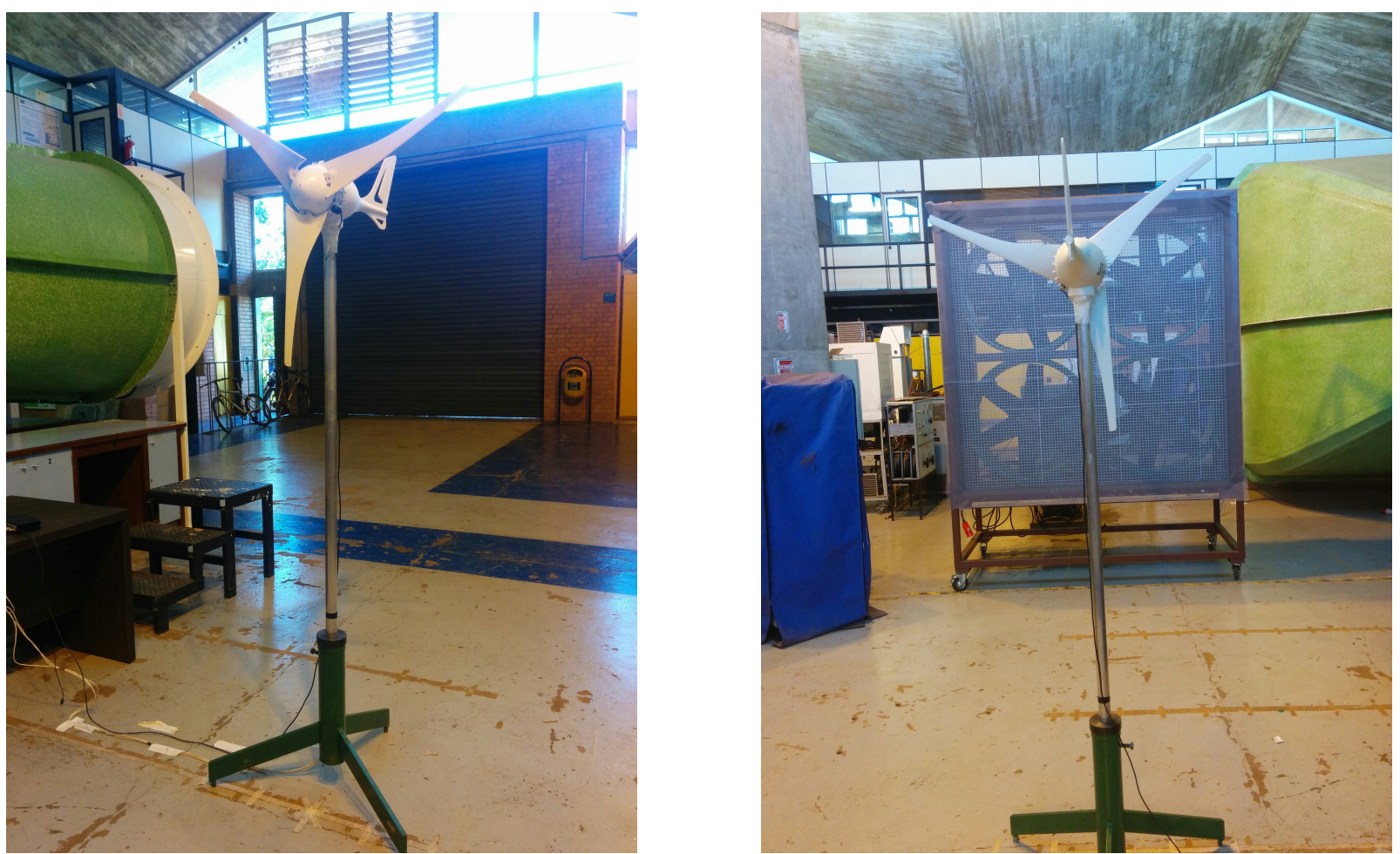

Figura 18 - Montagem experimental do ensaio da turbina em túnel de vento.

\subsubsection{Controle de velocidade da turbina}

O controle de velocidade no ensaio da turbina foi feito utilizando o mesmo circuito de carga adotado no ensaio do gerador. A Figura 19 apresenta o esquema eletromecânico utilizado no ensaio da turbina, o escoamento aciona a turbina trifásica, que está conectada a uma ponte retificadora, a um transistor e a uma resistência. A única diferença, em relação ao circuito do ensaio do gerador, é a troca do motor pelo rotor da turbina, desta forma o sistema todo passa a ser acionado pelo vento.

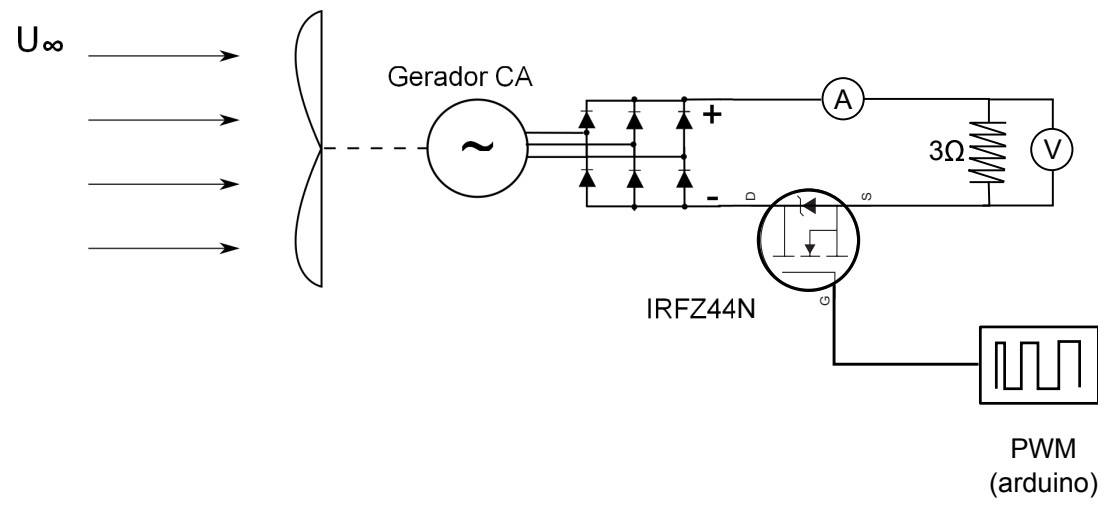

Figura 19 - Esquema elétrico do controle da turbina

Para o controle da velocidade foi utilizada um controlador do tipo proporcional integral derivativo, mais conhecido como PID. O controle da turbina é feito utilizando uma malha fechada. A Figura 20 mostra o diagrama de blocos utilizado no sistema de controle. 
O sistema funciona através da comparação da velocidade real da turbina com a velocidade pré determinada por um set point. Após a comparação, um valor de erro é utilizado para calcular o parâmetro de de controle, que é usada para o tempo de acionamento do PWM e assim aumentar ou diminuir a carga.

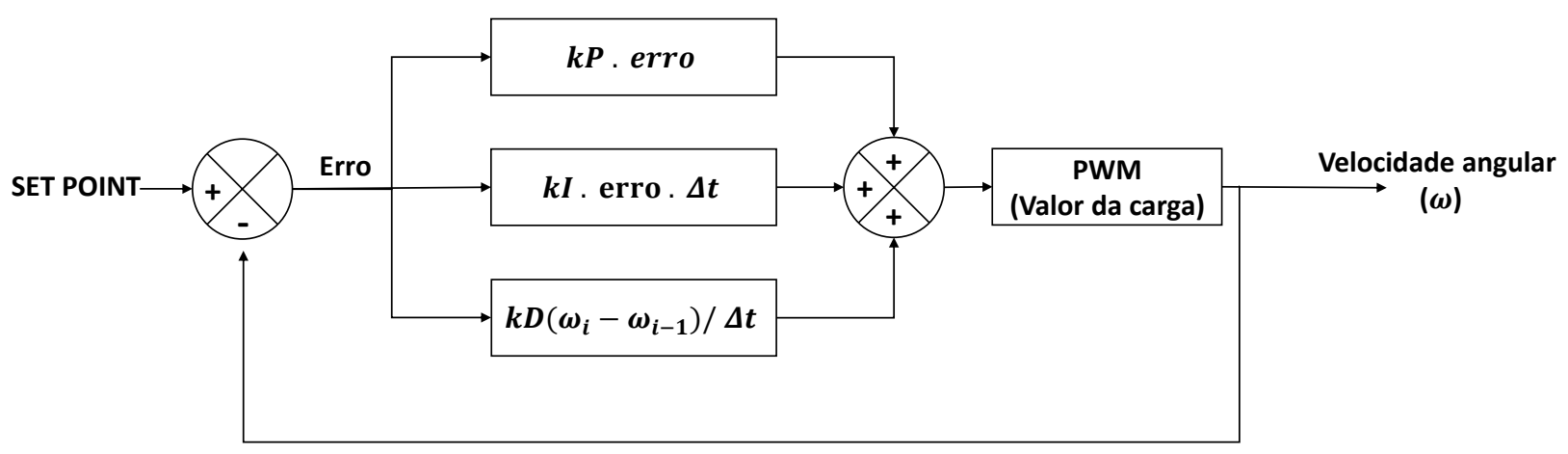

Figura 20 - Diagrama de bloco do controle PID da turbina

No diagrama, $\omega_{i}$ e $\omega_{i-1}$ são medidas de velocidade angular realizadas no tempo $i$ e $\Delta t$ o tempo entre as medidas. As constantes $k P, k I$ e $k D$ são as constantes do controlador PID, elas foram determinadas por meio de um ensaio estabilidade da turbina no túnel de vento. Nesse ensaio, os valores das constantes de controle são ajustados até a velocidade de rotação conseguir ser igual ao setpoint.

\subsubsection{Procedimentos dos ensaios de potência da turbina}

Os procedimentos utilizados para obter o coeficiente de potência da turbina no ensaio em túnel de vento são descritos na lista abaixo.

1. Acionar o túnel de vento, sendo que por meio de sua calibração é possível saber o perfil de velocidade na turbina;

2. Definir, utilizando o sistema de controle, a velocidade de rotação da turbina;

3. Medir corrente, tensão e velocidade de rotação;

4. Calcular da potência elétrica;

5. Identificar o rendimento $(\eta)$ do gerador, utilizando a velocidade rotação, valor da carga e curvas de calibração do gerador;

6. Calcular a potência mecânica do eixo da turbina, utilizando

$$
P_{\text {mec }}=\frac{P_{\text {ele }}}{\eta}
$$


7. Calcular o valor de $C p$ para a velocidade de rotação definida;

8. Definir outra velocidade de rotação e repetir os procedimento de 1 a 7 . 


\section{Metodologia numérica}

No presente trabalho, pretende-se realizar simulações numéricas de uma turbina de eixo horizontal com a metodologia RANS, utilizando o software CFX ANSYS. Primeiramente, um estudo de malha foi realizado comparando o ponto máximo do coeficiente de potência. Logo após, foram simulados pontos de $C p$ para diversas condições de operação da máquina. A validação foi realizada por meio da comparação das uma curvas de $C p \times \lambda$ numéricas e experimental. Por fim, uma metodologia para o cálculo do fator de indução axial por meio da utilização dos dados já simulados é apresentada nessa seção.

As simulações foram realizadas no Laboratório de energia e ambiente (LEA) da Universidade de Brasília (UnB), a Tabela 4 mostra a especificação do computador utilizado. Para todas as simulações foram utilizados a versão R15.0 do ANSYS.

Tabela 4 - Especificações computacionais.

\begin{tabular}{cc}
\hline Processador & Intel Xeon E5-2643 $3.50 \mathrm{GHz}$ \\
Quantidade de processadores & 2 \\
Quantidade de núcleos & 24 \\
Memória RAM & $32 \mathrm{~GB}$ \\
\hline
\end{tabular}

\subsection{Modelo de turbulência}

O escoamento que passa através do rotor é considerado incompressível e totalmente turbulento. Consequentemente, os campos de velocidade e pressão são governados pelas equações de Navier-Stokes. Visando considerar o fenômeno de turbulência sem resolver todas as escalas de vórtices, a metodologia RANS (Reynolds Average Navier-Stoke) foi utilizada. Nessa metodologia, a contribuição da flutuação da velocidade turbulenta $u_{i}^{\prime}$ para média temporal dos campos de velocidade e pressão a contribuição é dada pelo tensor de tensões de Reynolds $\tau_{i j}=\rho \overline{u_{i}^{\prime} u_{j}^{\prime}}$, o qual deve ser modelado (POPE, 2000; DAVIDSON, 2004). Existem inúmeros modelos disponíveis na literatura para resolver esse problema, como é visto em Wilcox (1988) e mais recente, Argyropoulos e Markatos (2015).

No presente trabalho, o modelo $\kappa-\omega$ Shear-Stress Transport $(S S T)$, descrito em Menter (1993) e Menter (1994), foi adotado. O modelo SST foi desenvolvido para dar uma resposta a necessidade dos modelos que lidam com escoamentos aeronáuticos com grandes gradientes adversos de pressão e descolamento da camada limite. Para resolver isso, o $S S T$ combina os modelos $\kappa-\omega$, em regiões próximas a paredes sólidas, com o $\kappa-\epsilon$, para regiões de escoamento livre fora da camada limite. Isso é possível devido a definição de "funções de troca", que dependem da quantidade de turbulência e da distância 
normal adimensional da parede. Dessa maneira, $\kappa-\omega$ calcula a contribuição da turbulência no interior da camada limite, sem nenhum amortecimento na flutuação. Por outro lado, $\kappa-\epsilon$ é aplicado fora da camada limite, evitando a sensibilidade que o modelo $\kappa-\omega$ tem para condições de escoamento livre. Portanto, o modelo SST tem encontrado bons resultados para escoamentos com a presença de camada limite, até em casos com regiões de camada limite totalmente separada. Nesse contexto, é natural a escolha desse modelo para simulações numéricas de turbinas de eixo horizontal.

\subsection{Modelo geométrico}

Para realizar uma simulação da turbina é necessário ter todos os dados geométricos do rotor, para assim reproduzi-los em um modelo. No caso da turbina utilizada nesse trabalho, a geometria não era conhecida, portanto foram necessário realizar medidas no rotor para assim obter um modelo correspondente. O modelo geométrico da turbina foi obtido por meio de medições experimentais realizadas por um braço de medição Romer AACM de seis graus de liberdade e com o auxilio do software Gpad. A Figura 21 mostra as marcações em que foram realizadas as medidas de coordenadas na pá e o resultado obtido para a elaboração do desenho da turbina.

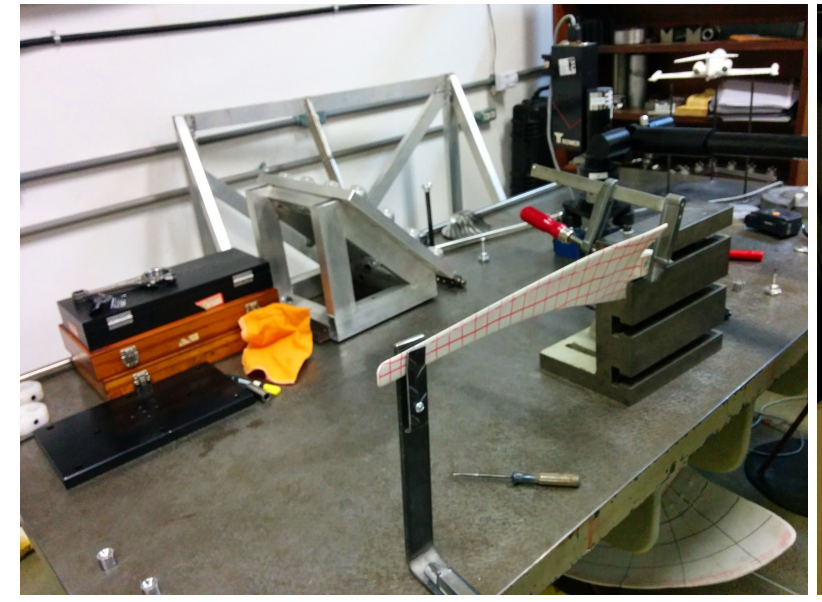

(a) Marcação utilizada para medição da pá.

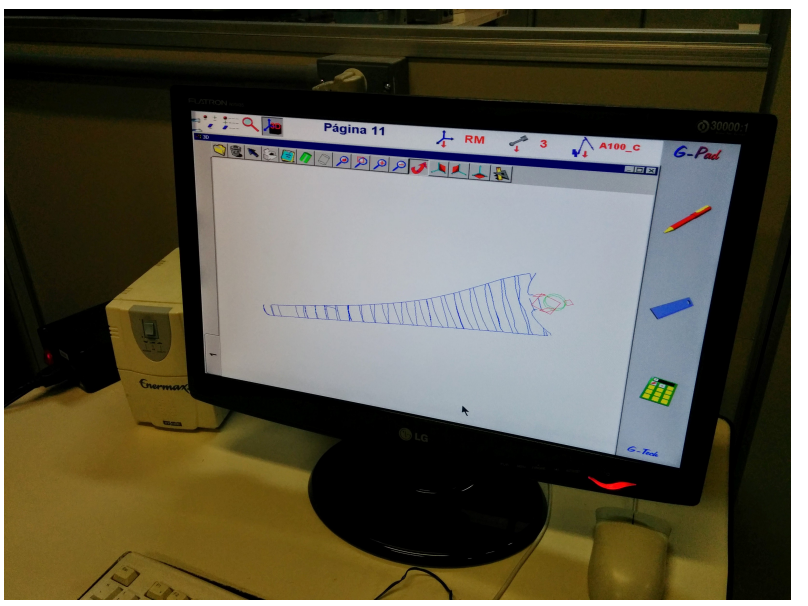

(b) Resultados obtidos.

Figura 21 - Metodologia experimental para medição da geometria da pá.

Após realizar a medição da pá, o modelo geométrico foi construído utilizando o software SolidWorks. A Figura 22 mostra o desenho tridimensional da pá, obtido após os procedimentos anteriormente descritos. Para a elaboração do modelo geométrico da turbina foram realizados algumas simplificações na geometria do cubo com a finalidade de eliminar pequenas superfícies e assim, facilitar a elaboração da malha numérica. Como resultado final, o cubo foi desenhado como a junção de uma semiesfera e um cilindro. A Figura 23 apresenta o resultado final do modelo utilizado para a construção da turbina. 


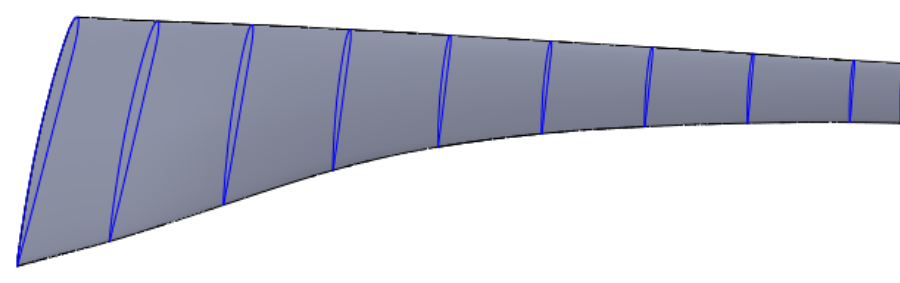

Figura 22 - Modelo da pá desenhado em SolidWorks.
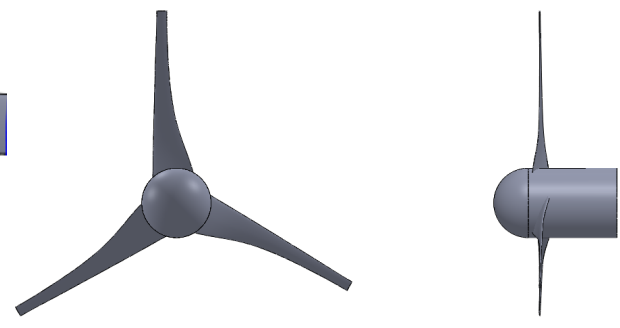

Figura 23 - Modelo completo da turbina.

\subsection{Condições de contorno}

Utilizou-se o software Ansys Meshing CFD para geração da malha computacional empregadas nas simulações numéricas. A malha foi dividida em dois domínios, um rotativo e outro estacionário, como observado na Figura 24. O domínio rotativo, representado pela parte cinza, é formado por um cilindro de diâmetro de $1.4 \mathrm{D}$ e $0.5 \mathrm{D}$ de espessura, sendo D o diâmetro da turbina (aproximadamente 1 metro), esse domínio apresenta uma alta densidade de elementos devido sua proximidade com a parede do rotor. O domínio estacionário é formado por um prisma retangular de dimensões 4Dx4D e espessura 10D. A posicionamento entre os dois domínios é muito importante, pois a as fronteiras do sistema podem influenciar o escoamento ao redor da turbina, produzindo condições de contorno eventualmente tão diferentes das condições físicas dos ensaios que influenciem nos resultados das simulações.
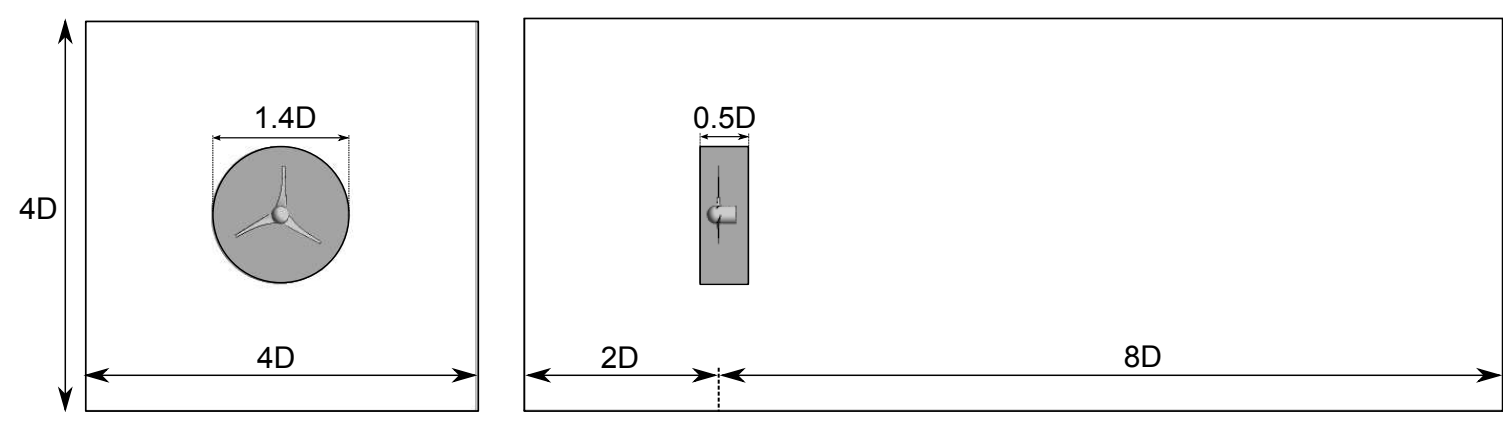

Figura 24 - Domínios utilizados para geração da malha. A região cilíndrica representa o domínio rotativo e o prisma externo representa a região sem rotação.

Segunda a literatura, para obter bons resultados do coeficiente de potência, a turbina deve ficar com no mínimo 1,5 diâmetros de distância da fronteira do domínio, sendo que uma distância muito pequena entre a turbina e limite do domínio pode causar um aumento artificial do fator de indução da turbina (LEE et al., 2012; MOSHFEGHI; SONG; XIE, 2012; SILVA, 2014).

A posição do final do domínio a jusante da turbina também é importante para que a fronteira não influencie no escoamento da esteira aerodinâmica formada pela turbina. 
Sendo assim, segundo Mo e Lee (2012) e Oggiano (2014), uma distância de no mínimo 3D é o suficiente para obter bons resultados para o coeficiente de potência.

As condições de contorno aplicadas neste trabalho são as mesmas usadas na maioria dos estudos de turbinas de fluxo livre (LEE et al., 2012; MOSHFEGHI; SONG; XIE, 2012; SILVA, 2014). Esses parâmetros visam representar a simulação o mais próximo do modelo real. A Figura 25 mostra o local em que cada condição de contorno foi aplicada.

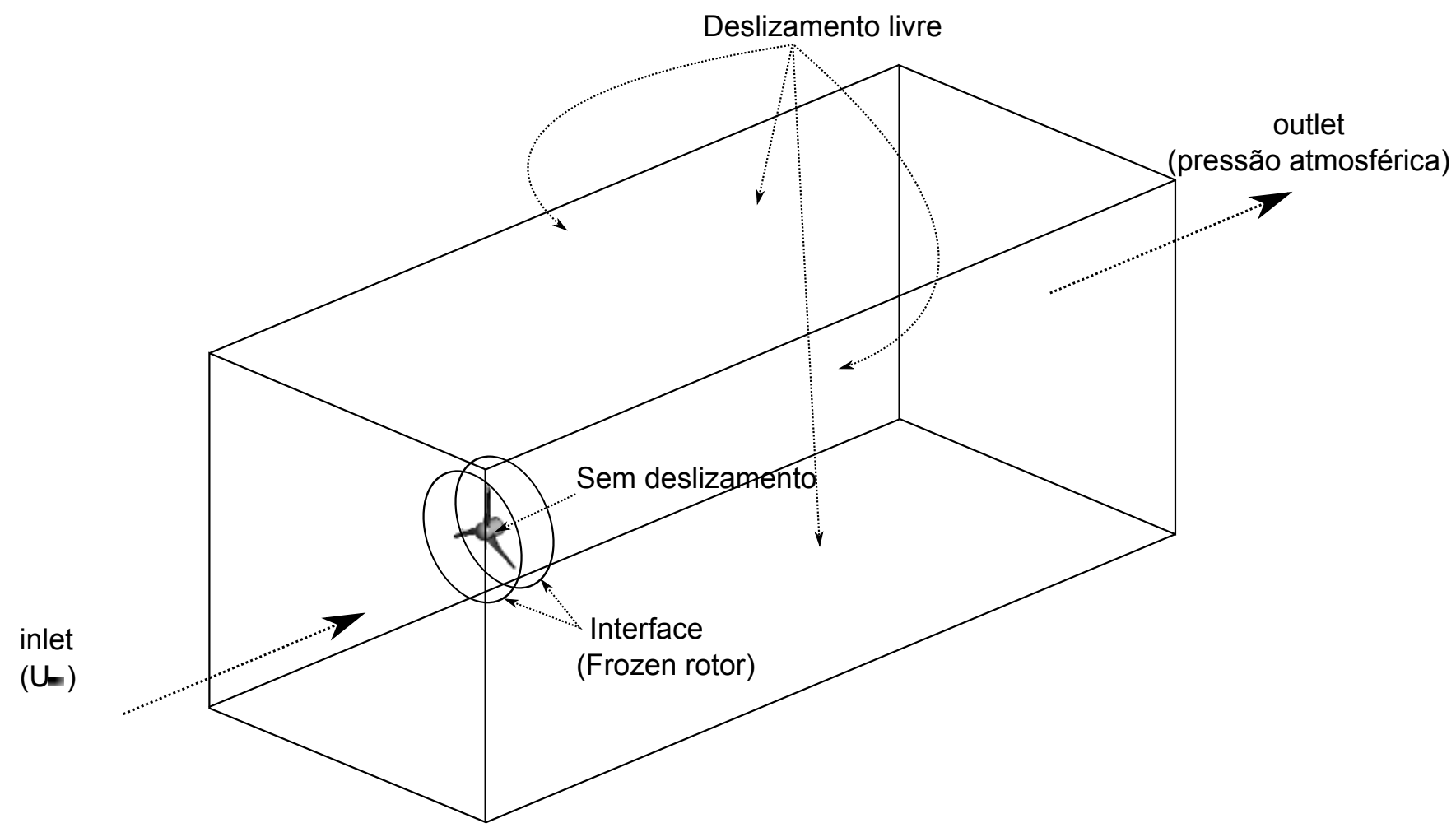

Figura 25 - Condições de contorno aplicadas na simulação numérica, sendo a região inlet a seção de entrada do escoamento e a outlet a seção saída.

- Seção de entrada do escoamento: perfil uniforme de velocidade a $5 \mathrm{~m} / \mathrm{s}$ com $10 \%$ de intensidade de turbulência;

- Seção de saída: pressão prescrita igual à pressão atmosférica com gradiente de velocidade nulo;

- Seção laterais do domínio: paredes impenetráveis com tensão de cisalhamento nula, evitando a formação de camadas limites nos extremos do domínio e reduzindo sua influência nos resultados;

- Superfície da turbina: condição de não deslizamento, i.e. velocidade nula sobre a superfície. 
É necessário especificar, no caso do CFX, que na interface entre domínios existe uma condição de continuidade de propriedades. Além disso, para que o efeito de rotação do rotor seja corretamente simulado, dentro do subdomínio cilíndrico, as forças Centrípeta e de Coriólis correspondentes a de um referencial rotativo, na direção axial com velocidade angular $\omega$, devem ser consideradas ${ }^{1}$.

Para obtenção da curva do coeficiente de potência $(C p)$ a velocidade do escoamento $\left(U_{\infty}\right)$ foi fixada em $5 \mathrm{~m} / \mathrm{s}$ e a velocidade de rotação $(\omega)$ foi variada. A Tabela 5 mostra os pontos de operação utilizados para obtenção da curva.

Tabela 5 - Pontos de operação utilizado nas simulações numérica.

\begin{tabular}{ccccccccc}
\hline$U_{\infty}$ & \multicolumn{10}{c}{$5 \mathrm{~m} / \mathrm{s}$} \\
Rotação [RPM] & 300 & 400 & 500 & 600 & 700 & 800 & 900 & 1000 \\
\hline
\end{tabular}

A convergência de todas as simulações foi monitorada por meio da variável $C p$. Utilizou-se uma tolerância de $1 \%$ para o controle das simulações, sendo que foram usados no mínimo 100 interações em cada caso.

\subsection{Estudo de convergência de malha}

A Figura 26 mostra os refinamentos realizados na malha, mostrando uma aproximação na região que representa a parede do rotor. Segundo o trabalho de Moshfeghi, Song e Xie (2012), o refinamento a jusante da turbina influencia o valor da potência total produzida pela turbina, tendo em vista que nessa área há um elevado gradiente de pressão e velocidade devido a esteira aerodinâmica da turbina. Outra região que foi realizado o adensamento da malha numérica foi na superfície do rotor, como mostrado na Figura 27. Essa região é onde está a camada limite da turbina, portanto além de refinar, foram colocados algumas camadas de elementos prismáticos para captar toda a produção e dissipação de turbulência. Por fim, uma região a montante da turbina foi refinada, para evitar interferência da malha no momento do cálculo do fator induzido axial.

$\overline{1}$ No presente trabalho, utilizou-se a propriedade "frozen rotor"para realizar a mudança dos componentes do domínio estacionário para um sistema de referência móvel. 


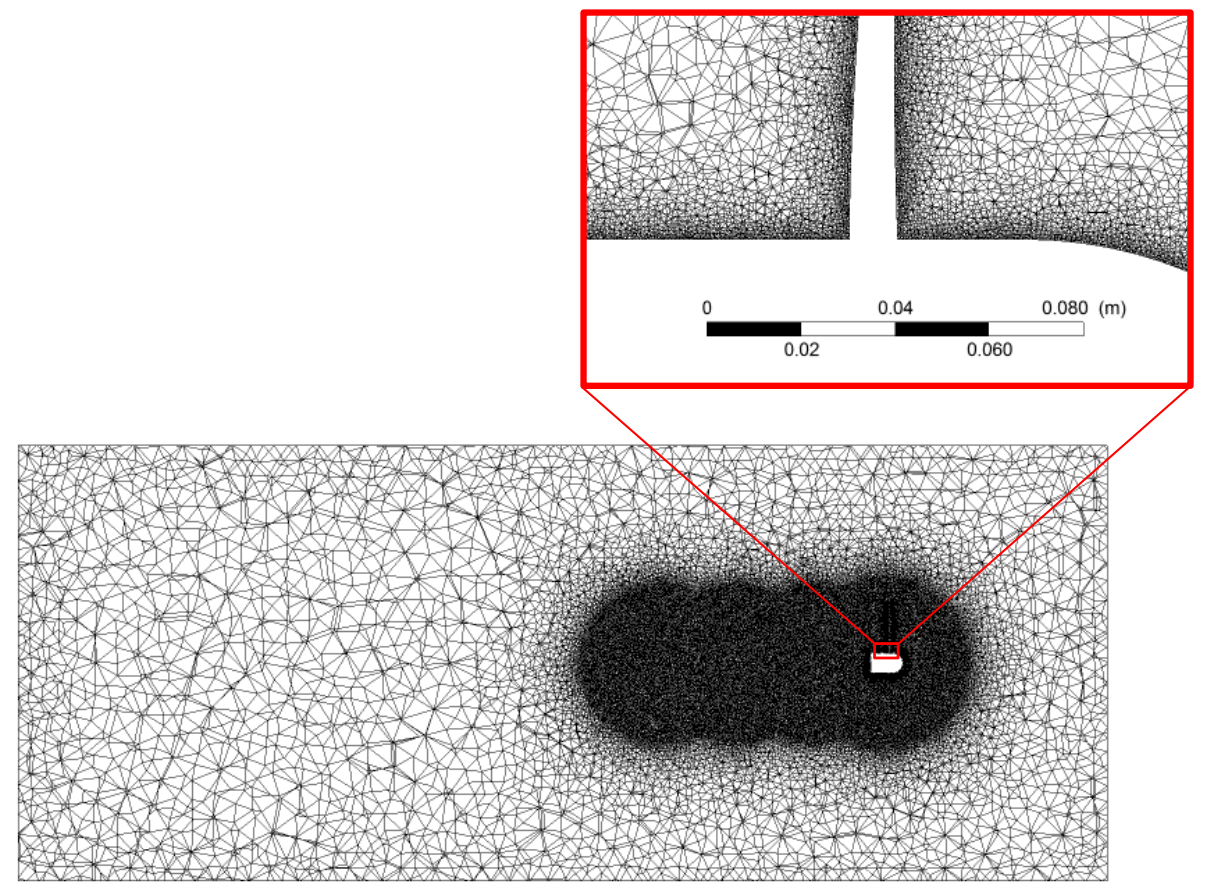

Figura 26 - Refinamento da malha ao longo dos domínios.

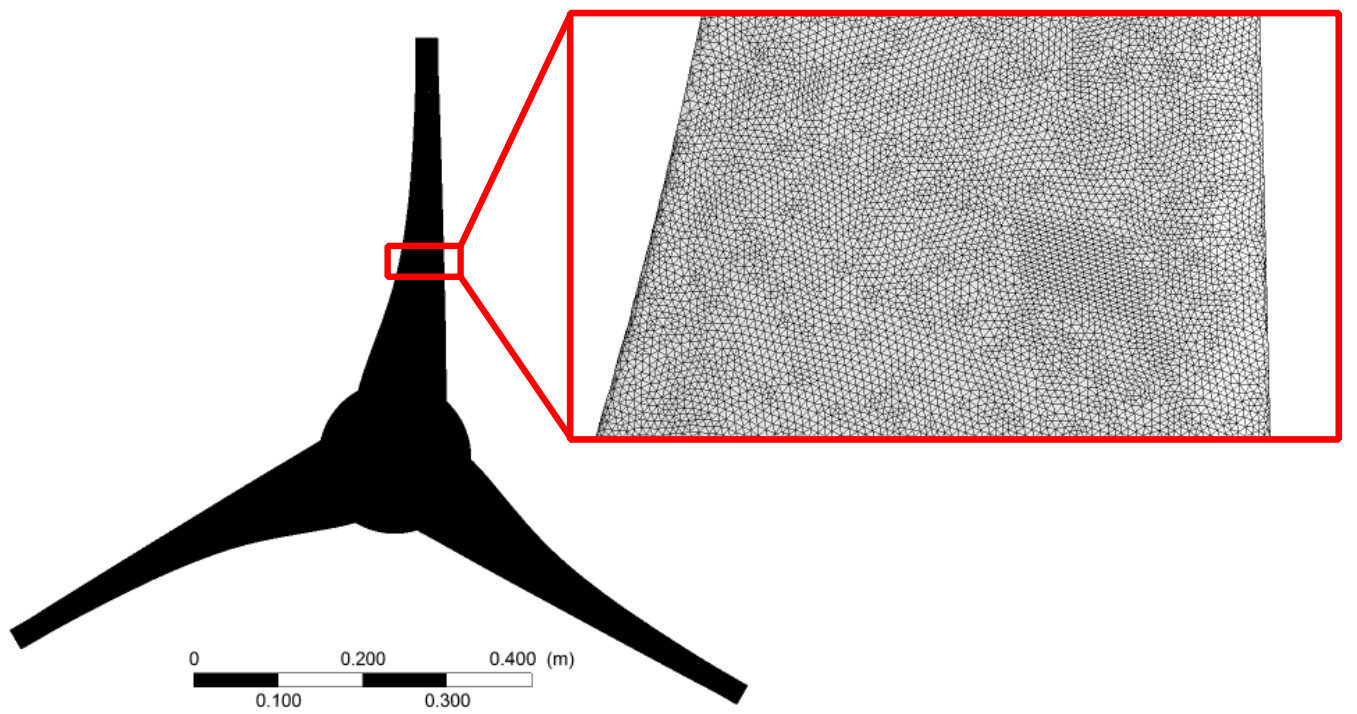

Figura 27 - Representação da malha na parede do rotor.

A Tabela 6 mostra o conjunto de malhas utilizadas para realização do estudo da convergência de malha. Os parâmetros mais relevantes foram o valor do $C p$, pois a validação será realizada por meio dessa variável e o valor do $y^{+}$, devido sua importância no modelo de turbulência $S S T$. O análise de convergência foi feita para o ponto de $C p$ máximo $(\lambda \approx 5,2)$. É possível observar na tabela que o valor de $C p$ melhora a medida do crescimento da quantidade de nós da malha, porém é possível notar que depois da Malha 
5 o aumento na quantidade de nós não surte uma melhora no valor de $C p$. Sendo assim, a malha escolhida para realizar todas as simulações desse trabalho foi a Malha 5.

Tabela 6 - Estudo de convergência de malhas.

\begin{tabular}{lcccccc}
\hline & \multicolumn{3}{c}{ Refinamento na } & \multicolumn{2}{c}{$y^{+}$} & \\
& N de nós & esteira[m] & Máximo & Médio & Potência & Cp \\
\hline Malha 1 & 168905 & 1.4 & 1661.55 & 58.7789 & 9.68 & 0.1655 \\
Malha 2 & 507514 & 2.1 & 717.596 & 45.6648 & 13.11 & 0.2253 \\
Malha 3 & 619682 & 2.8 & 769.535 & 40.0019 & 13.027 & 0.22398 \\
Malha 4 & 2068005 & 3.5 & 425.897 & 24.2143 & 13.367 & 0.2498 \\
Malha 5 & 3777520 & 2.8 & 58.1949 & 12.4628 & 19.8 & 0.36046 \\
Malha 6 & 7943106 & 3.5 & 79.1332 & 17.6941 & 15.64 & 0.36554 \\
Malha 7 & 10479423 & 5.6 & 23.8446 & 0.333001 & 16.538 & 0.36327 \\
\hline
\end{tabular}

\subsection{Investigação do fator de indução axial}

O objetivo dessa metodologia é investigar o comportamento do fator de indução axial na região do escoamento a montante da turbina. Pretende-se definir uma função própria para o fator de indução por meio do pós processamento de dados do campo de velocidade obtidos na simulação numérica realizada.

O fator de indução axial é classicamente definido (Equação 2.2) como uma grandeza integral do escoamento, associada à uma razão entre a velocidade média na seção do rotor (disco atuador) e a velocidade do escoamento não perturbado. Sua definição original implica em que o perfil de velocidade no disco atuador é uniforme e igual à velocidade média do escoamento naquele plano, o que claramente não corresponde às constatações experimentais e numéricas (MA et al., 2014; OGGIANO, 2014). Sendo assim, um dos principais objetivos do presente trabalho é definir uma quantidade local similar ao fator de indução axial, que permita considerar variações de velocidade ao longo da coordenada radial do disco atuador, representativo do rotor hidrocinético. Mais ainda, reconhecendo que a velocidade média do escoamento a montante do rotor varia continua e suavemente ao longo da coordenada axial, assume-se aqui que

$$
\tilde{a}=\tilde{a}(r, z)
$$

em que o til será usado para discernir grandezas locais (nesse caso o fator de indução) de grandezas integrais, classicamente definidos pela teoria unidimensional do disco atuador. Assume-se que a origem da coordenada $z$ é o plano do rotor e que a mesma cresce na direção a montante da turbina, i.e. contrária à direção do escoamento. Sendo assim $U(r, z)=U_{\infty}$, quando $z \rightarrow \infty$, e $U(r, z)=\tilde{U}_{d}(r)$, quando $z=0$, em que $\tilde{U}_{d}(r)$ é a velocidade do escoamento no plano do rotor, assumida agora como local e dependente de $r$. 
Um dos principais objetivos dessa abordagem é permitir que se descreva uma velocidade no plano do rotor dependente de $r$. A definição de $\tilde{a}$ deve estar correlacionada à noção de fator de indução original. Para garantir isso, o fator de indução axial local deve ser tal que

$$
\tilde{U}_{d}(r)=U_{\infty}(1-\tilde{a}(r, 0))
$$

Integrando a Equação (4.2) na superfície da circular correspondente ao disco atuador, mostra-se que

$$
U_{d}=U_{\infty}\left[1-\frac{1}{A_{d}} \int_{S} \tilde{a}(r, 0) d S\right]
$$

A Equação (4.3), quando comparada com a Equação 2.2 permite concluir que o fator de indução global é a média superficial do fator de indução local, dada por

$$
a=\frac{1}{A_{d}} \int_{S} \tilde{a}(r, 0) d S .
$$

O presente trabalho pretende realizar o cálculo do fator de indução axial utilizando dados de velocidade oriundos da simulação numérica. Segundo a teoria clássica, o fator de indução é calculado pela relação entre a velocidade na entrada do disco atuador e a velocidade não perturbada, analogamente, a metodologia proposta irá considerar o fator de indução local como a relação entre a velocidade local e a velocidade não perturbada. A velocidade local será calculada em discos perpendiculares ao escoamento e a montante da turbina, para eliminar os efeitos de rotação após o escoamento passar através do rotor.

Em um disco em uma posição axial $z \neq 0$ o fator de indução médio em $\delta, a_{\delta}(r, z)$, será calculado utilizando-se inicialmente a vazão através de um anel circular de espessura $\delta$, centrado em $r$, como mostrados na Figura 28.
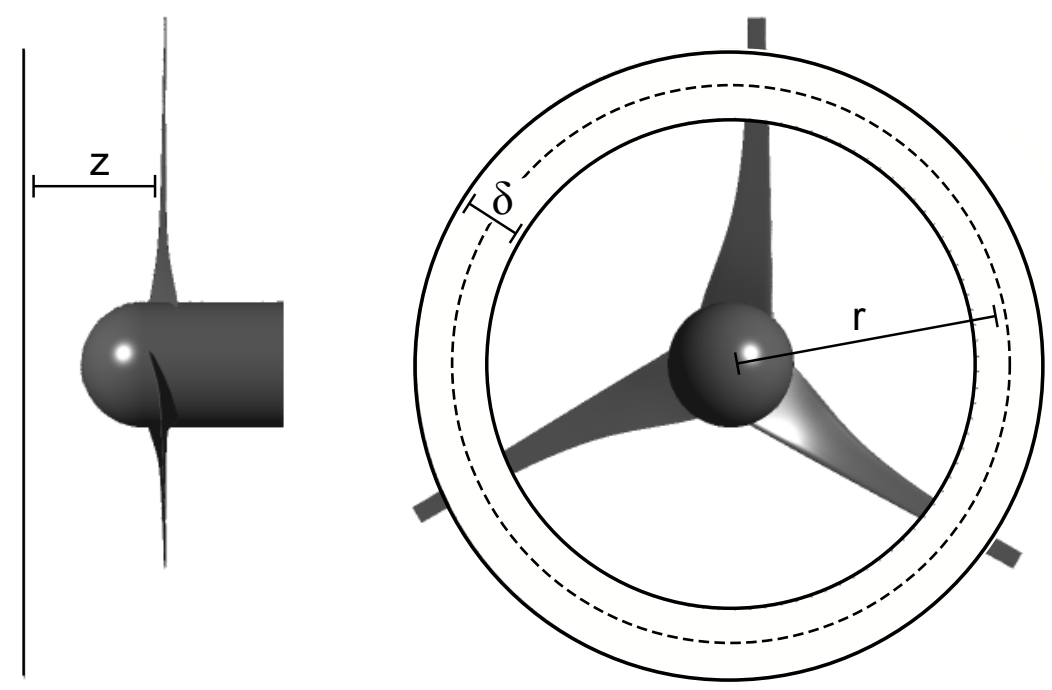

Figura 28 - Coordenadas utilizadas no cálculo do fator de indução axial. 
Mantendo a posição $r$ fixa, são tomados valores cada vez menores de $\delta$, estimando-se o limite de $a_{\delta}(r)$ para $\delta \rightarrow 0$. Utilizando uma extrapolação da curva $a_{\delta} \times \delta$ para $\delta=0$ é possível obter um fator de indução para um determinado $r$. Dessa forma, para um disco na posição $z$ o fator de indução axial pode ser computado para valores diferentes de $r$, tendo em vista que a variação de $r$ pode ser contínua. Esse procedimento pode ser realizado para vários planos de distância $z$ a montante da turbina, sendo que em cada um terá sua função $a_{\delta} \times \delta$. Entretanto, no planos $z=0$ não é possível empregar a mesma técnica devido a presença do rotor neste plano. Para poder obter o fator de indução no rotor nessa metodologia, a função $a(r)$ foi calculada para valores de discos cada vez mais próximos do rotor e extrapolada para $z=0$. Essa mesma metodologia pode ser aplicada experimentalmente, visto que ela só depende de medidas de velocidades a montante da turbina. 


\section{Resultados e discussões}

\subsection{Determinação do perfil de velocidades no túnel aberto}

As medidas de velocidade média do escoamento a jusante do túnel de vento aberto foram realizadas em quatro planos distintos localizados a 1,2,3 e 4 metros da parede de ventiladores. A Figura 29 apresenta os resultados da medição dos perfis de velocidade do túnel de vento atmosférico. Observa-se que a distribuição de velocidade média varia de acordo com a proximidade com o túnel. Nos planos de 1 e 2 metros é possível ver quatro regiões de menor velocidade, isso acontece devido a interferência causada pelo posicionamento ventiladores, representados pelos círculos na Figura 29. A medida que o escoamento se afasta da parede de ventiladores o campo de velocidade tende a ficar mais uniforme, como observado nos planos 3 e 4 metros.

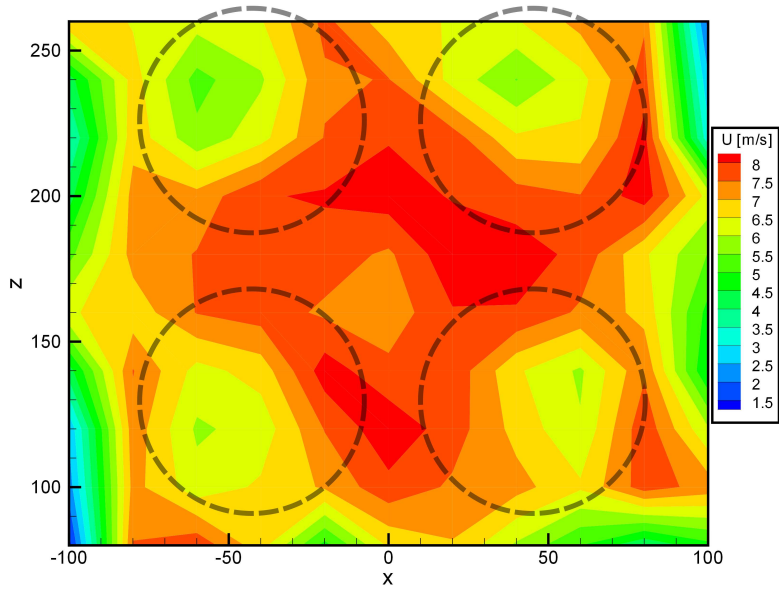

(a) 1 metro

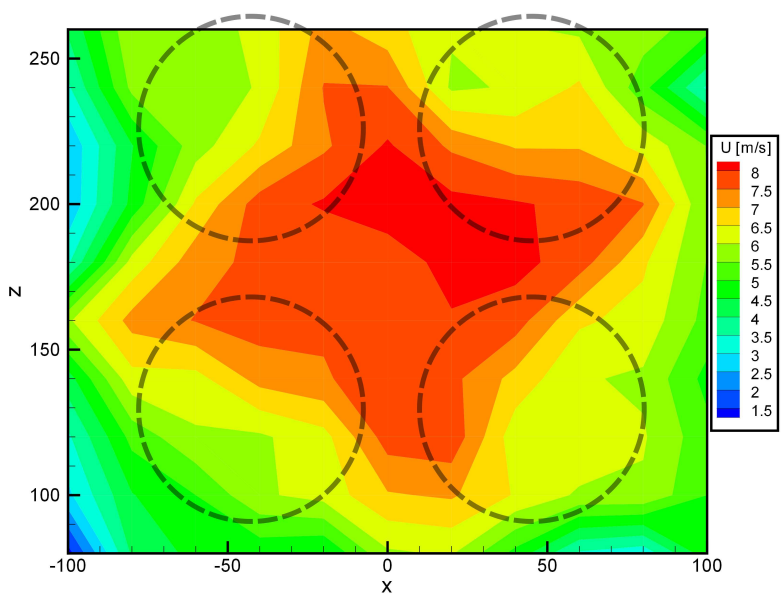

(c) 3 metros

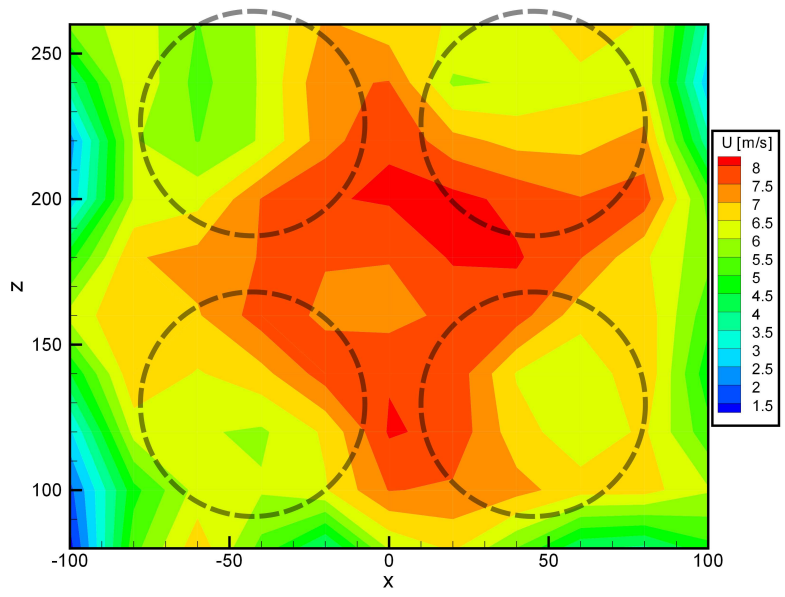

(b) 2 metros

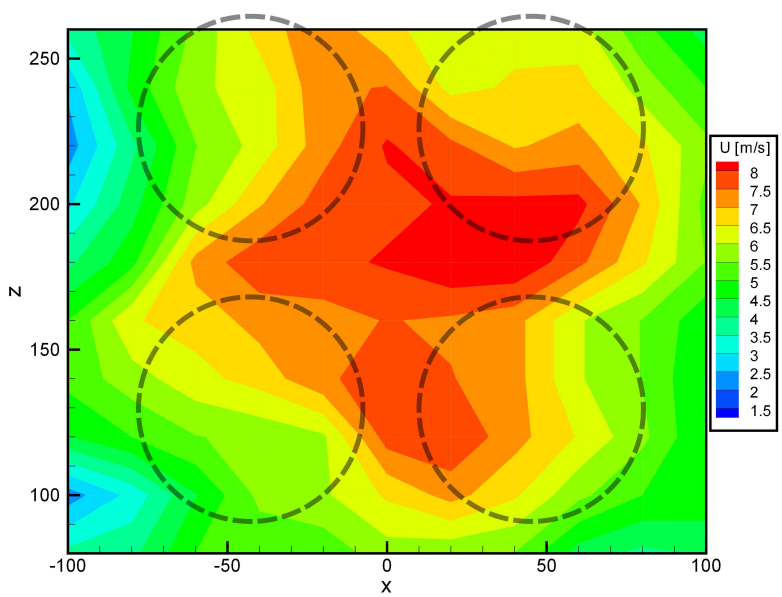

(d) 4 metros

Figura 29 - Velocidade nas seções de ensaio do túnel de vento aberto. 
A Figura 30 é a representação espacial dos perfis de velocidade, sendo que a parede com os ventiladores está localizada na posição $\mathrm{y}=0$.

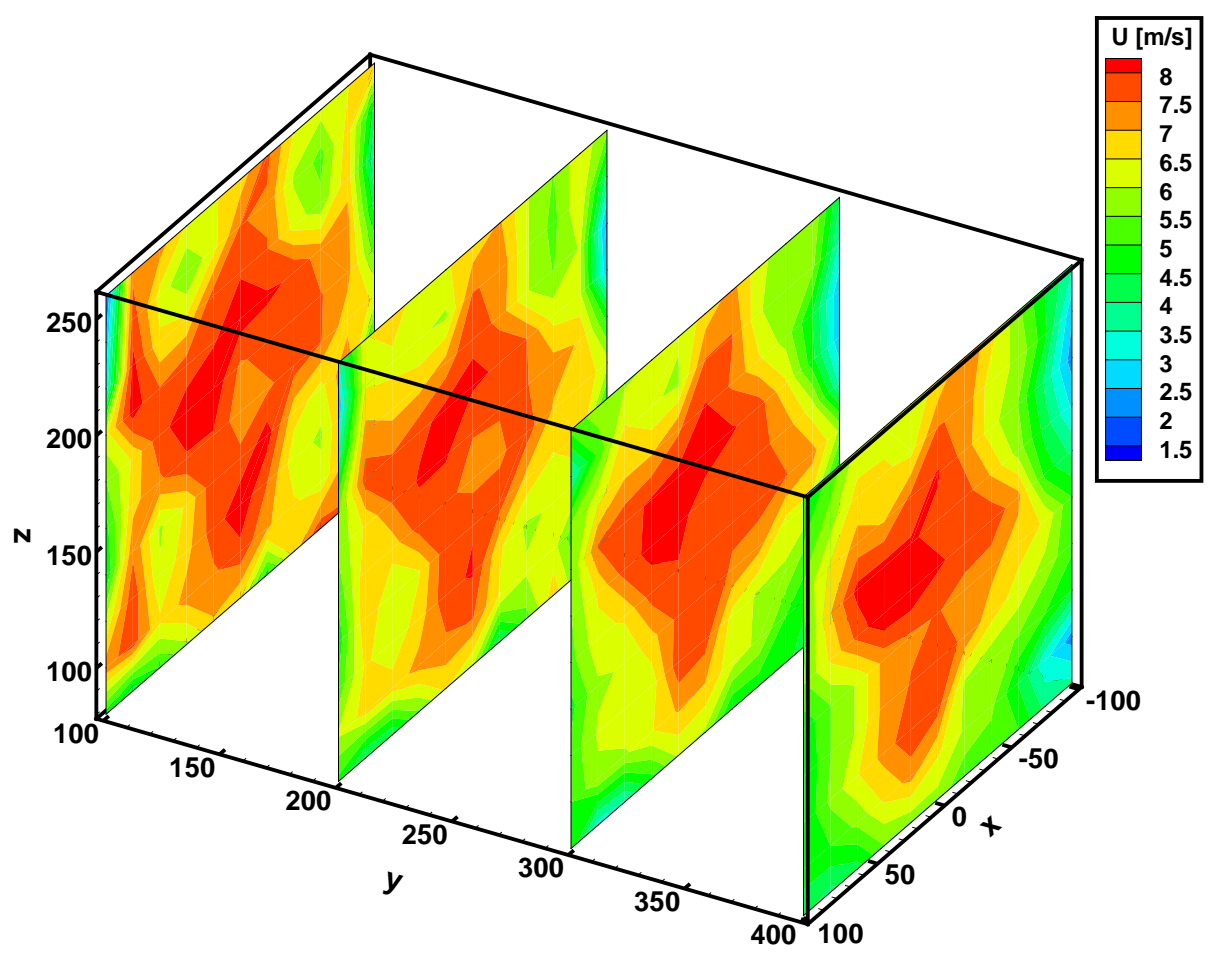

Figura 30 - Distribuição dos perfis de velocidade no espaço a jusante do túnel de vento.

Para escolher a melhor posição para executar ensaios com a turbina realizou-se um estudo visando identificar uma região no escoamento em que o perfil de velocidade mais se aproxima de uniforme. Para isso, cada plano foi subdividido em subseções progressivamente menores, como ilustra a Figura 31. A média e o desvio padrão entre todas as tomadas de velocidade dentro de cada subseção foram calculadas, sendo apresentados na Figura 32.

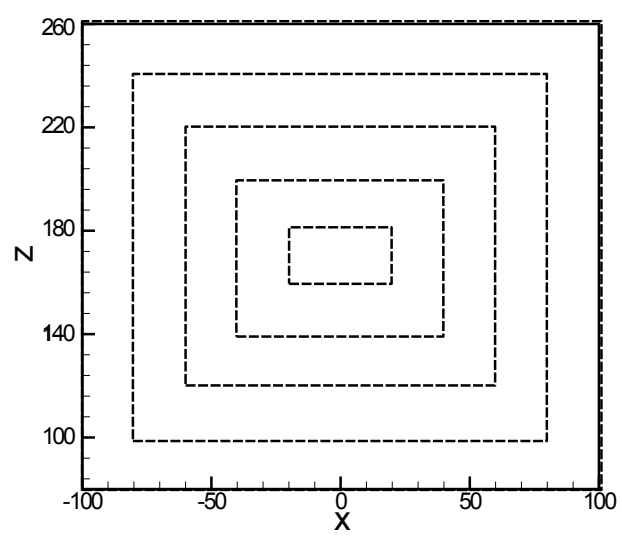

Figura 31 - Áreas utilizadas na análise do perfil de velocidade. 


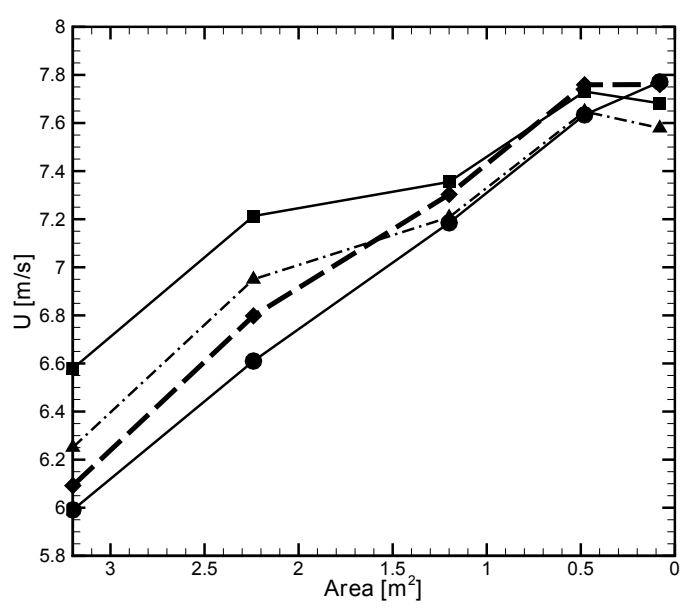

(a) Velocidade média

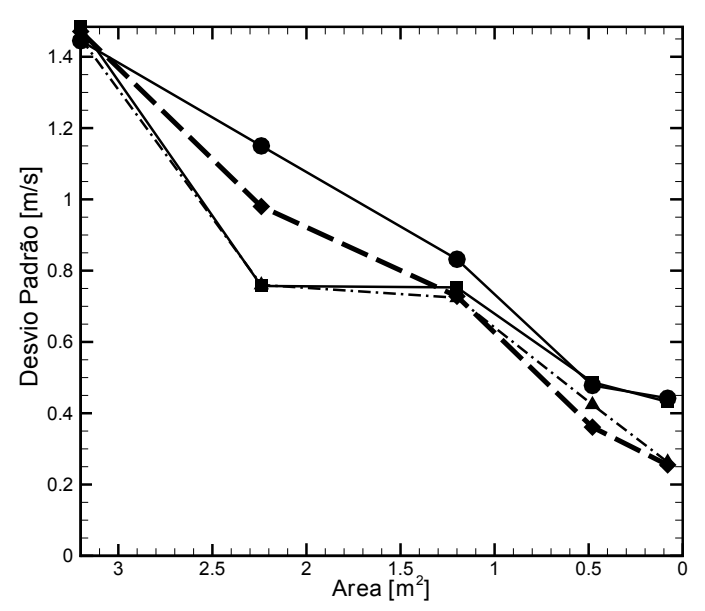

(b) Desvio padrão

Figura 32 - Análise da velocidade em função da área da seção. Cada linha representa um plano.

-: 1 metro; $\mathbf{\Delta}: 2$ metros;

$\checkmark$ : 3 metros; $\bullet: 4$ metros.

Pela Figura 32, nota-se que a velocidade aumenta enquanto o desvio diminui, ou seja, para áreas mais ao centro das seções do túnel de vento, o perfil de velocidade do escoamento é maior e mais uniforme, portanto a região central é o lugar ideal para se posicionar a turbina.

É possível notar, pelos primeiros pontos de cada curva da Figura 32(a), que o escoamento desacelera à medida que os planos se afastam da parede de ventiladores. Entretanto, próximo ao centro dos planos essa diferença se torna menor, fazendo com que as áreas centrais de cada plano tenham aproximadamente a mesma velocidade, independentemente da distância do plano à parede de ventiladores, dentro do domínio analisado no presente estudo.

A turbina utilizada nos ensaios tem aproximadamente $0,8 \mathrm{~m}^{2}$. A análise dos gráficos da Figura 32 indica que a melhor posição para realização dos experimentos é no centro do plano a 3 metros da parede de ventiladores, onde o desvio padrão é mínimo e o perfil de velocidade mais se aproxima de uniforme.

\subsection{Calibração do gerador}

A Figura 33 é o resultado das curvas de calibração do gerador da turbina. Cada curva do gráfico representa a eficiência $(\eta)$ do gerador para determinada carga em função da velocidade angular $(\omega)$ em RPM. Os pontos do gráficos foram obtidos através dos ensaios experimentais. Já as curvas foram obtidas utilizando um ajuste no conjunto de dados para cada carga. A função escolhida para o ajuste foi equação logaritma do tipo

$$
\eta=a \ln (\omega)+b
$$


Essa função foi escolhida devido ao seu comportamento ajustar os pontos encontradas para todas as cargas. A Tabela 11 apresenta os coeficientes $a, b$ e $R^{2}$ para cada carga. A variável $R^{2}$ é o Coeficiente de Determinação para o ajuste, ele é uma representação adimensional da qualidade de aproximação. O ajuste é tanto melhor quanto mais próximo da unidade é o Coeficiente de Determinação.

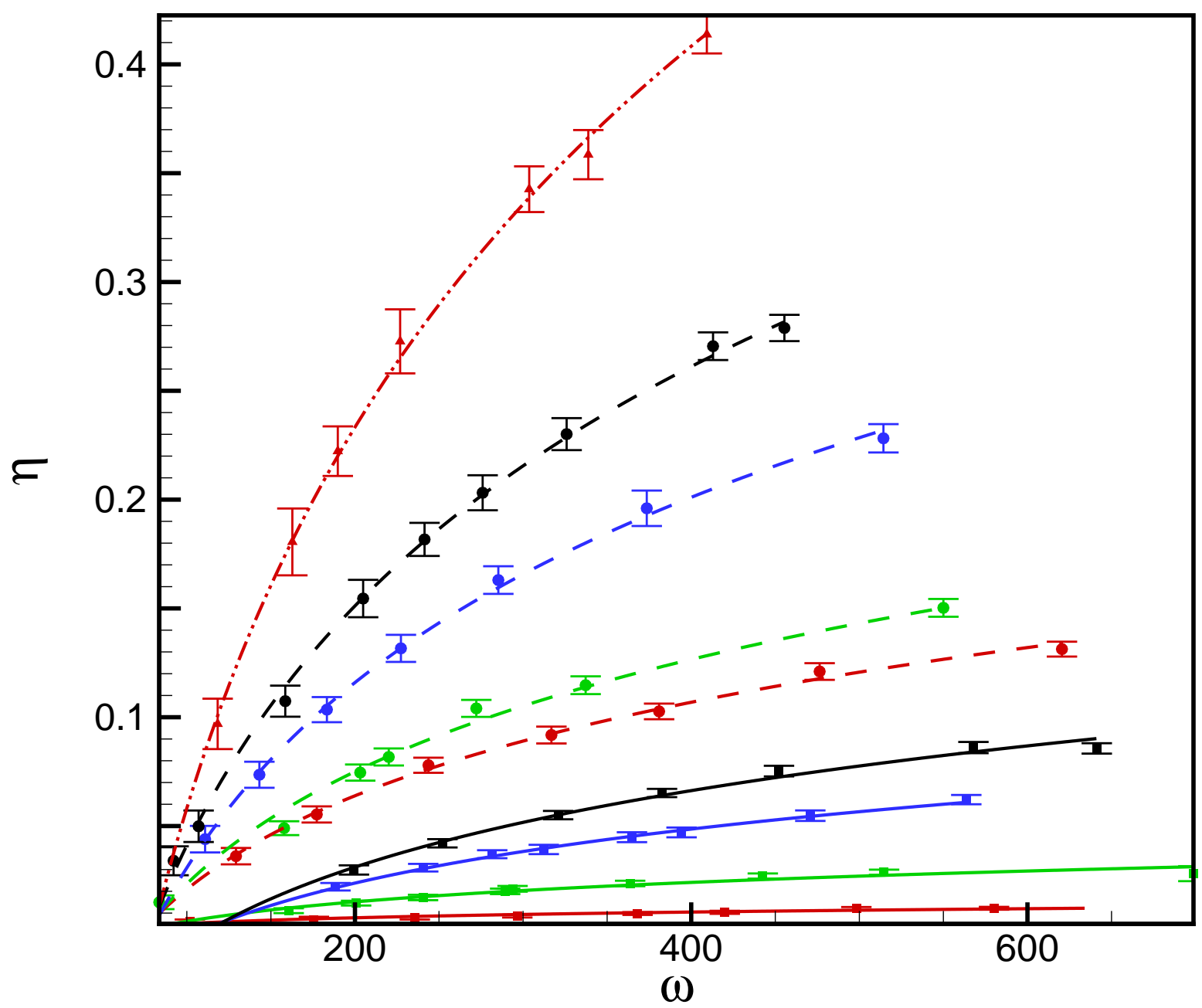

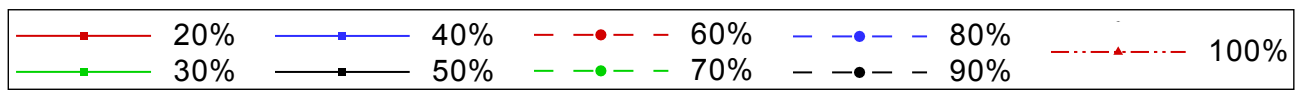

Figura 33 - Curvas de eficiência do gerador. Os pontos foram obtidos por meio de ensaios experimentais e as curvas calculadas utilizando o ajuste descrito pela Equação 5.1. Cada curva representa um ensaio utilizando uma porcentagem diferente da carga.

Observando os valores de $R^{2}$ obtidos chega-se a conclusão que a aproximação utilizada é satisfatória para os fins do presente trabalho, desde que as curvas ajustadas para cada carga resistiva mantiveram-se fora das barras de erros das curvas vizinhas. 
A partir das curvas de calibração, mostradas na Figura 33, e na Tabela 11 do Apêndice B, é possível obter o valor do rendimento para qualquer carga aplicada na turbina ensaiada. Para achar a equação do rendimento para uma carga que não esteja presente na tabela, é preciso fazer uma interpolação linear utilizando os coeficientes dos elementos mais próximos.

\subsection{Controle de velocidade de rotação da turbina}

A Figura 34 mostra a diferença de dois ensaios realizados no modelo de turbina com e sem controle de velocidade de rotação. Na Figura 34(a) são mostradas as curvas de carga resistiva, a qual era variada manualmente, e da velocidade de rotação correspondente, ambas em função da velocidade angular. O aumento da carga foi constante em passos de $10 \%$, nota-se que a velocidade diminui proporcionalmente à carga aplicada. Entretanto no aumento de $70 \%$ para $80 \%$ da carga máxima, uma instabilidade ocorre, causando um queda abrupta da velocidade, cerca de 500 RPM. Essa queda está relacionada ao comportamento não linear complexo do sistema de geração, que é composto pelo rotor hidrocinético e pelo gerador trifásico, acomplados. Portanto, como visto na metodologia experimental, um sistema de controle PID foi utilizado para controlar a velocidade.

A Figura 34(b) mostra um ensaio utilizando o sistema de controle. Esse ensaio foi configurado para elevar a velocidade de rotação em passos fixos de 100 RPM. Observa-se que o sistema de controle estabiliza a velocidade em todos os pontos, incluindo na região da curva em que se observou a queda acentuada de velocidade angular.

Como foi visto nas curvas de calibração do gerador, a eficiência do gerador depende da carga. Porém, diferentemente do ensaio anterior, a carga do ensaio com sistema de controle não é constante, o que leva a necessidade de medir a carga aplicada para relacionar a uma curva de calibração. Portanto, no ensaio da turbina, foi realizada a medição da carga média utilizada, para assim determinar o rendimento do gerador. Os picos observados na curva de carga aparecem no período de transição de velocidade e foram desconsiderados.

\subsection{Validação de resultados numéricos}

A Figura 35 é um resultado final para o gráfico de $C p$ em função de $\lambda$. O gráfico apresenta três curvas distintas, sendo elas a simulação em CFX, o resultado do ensaio em túnel de vento e o resultado BEM obtido utilizando o sofware $Q-B L A D E$.

A Tabela 7 mostra os valores máximos obtidos para $C p$, juntamento com o $\lambda$ correspondente. Nota-se que as três curvas tem o valor de $C p$ máximo igual, porém esse resultados ocorrem para $\lambda$ diferentes. 


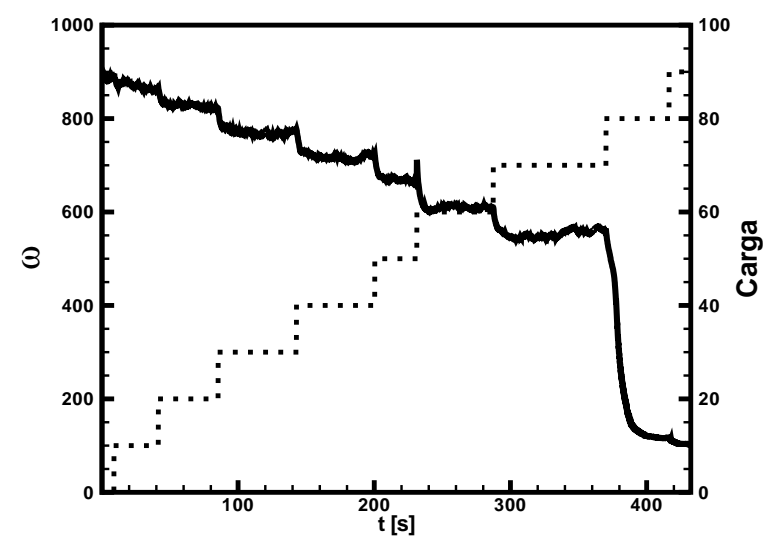

(a) Ensaio da turbina sem controle

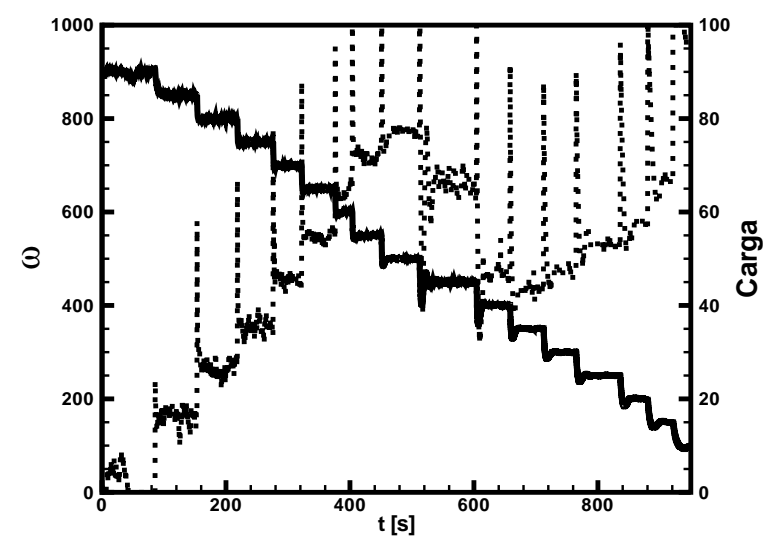

(b) Ensaio da turbina com controle

Figura 34 - Curva de ensaio experimental da turbina. Curva cheia: velocidade $\omega$; curva pontilhada: \% da carga aplicada no gerador.

Tabela 7 - Comparação do $C p$ máximo obtido pelo BEM, CFX e experimento.

\begin{tabular}{ccc} 
& $\lambda$ & $C p$ \\
\hline Exp & 5.56 & $0.39 \pm 0.03$ \\
CFX & 6.28 & 0.36 \\
BEM & 5.86 & 0.36 \\
\hline
\end{tabular}

O maior erro experimental na curva do gráfico de $C p$ ocorre no ponto de $\lambda=5.06$, sendo um erro relativo de aproximadamente $12 \%$. Considerando todas as faixas de erros observadas na curva experimental, pode-se considerar que as simulações de CFX e BEM reproduzem satisfatoriamente o comportamento real da turbina ensaiada. 


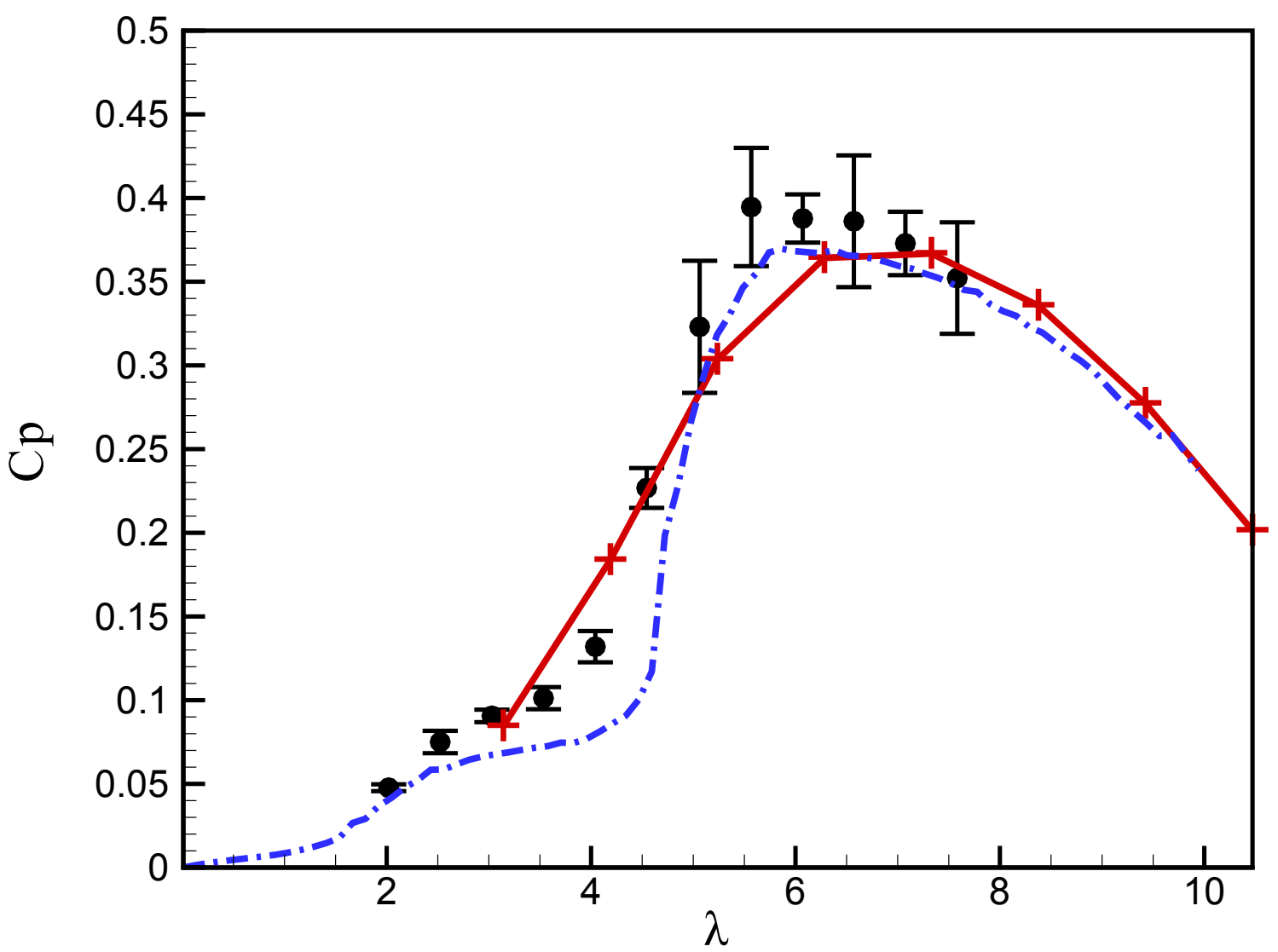

Figura 35 - Comparação das curvas numéricas e experimental de $C p \times \lambda$. $\cdots$ : BEM; +: CFX; •: pontos experimentais.

\subsection{Resultados numéricos}

A Figura 36 é a representação das linhas de corrente no extradorso de uma das pás, para diferentes rotações da turbina, mantendo-se a velocidade média do escoamento não perturbado constante e igual a $5 \mathrm{~m} / \mathrm{s}$.

É possível observar que as linhas de corrente para maiores valores de $\lambda$ estão bem orientadas e quando a velocidade de rotação da turbina é reduzida as linhas de corrente assumem um padrão desordenado, típico de regiões de escoamentos secundários (recirculações), geradas pelo colapso da camada limite. A medida que a velocidade de rotação cai, o angulo de ataque entre a pá e o escoamento aumenta, fazendo com que as linhas de corrente na pá se desorganizem. 


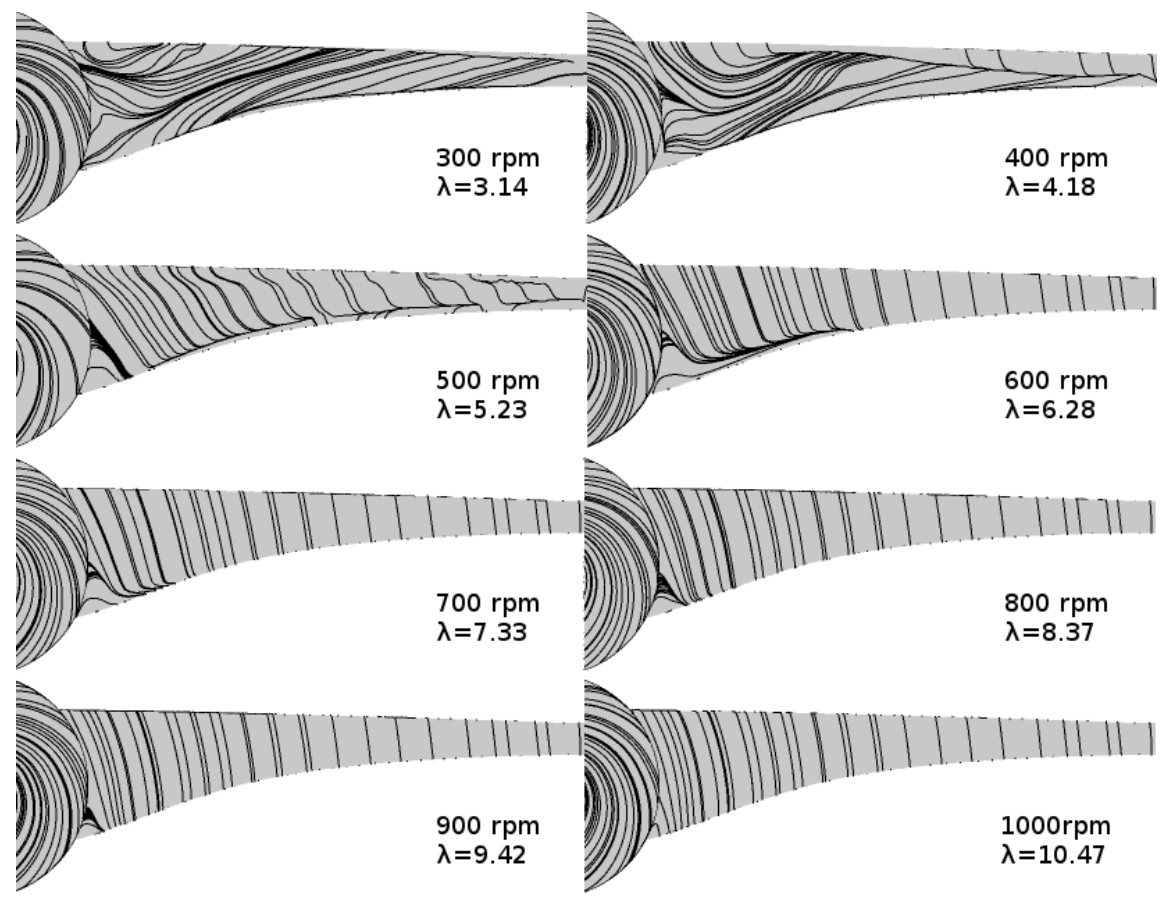

Figura 36 - Representação das linhas de corrente no extradorso da pá.

Para $\lambda=5.23$ observamos que o escoamento está praticamente todo aderido ao extradorso da pá. Apenas uma faixa muito estreita, praticamente no bordo de fuga, apresenta sinais de descolamento. Ou seja, nessa velocidade de rotação o ângulo de ataque é o maior possível, sem que haja estol significativo. Logo, como o ângulo de ataque é máximo, a sustentação também é. Por isso é nas vizinhanças dessa condição de operação que o Cp é o máximo. Em velocidades de rotação mais elevadas, o escoamento no extradorso da pá assume ângulos de ataques cada vez menores e, portanto, a sustentação tende a cair, em um regime sem estol, majoritariamente governado pela equação de Euler, ou mesmo pela teoria do escoamento potencial.

Utilizando a análise das linhas de corrente na pá é possível definir um ponto crítico em $\lambda \approx 5,23$, antes do qual há subaproveitamento de conversão, porque há colapso de camada limite com consequente aumento de pressão no extradorso e também geração de turbulência, e depois do qual também temos um subaproveitamento de conversão, mas dessa vez porque os ângulos de ataque são baixos e a pá não gera toda sustentação que poderia. O ponto crítico também foi observado nos ensaios de túnel de vento, por meio da queda de velocidade descrita ante na Figura 34. Nota-se que nessa figura, a para velocidades maiores que 500 RPM a turbina encontra-se estável, após passar pelo ponto crítico a velocidade cai abruptamente, fenômeno esse explicado pelo estol da máquina.

A Figura 37, mostra as linhas de corrente e o campo de pressão no escoamento em torno de uma seção da pá localizada à $1 / 2 \mathrm{R}$ do centro da turbina, para $\lambda=3,14,4,18,5,23$ e 6,28 . Esses valores de $\lambda$ estão próximos da região de estol da pá. É possível observar 
que após o estol, $\lambda<5$, o escoamento não está mais colado na pá, sendo assim os ângulos do triângulo de velocidade na saída da pá não estão alinhados com o bordo de fuga.

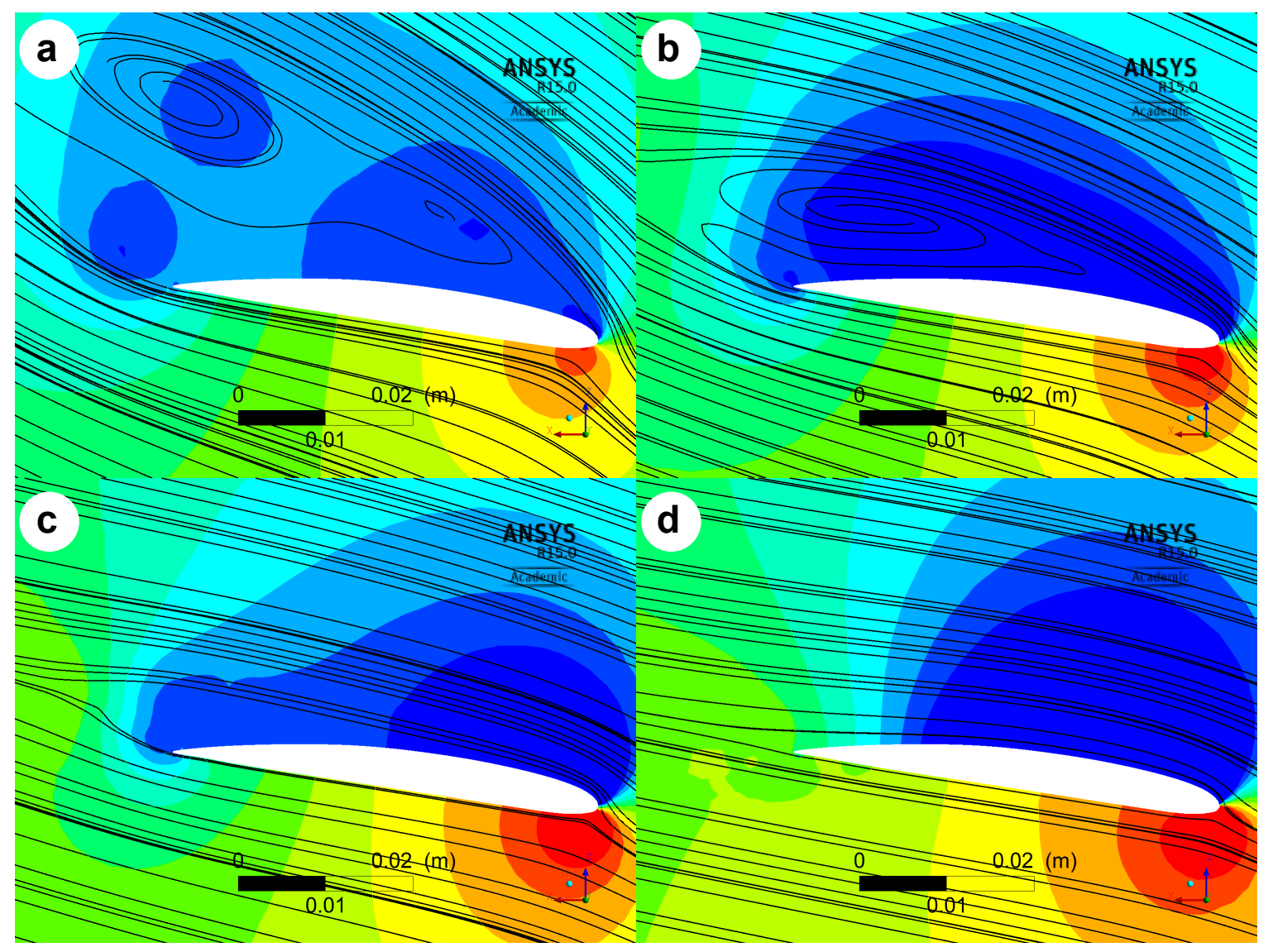

Figura 37 - Escoamento em torno do aerofólio $\mathrm{r}=1 / 2 \mathrm{R}$. a: $\lambda=3,14 ; \mathrm{b}: \lambda=4,18$; $\mathrm{c}: \lambda=5,23$; $\mathrm{d}: \lambda=6,28$.

A Figura 38 representa o campo de velocidade em torno da turbina, sendo essa simulação para $\lambda=5,23$. O campo de pressão gerado pelo rotor é perceptível a cerca de 1 m a montante da turbina. Portanto, o fator de indução axial tende a ser diferente de zero a partir desse ponto.

A Figura 39 representa a variação da velocidade do escoamento ao longo das linhas mostradas no desenho da turbina. As linhas estão posicionadas no centro, na metade do raio e ná ponta da pá. Novamente é possível ver a influência que a turbina exerce no escoamento. Após passar pela turbina, o escoamento desacelera de maneira abrupta, pois parte da energia total foi absorvida pela turbina e parte da energia foi utilizada para realizar a mudança na direção do escoamento. A jusante da turbina, cada linha de velocidade sofre uma desaceleração diferente, sendo assim, pode-se concluir que o fator de indução nessa área seja uma função do raio, sendo o centro do escoamento a posição de maior fator de indução. 


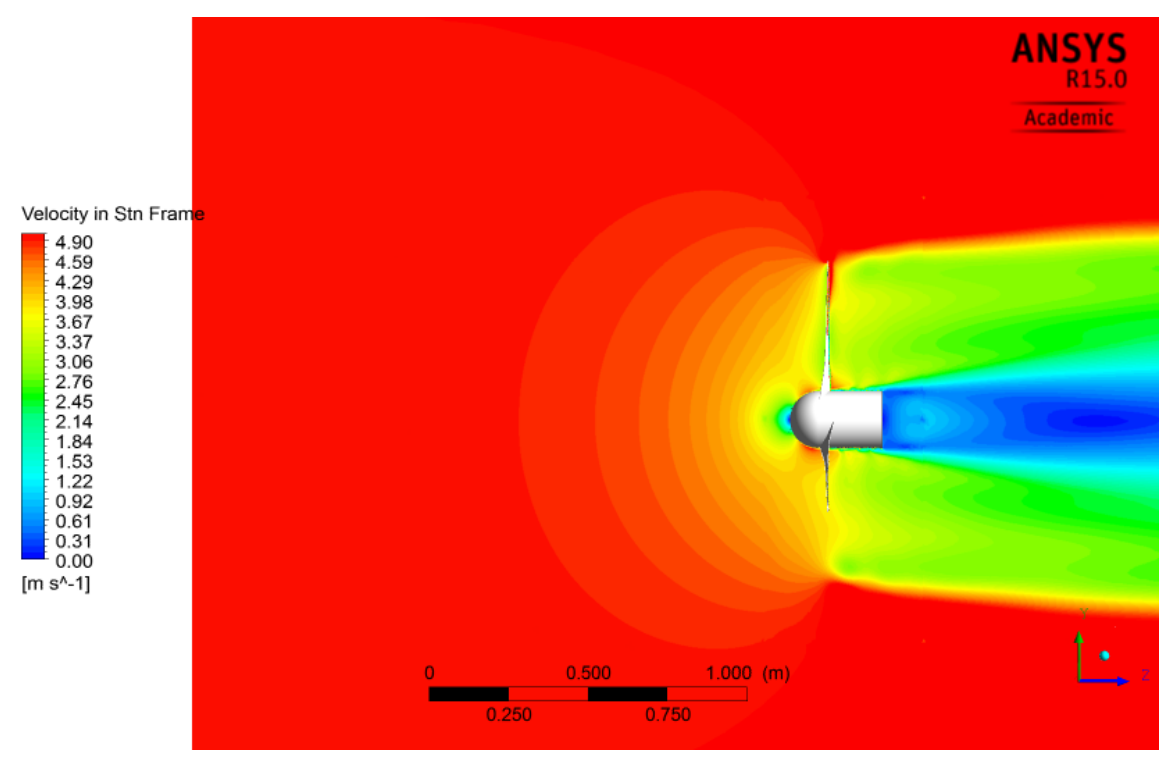

Figura 38 - Distribuição da velocidade a montante da turbina para $\lambda=5,23$.
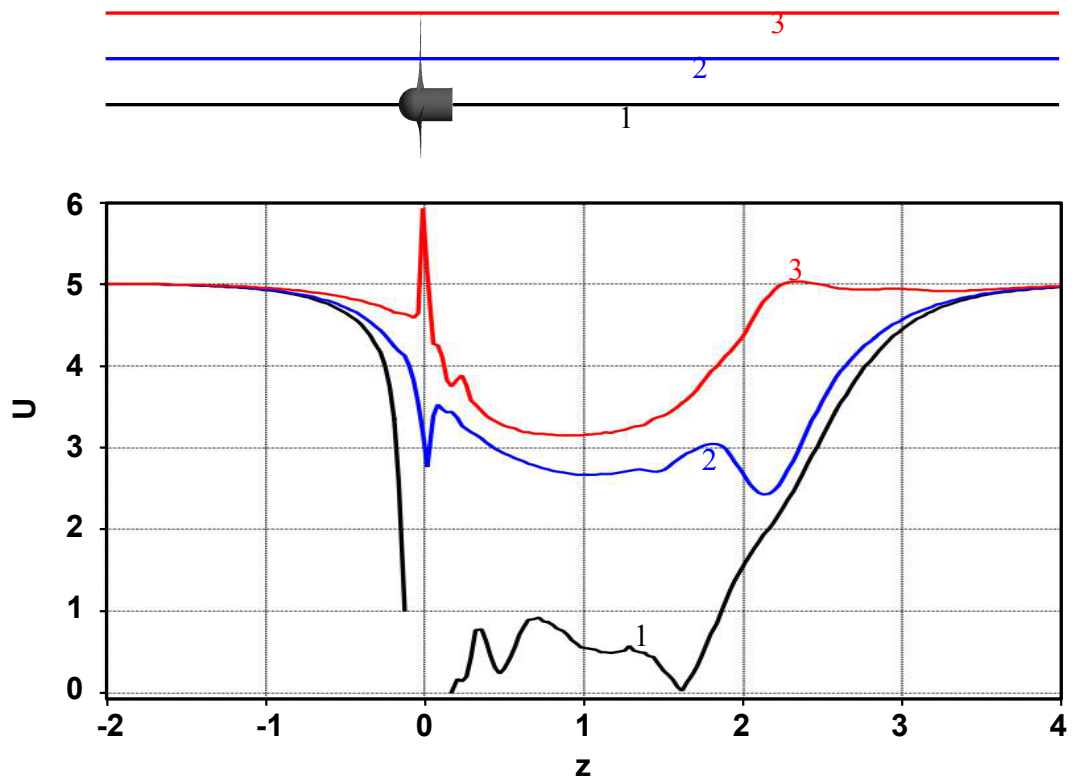

Figura 39 - Velocidade ao longo do escoamento para $\lambda=5,23$.

\subsection{Análise do fator de indução axial}

Pretende-se modelar o fator de indução axial utilizando dados de velocidade, em planos a montante da turbina, obtidos de simulações numéricas. Seguindo a metodologia para a determinação do fator de indução axial utilizando resultados das simulações numéricas, estabelecida na seção 4.5, para cada plano $z$ e raio $r$, é preciso determinar o valor de $a_{\delta}$ em várias larguras de anel circular, $\delta$, tal que se possa realizar um processo de extrapolação que permita computar o valor de $\tilde{a}=\lim _{\delta \rightarrow 0} a_{\delta}$. Esse procedimento deve ser repetido sistematicamente para valores de $r$ e $z$ no domínio de interesse do estudo. No 
presente trabalho, foram empregados 5 valores de $\delta$, distribuídos entre $\delta=0,05$ e $\delta=0,4$.

A Figura 40 apresenta resultados desse estudo para o plano $z=0,2 m$. Neste gráfico, os pontos representam os valores de $a_{\delta}$ enquanto as linhas são retas ajustadas pelo método dos mínimos quadrados. O ajuste foi praticamente analítico $\left(R^{2} \approx 1\right)$ em todos os casos, de forma que o procedimento de extrapolação de resultados para $\delta \rightarrow 0$ parece ser bastante seguro. Sendo assim, para cada reta $a_{\delta}=a_{\delta}(\delta)$, o valor de $\tilde{a}$ é igual ao coeficiente linear da função afim.

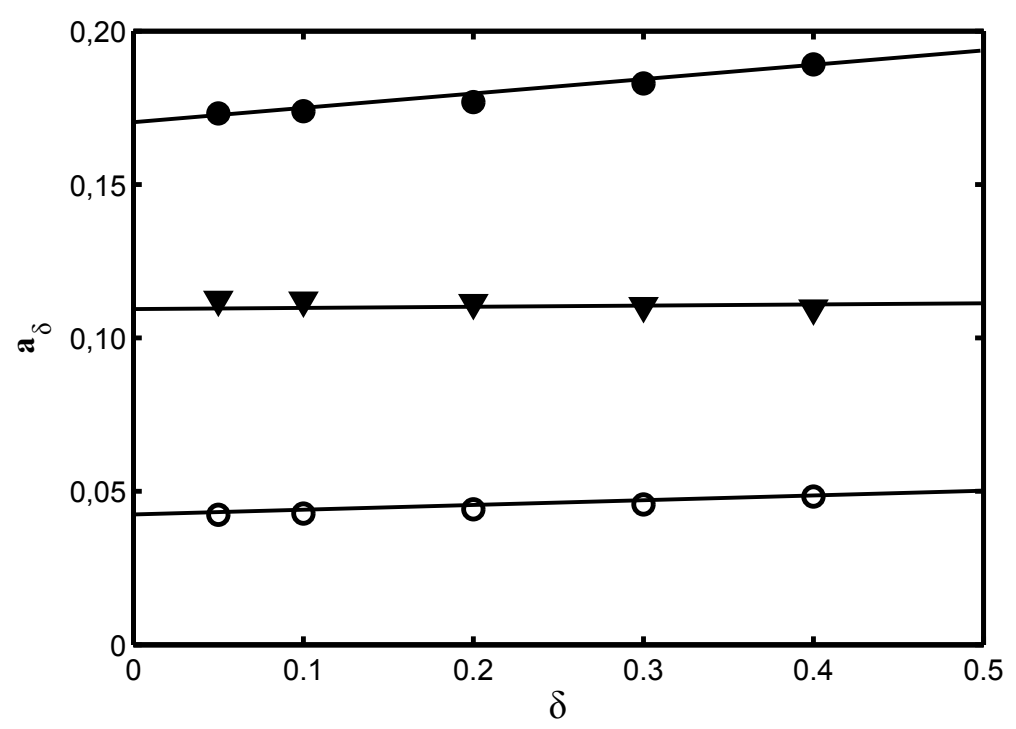

Figura 40 - Fator de indução no disco de raio $r$ em função da largura do disco. •: $0.2 m$; $\boldsymbol{\nabla}: 0.4 m ; \circ: 0.6 m$.

A metodologia de determinação do fator de indução local foi executada para diversas posições radiais, em diferentes planos a montante do rotor. Os resultados obtidos são apresentados na Figura 41. Para cada plano $z$ o comportamento do fator de indução local é marcadamente linear, no sentido de que as curvas podem ser consistentemente ajustadas por equações de retas. Como é esperado, para altos valores de $z$, o valor de $\tilde{a}$ tende a zero, independentemente do valor de $r$.

Em face da dependência linear de $\tilde{a}$ em função do raio, propõem-se que o fator de indução axial possa ser bem representado por uma função do tipo

$$
a(r, z)=\lim _{z \rightarrow \infty} a(r, z)=0 .
$$

Portanto, sabendo que a variação das curvas da Figura 41 depende da distância z e sabendo que as curvas são polinômios de primeiro grau, pode-se descrever modelar o 


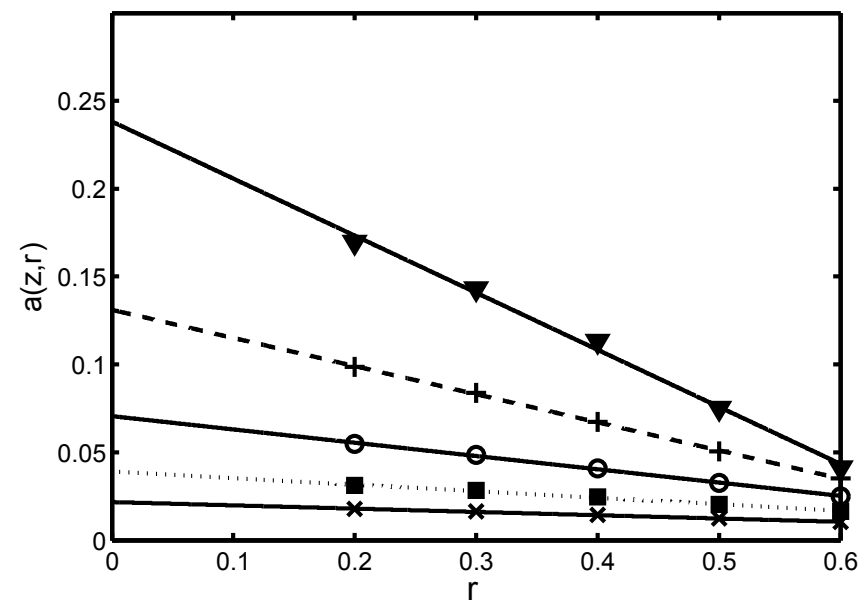

Figura 41 - Fator de indução local no plano $z$ em função do raio. $\mathbf{\nabla}: 0.2 m ;+$ : $0.4 m$; o: $0.6 \mathrm{~m} ; \mathbf{\mathbf { a }}: 0.8 \mathrm{~m} ; \times \mathrm{x}: 1.0 \mathrm{~m}$.

fator de indução como

$$
a(r, z)=\xi(z) r+a_{0}(z)
$$

sendo $\xi(z)$ e $a_{0}(z)$ os coeficiente angular e linear das retas ajustadas aos pontos do gráfico da Figura 41.

Para determinar $\xi(z)$ e $a_{0}(z)$ foram geradas curvas do coeficiente angular $\xi$ e do coeficiente linear $a_{0}$ (que são únicos para cada curva ajustada aos pontos do gráfico da Figura 41) como funções de z. Os resultados dessa análise são mostrados nas Figuras 42 e 43. Em ambos os casos o ajuste por uma função exponencial é praticamente analítico, sendo que o coeficiente de determinação afasta-se da unidade dentro de uma tolerância compatível com os erros de ponto flutuante do computador utilizado para fazer o pós-processamento.

O modelo completo para o fator de indução axial do escoamento a montante do rotor, proposto no presente trabalho, é dado pela Equação (5.3) e por

$$
\xi(z)=-\xi_{0} e^{-z / L_{\xi}}
$$

e

$$
a_{0}(z)=a_{00} e^{-z / L_{a 0}} .
$$

Nas Equações (5.4) e (5.5) os parâmetros $\xi_{0}, L_{\xi}, a_{00}$ e $L_{a 0}$ são constantes do modelo que, no caso do presente trabalho, resultam conforme mostra a Tabela (8).

O parâmetros $\xi_{0}$ e $a_{00}$ são facilmente identificados como sendo os coeficientes angular e linear da reta que ajusta o fator de indução axial no plano do rotor. Essas duas constantes assumirão papel relevante no cálculo do coeficiente de potência máximo admissível, levando em conta um modelo como o da Equação (5.3). Por sua vez, os 


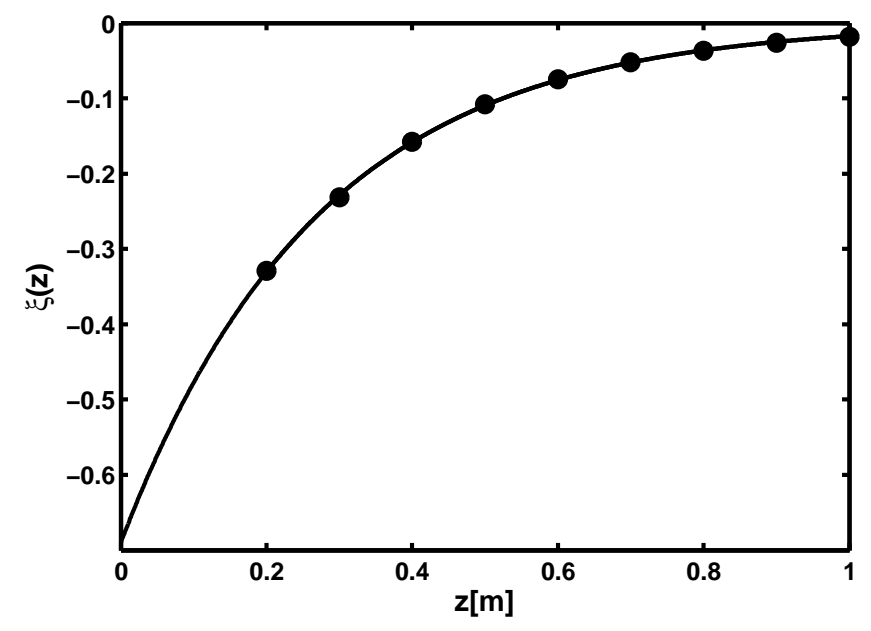

Figura 42 - Coeficiente angular das retas ajustas aos pontos do gráfico da Figura 41. A função $\xi(z)=\xi_{0} \exp \left(-z / L_{x} i\right)$, com $\xi_{0}=-0,69$ e $L_{x} i=0,27$ ajusta-se aos pontos com $R^{2}=1$, dentro de uma tolerância compatível com os erros de ponto flutuante do computador empregado no tratamento dos dados.

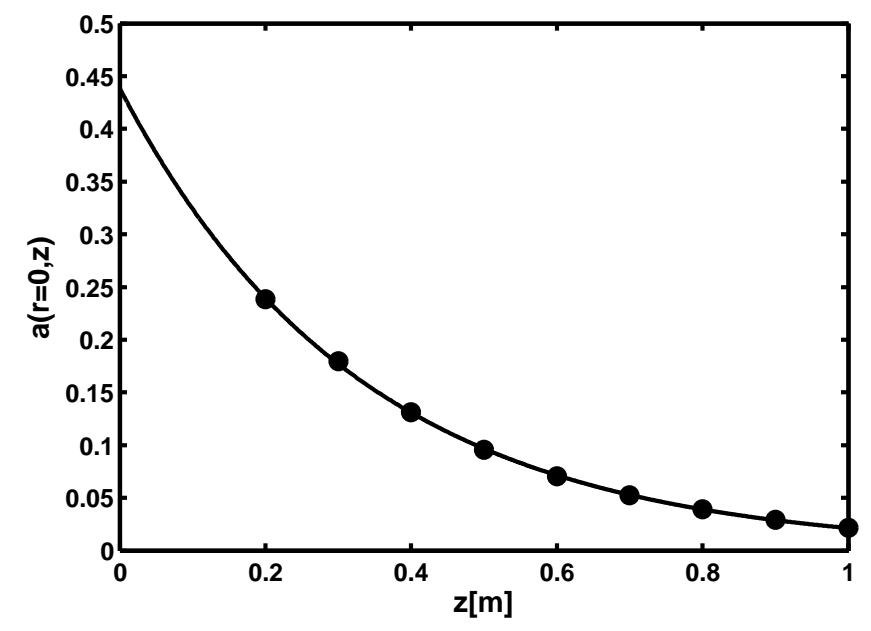

Figura 43 - Fator de indução no centro do escoamento $(r=0)$ A função $a_{0}(z)=a_{00} e^{-z / L_{a 0}}$., com $a_{00}=0,43$ e $L_{a 0}=0,33$ ajusta-se aos pontos com $R^{2}=1$.

Tabela 8 - Parâmetros do modelo para o fator de indução axial, dado pelas Equações (5.4), (5.4) e (5.5).

\begin{tabular}{|c|c|c|c|}
\hline$\xi_{0}$ & $L_{\xi}$ & $a_{00}$ & $L_{a 0}$ \\
\hline 0,69 & 0,27 & 0,43 & 0,33 \\
\hline
\end{tabular}

comprimentos caraterísticos $L_{\xi}$ e $L_{a 0}$ estão relacionados à distâncias típicas de variação do fator de indução no escoamento a montante do rotor. Levando em conta que no presente caso ambas essas constantes são da ordem de $0,3 m$, e participam como comprimentos de decaimento em um modelo exponencial, podemos esperar que a uma distância de aproximadamente $10 L_{\xi}$ ( ou $10 L_{a 0}$ ), i.e. a cerca de $3 m$ do rotor, o escoamento possa ser considerado não perturbado para fins experimentais ou de simulações numéricas. 
Seguramente o fato dos modelos exponenciais das Equações (5.4) e (5.5) haverem se ajustado tão precisamente aos dados processados das simulações numéricas deve encontrar rebatimento nos fenômenos físicos que dominam o escoamento a montante do rotor. $\mathrm{O}$ mesmo deve ocorrer para a Equação (5.3), mais uma vez considerando a estreita correlação entre os dados das simulações e o modelo linear (reta) deste ajuste de curvas. No entanto, mesmo supondo com segurança que a dinâmica do escoamento a montante deva ser completamente governada pelas Equações de Euler, não se pôde, até o momento da redação deste texto, identificar claramente a conexão entre essa lei da Mecânica dos Fluidos e o modelo fenomenológico empiricamente aqui construído.

Substituindo a função do modelo do fator de indução, descrito na Equação 5.3, na Equação 4.4 é possível definir o fator de indução global para a turbina simulada, sendo ele

$$
\begin{aligned}
a & =\frac{1}{A_{d}} \int_{S} \tilde{a}(r, 0) d S \\
& =\frac{1}{R^{2}} \int_{0}^{R} a_{00} r-\xi_{0} r^{2} d r \\
& =a_{00}-\frac{2}{3} \xi_{0} R
\end{aligned}
$$

aplicando os valores da Tabela 8

$$
a=0,521 \text {. }
$$

Substituindo o fator de indução encontrado na formula utilizada por Betz para o cálculo do coeficiente de potência, descrita na Equação 2.14, é possível encontrar

$$
C p=0,478
$$

que é uma cota máxima a do coeficiente de potência que pode atingido por essa turbina (inferior os de Betz e inferior ao de Glauert, para o mesmo $\lambda$ ).

\subsubsection{Influência do cubo no fator de indução}

Na média anterior, o fator de indução é calculado a partir do centro do escoamento, porém na prática o escoamento dessa região não entra em contato direto com o rotor. Por isso é necessário desconsiderar essa parte do escoamento no momento do cálculo da média. Considerando um cubo de raio $R_{0}$, o fator de indução pode ser calculado por

$$
\begin{aligned}
a_{c} & =\frac{2}{R^{2}} \int_{R_{0}}^{R}\left(a_{00}-\xi_{0} r\right) r d r \\
& =a_{00}\left[1-\left(\frac{R_{0}}{R}\right)^{2}\right]-\frac{2}{3} \xi_{0} R\left[1-\left(\frac{R_{0}}{R}\right)^{3}\right] .
\end{aligned}
$$


Na Equação 5.11, nota-se o aparecimento de dois termos de correção, sendo os dois funções da razão $R_{0} / R$. Considerando o valor de $\xi_{0}$ e $a_{00}$ da Tabela (8) encontra-se

$$
a_{c}=0,508
$$

Comparando com o resultado anterior, o valor do fator de indução axial médio corrigido para considerar o bloqueio do escoamento pelo cubo do rotor é apenas 2,4\% menor. É curioso o fato de que, como o valor do coeficiente de indução diminui a partir de valores superiores a $1 / 3$, a influência do bloqueio ocasionado pelo cubo é favorável ao coeficiente de potência, elevando o valor original (que não considera o cubo) de um fator aproximadamente $2,8 \%^{1}$.

\subsubsection{Cálculo do máximo coeficiente de potência}

Utilizando a da teoria do momento angular de turbinas de eixo horizontal, explicada anteriormente nesse trabalho, sabe-se que o $C p$ pode ser calculado como função dos fatores de indução axial e tangencial, segundo a Equação 2.25.

Pretende-se usar a Equação 2.25 juntamente com o modelo do fator de indução axial, propostas no presente trabalho pelas Equações (5.3), (5.4) e (5.5), para encontrar um $C p$ máximo em função do $\lambda$, seguindo a mesma metodologia aplicada para obtenção da otimização realizada por Glauert.

Para correlacionar o fator de indução tangencial e axial, foi usada uma relação geométrica do triângulo de velocidades da pá definida pela Equação 2.30.Essa relação só é válida para situações pré estol, pois depois do estol os fenômenos de turbulência começam a interferir no escoamento em torno da pá.

Uma vez que temos um modelo para o fator de indução axial (Equações 5.3, 5.4 e 5.5) é possível determinar o coeficiente de potência máximo para o rotor empregando a Equação 2.25. No entanto, essa Equação está escrita em termos do fator de indução axial e também do tangencial. Para contornar essa dificuldade, utilizamos a correlação entre $a$ e $a^{\prime}$ originada do triângulo de velocidades na pá, dada pela Equação 2.30, de forma que

$$
a^{\prime}=\frac{1}{2}\left[\sqrt{1+\frac{4 a(1-a)}{\lambda_{r}^{2}}}-1\right] .
$$

Lembrando que $\lambda_{r}$ é dado pela Equação 2.24, tal que $\lambda_{r}=\omega r / U_{\infty}$, é possível utilizar a Equação 5.13 e a Figura 41, calculada em $z=0$, para se determinar o valor de Cp em função de $\lambda$. Como a integral é algebricamente complicada, optou-se por calculá-la numericamente empregando a regra do trapézio.

1 Um resultado da mesma magnitude foi obtido na prática utilizando o mesmo conceito de análise da interferência do cubo. Recentemente, a GE aumentou a área de bloqueio do cubo para elevar a produção de energia de eólicas em cerca de 3\%. (KELLNER, 2015) 
Considerando que os valores de $\xi_{0}$ e $a_{00}$ foram determinados utilizando resultados de uma simulação realizada em um $\lambda$ constante, é razoável supor que esses parâmetros do modelo sejam funções da razão de velocidade de ponta de pá. Sendo assim, para resolver a Equação 2.25 é necessário obter novos $\xi_{0}$ e $a_{00}$ para cada $\lambda$. A Figura 44 apresenta a resolução da Equação 2.25 utilizando as constantes $\xi_{0}$ e $a_{00}$ obtidas para $\lambda=4.1,6,2,7,3$ e 9,4 , juntamente com os limites de Betz e Glauert e com as curvas simuladas/ensaiadas. Chama-se a curva de $C p_{\max }$ o ajuste parabólico realizados com os valores de $C p$ para os $\lambda$ simulados. Esse ajuste é feito, pois como explicado anteriormente, as constantes da equação do fator de indução dependem diretamente do valor de $\lambda$, fazendo com que a resolução da Equação 2.25 seja válida somente para o ponto de $\lambda$ em que a simulação foi realizada, no caso, o último ponto de cada curva preta do Figura 44. A Tabela 9 mostra os pontos encontrados utilizando Equação 2.25 para os valores de $\lambda$ simulados.

Da teoria clássica de rotores, Glauert utilizou da Equação 2.25 para calcular máximo $C p$ para qualquer, sendo assim a curva $C p_{\max }$ representa o limite teórico disponível para a turbina ensaiada. Nota-se que essa suposição é perfeitamente plausível, tendo em vista que a curva de encontra abaixo $C p_{\max }$ dos limites de Betz e Glauert e acima de todos os pontos simulados/ensaiados (BEM, CFX e EXP).

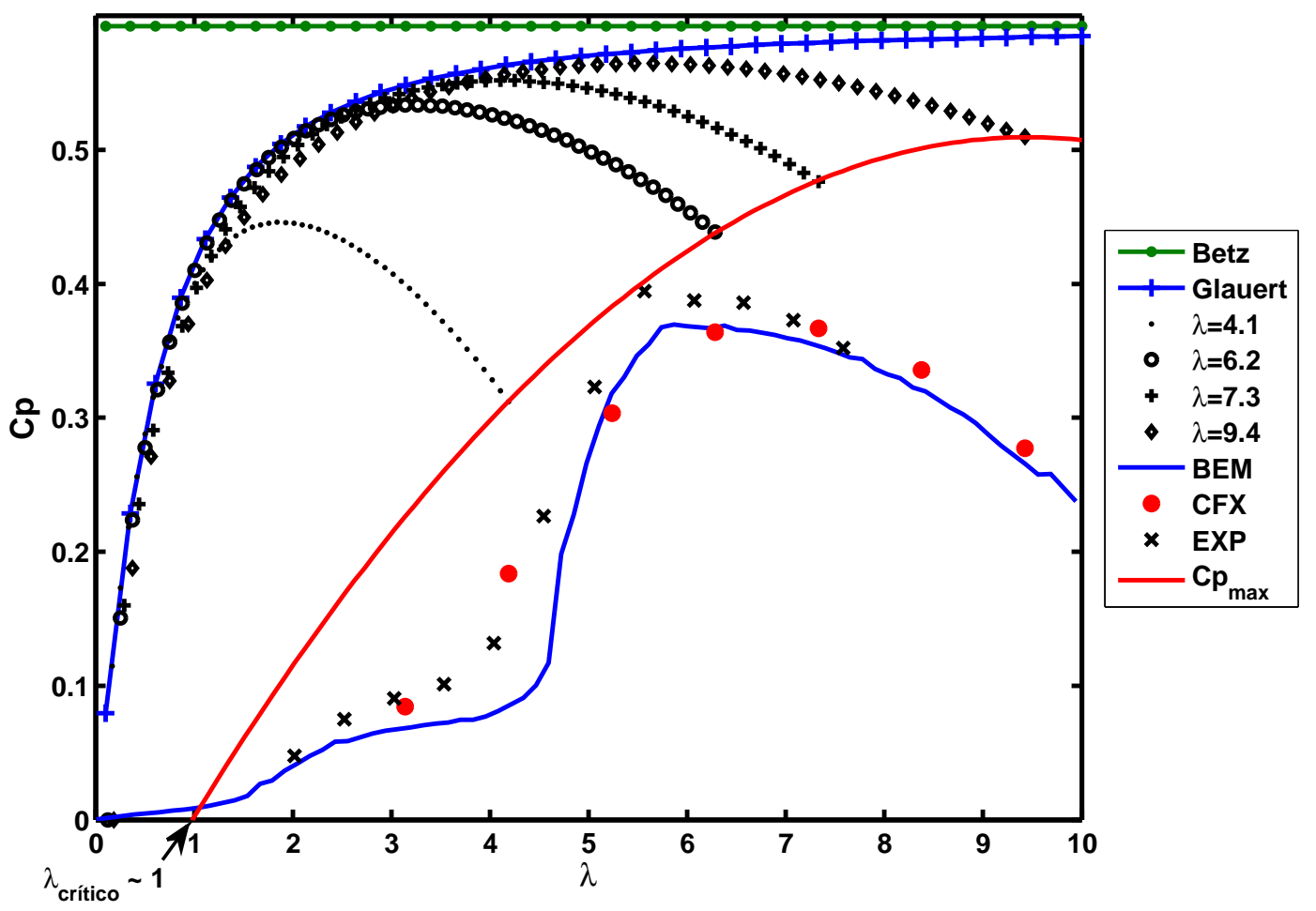

Figura 44 - Cuvas do coeficiente de potência em função da velocidade de ponta de pá. As curvas pretas são resultados da resolução numérica da Equação 2.25 utilizando a fator de indução descrito neste trabalho; as curvas de CFX, BEM e EXP são as mesmas utilizadas na Figura 35; a de $C p_{\max }$ é o ajuste parabólico dos pontos da Tabela 9 . 
Tabela 9 - Resolução da Equação 2.25 para $\lambda$ simulados.

\begin{tabular}{cc}
\hline$\lambda$ & $C p$ \\
\hline 4.1 & 0.31 \\
6.2 & 0.43 \\
7.3 & 0.47 \\
9.4 & 0.50 \\
\hline
\end{tabular}

O ajuste parabólico empregado para produzir o gráfico de $C p_{\max }$ na Figura 44 não pretendo ser um modelo absolutamente exato. Mais do que isso nos interessa os desdobramentos teóricos que podem decorrer dele. Com isso em mente, há um aspecto óbvio do modelo, associado à redução dos valor máximo teórico do coeficiente de potência em relação aos modelos de Betz e Glauert, que permitem que se produza uma aproximações mais realistas do comportamento fluidodinâmico da turbina, previsto por uma teoria unidimensional integral. Adicionalmente, a aplicação do modelo de fator de indução axial proposto para geração de curvas de coeficiente de potência máximo aparentemente indica a existência de um valor finito de $\lambda$ a partir do qual a turbina inicia seu movimento de rotação, dado pela raiz da curva de $C p_{\max }$ (linha vermelha) da Figura 44. A provável existência dessa razão de velocidade de ponta de pá crítica $\left(\lambda_{\text {crit }}\right)$ aponta para uma condição operacional da turbina (i.e., $\omega$ e $U_{\infty}$ ) em que há rotação sem a geração de potência de eixo. Esta condição de operação está, provavelmente, relacionada a uma taxa de variação do momento angular do escoamento que não produziria potência de eixo, mas seria completamente dissipada pelas estruturas turbulentas, e pela tensão de cisalhamento nas superfícies em menor parte, geradas naquela condição de trabalho. Também é possível interpretar essa condição como a e mínima rotação para uma dada velocidade de escoamento não perturbado, indicando que o rotor não apresentaria velocidades de rotação de regime permanente em infinitamente próximas de zero. Tomando por exemplo a turbina simulada no presente trabalho $\left(U_{\infty}=5 \mathrm{~m} / \mathrm{s}\right.$ e $\left.R=0,5 \mathrm{~m}\right)$, e assumindo que $\lambda_{\text {crit }} \approx 1$, o valor mínimo de rotação possível para o presente rotor seria da ordem 100RPM. Esse valor é compatível com as menores velocidades de rotação obtidas durantes os ensaios experimentais realizados. 


\section{Conclusões}

O presente trabalho teve a finalidade de investigar o fator de indução axial de turbina de eixo horizontal, por meio de simulações numéricas realizadas utilizando o software ANSYS e validadas por ensaios em túnel de vento. Todo o trabalho foi realizado em torno de uma pequena turbina eólica de $1 \mathrm{~m}$ de diâmetro e $500 \mathrm{~W}$ de potência nominal.

Para simular a turbina, foi necessário realizar medições para se obter a geometria do rotor. Para isso foi utilizado um braço de medição com seis graus de liberdade. Utilizando os dados obtidos, um modelo foi desenhado em Solidworks.

As simulações realizadas foram do tipo RANS, utilizando o modelo de turbulência SST, esse modelo foi escolhido devido a boa qualidade de resultados sobre turbinas de eixo horizontal presentes na literatura recente. Utilizando do Ansys, foram realizadas simulações para diversas condições de operação, chegando a resultados de $C p$ máximo de 0.36 em valores de $\lambda \approx 6$. De acordo com a simulação, o estol da máquina acontece um pouco depois do $\lambda$ máximo, para $U_{\infty}=5 \mathrm{~m} / \mathrm{s}$ o estol acontece entre 500 e 600 RPM.

A validação foi feita utilizando resultados experimentais obtidos em ensaio de túnel de vento. O túnel de vento, que foi construído para este trabalho, tem 2x2 metros e é formado por 4 ventiladores axiais em paralelos. Um ensaio de perfil de velocidade foi realizado, mostrando que a melhor posição para o ensaio da turbina é a 3 metros do túnel de vento.

A potência mecânica no ensaio da turbina foi calculada por meio da velocidade angular da turbina e de curvas de calibração do gerador, obtidas em ensaios anteriores fora do túnel de vento. A potência do vento foi calculada por meio de medidas realizadas com tubo de Pitot.

O controle PID se fez necessário no ensaio da turbina para manter a velocidade constante em todas os pontos de operação desejado. Eliminando uma instabilidade do sistema da turbina que não permitia operar em todos os valores de $\lambda$.

Os resultados do BEM, CFX e experimental deram muito próximos um do outro. Em relação ao $C p$ máximo, os resultados deram o mesmo( $C p \approx 0,36)$, porém para diferentes valores de $\lambda$.

Um novo modelo para o fator de indução axial, visto como uma grandeza local em função das coordenadas radial e axial do escoamento a montante do rotor, foi proposto. Baseado nesse modelo, os limites para $C p_{\max }$ postos por Glauert (1963) foram revistos. Esse modelo prevês a existência de um valor diferente de zero para a mínima rotação de uma turbina axial de eixo horizontal submetida a ação de um escoamento. As estimativas 
desse modelo são compatíveis com resultados experimentais obtidos durante a realização deste trabalho.

O conceito de $\lambda_{\text {crítico }}$ foi descrito para uma condição operacional da turbina em que há rotação sem a geração de potência de eixo, ou seja, existe um certo $\lambda \neq 0$ para que $C p=0$. Esta condição de operação está, provavelmente, relacionada a uma taxa de variação do momento angular do escoamento que não produziria potência de eixo, mas seria completamente dissipada pelas estruturas turbulentas, e pela tensão de cisalhamento nas superfícies em menor parte, geradas naquela condição de trabalho.

Sugere-se que para trabalhos futuros o estudo de um modelo matemático, com um significado físico real, para a de curva da calibração do gerador. Esse modelo deve correlacionar a rotação da turbina, a carga e as potências de entrada e saída do gerador.

Outro trabalho futuro possível, é continuar a investigação do fatores de indução, sugere-se realizar uma metodologia semelhante, porém para encontrar o valor do fator de indução tangencial a jusante da turbina e com isso poder relacionar os fatores de indução axial e tangencial.

Para melhorar a metodologia aplicada para o cálculo numérico do fator de indução axial, sugere-se a validação das equações encontradas do fator de indução, por meio de ensaios em túnel de vento. Ainda é preciso entender o motivo físico do comportamento exponencial dos coeficientes. 


\section{Referências}

ARGYROPOULOS, C.; MARKATOS, N. Recent advances on the numerical modelling of turbulent flows. Applied Mathematical Modelling, v. 39, n. 2, p. 693 - 732, 2015. ISSN 0307-904X. Citado na página 27.

BETZ, A. Maximum der theoretisch möglichen ausnützung des windes durch windmotoren. Zeitschrift für das gesamte Turbinenwesen, v. 26, p. 307-309, 1920. Citado na página 4.

BRASIL, A. C. P. et al. Turbina hidrocinética geração 3. CITENEL, 2007. Citado 2 vezes nas páginas 2 e 3 .

BURTON, T. et al. Wind Energy Handbook. [S.l.]: John Wiley \& Sons, 2001. ISBN 9780471489979. Citado 2 vezes nas páginas 6 e 9.

DAVIDSON, P. Turbulence: an introduction for scientists and Engineers. [S.l.]: Oxford, 2004. 688 p. ISBN 0191589853. Citado na página 27.

FROUDE, R. On the part played in propulsion by difference of fluid pressure. Transactions of the Royal Institution of Naval Architects, v. 30, p. 390-405, 1889. Citado na página 4.

GLAUERT, H. Windmills and fans. Aerodynamic theory, Dover Publications, v. 4, p. 169-360, 1963. Citado na página 4.

GOMEZ-IRADI, S.; STEIJL, R.; BARAKOS, G. N. Development and validation of a cfd technique for the aerodynamic analysis of hawt. J. Sol. Energ., 2009. Citado na página 5.

HANSEN, M. Aerodynamics of Wind Turbines: second edition. 2. ed. [S.1.]: Earthscan Publications Ltd, 2008. ISBN 978-1-84407-438-9. Citado na página 10.

HERBERT, G. J. et al. A review of wind energy technologies. Renewable and Sustainable Energy Reviews, v. 11, n. 6, p. 1117 - 1145, 2007. ISSN 1364-0321. Citado na página 1.

HIRZEL, T. Pulse Width Modulation (PWM). https://www.arduino.cc/en/Tutorial/PWM, 2006. Citado na página 21.

KELLNER, T. How Does a Wind Turbine Work? With GE's New ecoROTR, Better than Ever. http://www.gereports.com/post/120795016210/how-does-a-wind-turbine-workwith-ges-new, 2015. Citado na página 50.

KULKARNI, V.; SAHOO, N.; CHAVAN, S. D. Simulation of honeycomb-screen combinations for turbulence management in a subsonic wind tunnel. Journal of Wind Engineering and Industrial Aerodynamics, v. 99, n. 1, p. 37 - 45, 2011. ISSN 0167-6105. Citado na página 16.

LANZAFAME, R.; MESSINA, M. Fluid dynamics wind turbine design: Critical analysis, optimization and application of $\{$ BEM $\}$ theory. Renewable Energy, v. 32, n. 14, p. 2291 2305, 2007. ISSN 0960-1481. Citado na página 4.

LANZAFAME, R.; MESSINA, M. \{BEM $\}$ theory: How to take into account the radial flow inside of a 1-d numerical code. Renewable Energy, v. 39, n. 1, p. 440 - 446, 2012. ISSN 0960-1481. Citado na página 14. 
LEE, S. G. et al. Performance prediction of $\{$ NREL $\}$ (national renewable energy laboratory) phase $\{\mathrm{VI}\}$ blade adopting blunt trailing edge airfoil. Energy, v. 47, n. 1, p. 47 - 61, 2012. ISSN 0360-5442. Asia-Pacific Forum on Renewable Energy 2011. Citado 3 vezes nas páginas 5,29 e 30 .

LI, Y. et al. Dynamic overset cfd simulations of wind turbine aerodynamics. Renew. Energ., v. 37, p. 285-298, 2012. Citado na página 5.

LOCK, C. N. H. Experiments to verify the independence of the elements of an airscrew blade. $A R C R R \mathscr{E} M$, n. 953, 1924. Nenhuma citação no texto.

MA, P. et al. A comparison of coarse-resolution numerical simulation with experimental measurements of wind turbine aerodynamic performance. Procedia Engineering, v. 79, n. 0, p. $17-27,2014$. ISSN 1877-7058. 37th National Conference on Theoretical and Applied Mechanics (37th \{NCTAM\} 2013) \&amp; The 1st International Conference on Mechanics (1st ICM). Citado na página 33.

MENTER, F. Zonal two equation k-w turbulence models for aerodynamic flows. In: Fluid Dynamics and Co-located Conferences. [S.l.]: American Institute of Aeronautics and Astronautics, 1993. p. -. Citado na página 27.

MENTER, F. R. Two-equation eddy-viscosity turbulence models for engineering applications. AIAA Journal, American Institute of Aeronautics and Astronautics, v. 32, n. 8, p. 1598-1605, ago. 1994. ISSN 0001-1452. Citado na página 27.

MO, J.-O.; LEE, Y.-H. Cfd investigation on the aerodynamic characteristics of a small-sized wind turbine of nrel phase vi operating with a stall-regulated method. Journal of Mechanical Science and Technology, Korean Society of Mechanical Engineers, v. 26, n. 1, p. 81-92, 2012. ISSN 1738-494X. Citado na página 30.

MOSHFEGHI, M.; SONG, Y. J.; XIE, Y. H. Effects of near-wall grid spacing on sst-k- $\omega$ model using $\{\mathrm{NREL}\}$ phase $\{\mathrm{VI}\}$ horizontal axis wind turbine. Journal of Wind Engineering and Industrial Aerodynamics, v. 107108, n. 0, p. $94-105,2012$. ISSN 0167-6105. Citado 3 vezes nas páginas 29, 30 e 31.

NILSSON, K. Numerical computations of wind turbine wakes and wake interaction Optimization and control. [S.1.], 2012. Citado na página 12.

OGGIANO, L. $\{\mathrm{CFD}\}$ simulations on the $\{$ NTNU $\}$ wind turbine rotor and comparison with experiments. Energy Procedia, v. 58, n. 0, p. 111 - 116, 2014. ISSN 1876-6102. Renewable Energy Research Conference, \{RERC\} 2014. Disponível em: $<$ http://www.sciencedirect.com/science/article/pii/S1876610214017834>. Citado 2 vezes nas páginas 30 e 33.

PAPE, A. L.; LECANU, J. 3d navier-stokes computations of a stall-regulated wind turbine. v. 7, p. 309-324, 2004. Citado na página 5.

POPE, S. Turbulent flows. [S.1.]: Cambridge, 2000. 771 p. ISBN 0521598869. Citado na página 27.

RANKINE, W. J. M. On the mechanical principles of the action of propellers. Transaction of the Institute of Naval Architects, v. 6, p. 13-39, 1865. Citado na página 4. 
SAGOL, E.; REGGIO, M.; ILINCA, A. Assessment of two-equation turbulence models and validation of the performance characteristics of an experimental wind turbine by cfd. ISRN Mechanical Engineering, 2012. Citado na página 4.

SILVA, P. A. S. F. e. ESTUDO NUMÉRICO DE TURBINAS HIDROCINÉTICAS DE EIXO HORIZONTAL. Dissertação (Mestrado) — Universidade de Brasília, 2014. Citado 2 vezes nas páginas 29 e 30 .

SØRENSEN, N. N.; MICHELSEN, J. A.; SCHRECK, S. Navier-stokes predictions of the nrel phase vi rotor in the nasa ames $80 \mathrm{ft} \times 120 \mathrm{ft}$ wind tunnel. Wind Energy, v. 5, p. 151-169, 2002. Citado na página 5.

SOUZA, F. M. de; OLIVEIRA, T. F.; JUNIOR, A. C. P. B. Estudo experimental de um modelo reduzido de turbina hidrocinÉtica. 16 $6^{\circ}$ POSMEC, 2006. Citado na página 3.

VRIES, D. Fluid dynamic aspects of wind energy conversion. AGARD-AG-243, 1979. Citado na página 4.

WILCOX, D. C. Reassessment of the scale-determining equation for advanced turbulence models. AIAA Journal, American Institute of Aeronautics and Astronautics, v. 26, n. 11, p. 1299-1310, nov. 1988. ISSN 0001-1452. Citado na página 27.

WILSON, R. E.; LISSAMAN, P. B. S. Applied aerodynamics of wind-power machines. Corvallis, OR: Oregon State University, 1974. Citado na página 4.

YUCE, M. I.; MURATOGLU, A. Hydrokinetic energy conversion systems: A technology status review. Renewable and Sustainable Energy Reviews, v. 43, n. 0, p. 72 - 82, 2015. ISSN 1364-0321. Citado na página 1. 


\section{APÊNDICE A - Elementos geométricos da pá}

Tabela 10 - Dados da geometria da pá.

\begin{tabular}{ccc}
\hline Corda $[\mathrm{mm}]$ & Torção[rad] & Raio[mm] \\
\hline 26.0 & -1.57 & 40.7 \\
26.0 & -1.57 & 65.7 \\
27.0 & -1.53 & 90.7 \\
30.5 & -1.50 & 140.7 \\
35.1 & -1.47 & 190.7 \\
41.0 & -1.46 & 240.7 \\
49.6 & -1.44 & 290.7 \\
62.9 & -1.41 & 340.7 \\
82.3 & -1.33 & 390.7 \\
105.1 & -1.21 & 440.7 \\
121.3 & -1.17 & 483.0 \\
10.7 & 0.03 & 515.0 \\
11.5 & 0.01 & 515.0 \\
\hline
\end{tabular}

Figura 45 - Aerofólio da turbina

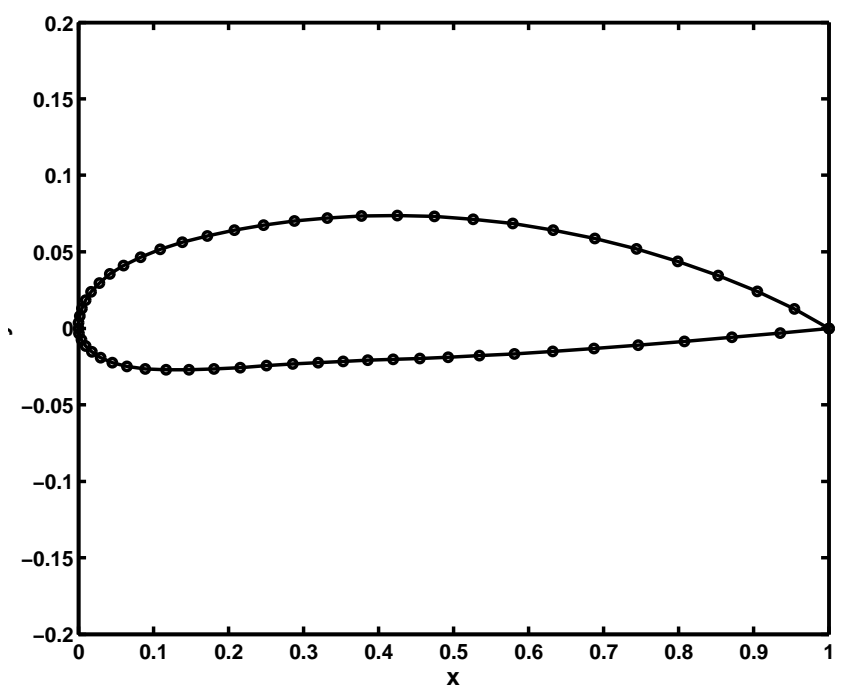




\section{APÊNDICE B - Calibração dos sensores}

Tabela 11 - Coeficientes das equações de ajuste de curvas utilizados na calibração do gerador.

\begin{tabular}{cccc}
\hline Carga & $a$ & $b$ & $R^{2}$ \\
\hline $20 \%$ & 0.0038 & -0.0123 & 0.9369 \\
$30 \%$ & 0.0129 & -0.0532 & 0.9408 \\
$40 \%$ & 0.0358 & -0.1659 & 0.9963 \\
$50 \%$ & 0.0507 & -0.2375 & 0.9873 \\
$60 \%$ & 0.062 & -0.2646 & 0.9965 \\
$70 \%$ & 0.0744 & -0.3192 & 0.9800 \\
$80 \%$ & 0.1228 & -0.5347 & 0.9984 \\
$90 \%$ & 0.1587 & -0.6897 & 0.9982 \\
$100 \%$ & 0.2526 & -1.1051 & 0.9979 \\
\hline
\end{tabular}

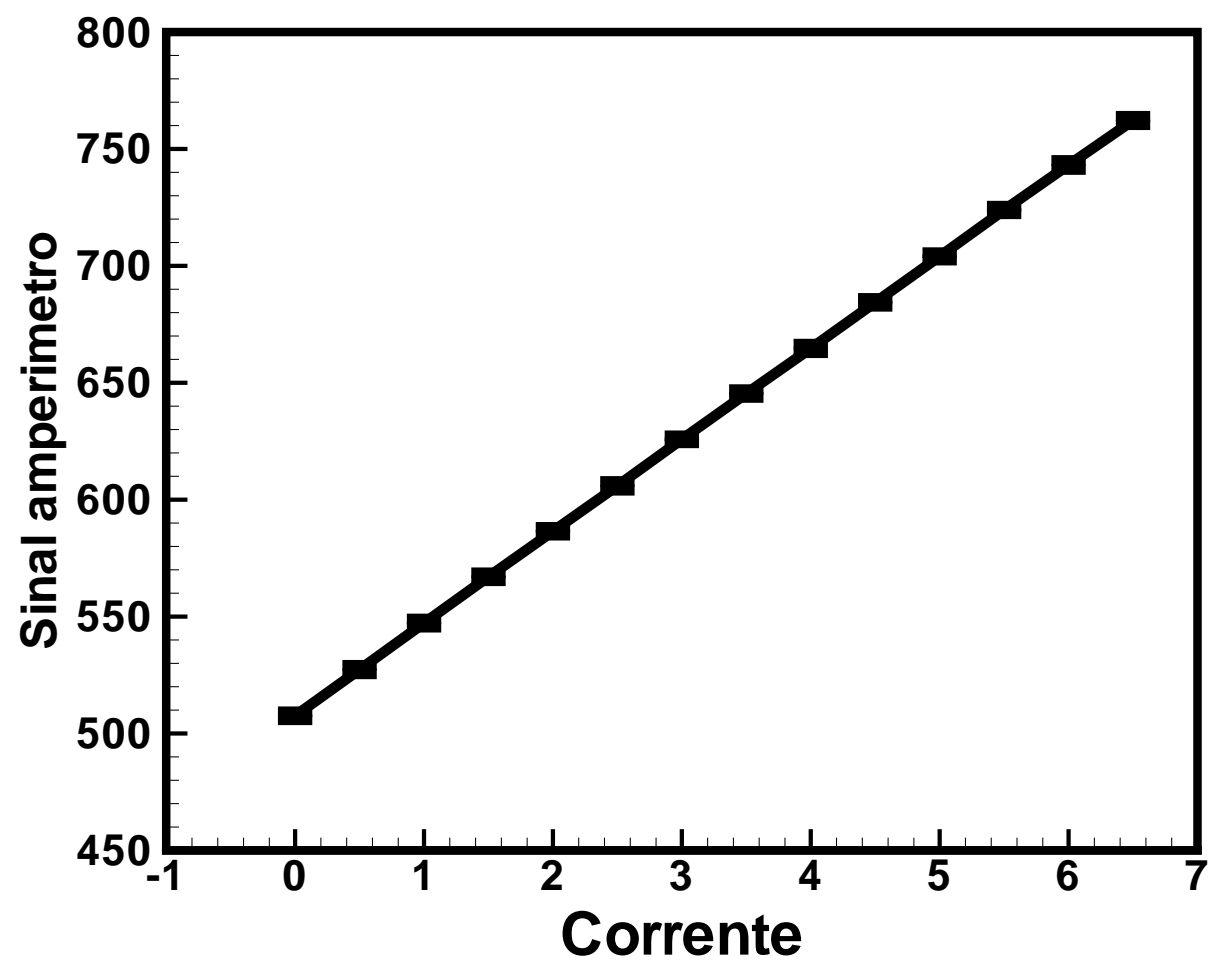

Figura 46 - Sensor de corrente $y=0.025 x-12.95$ 


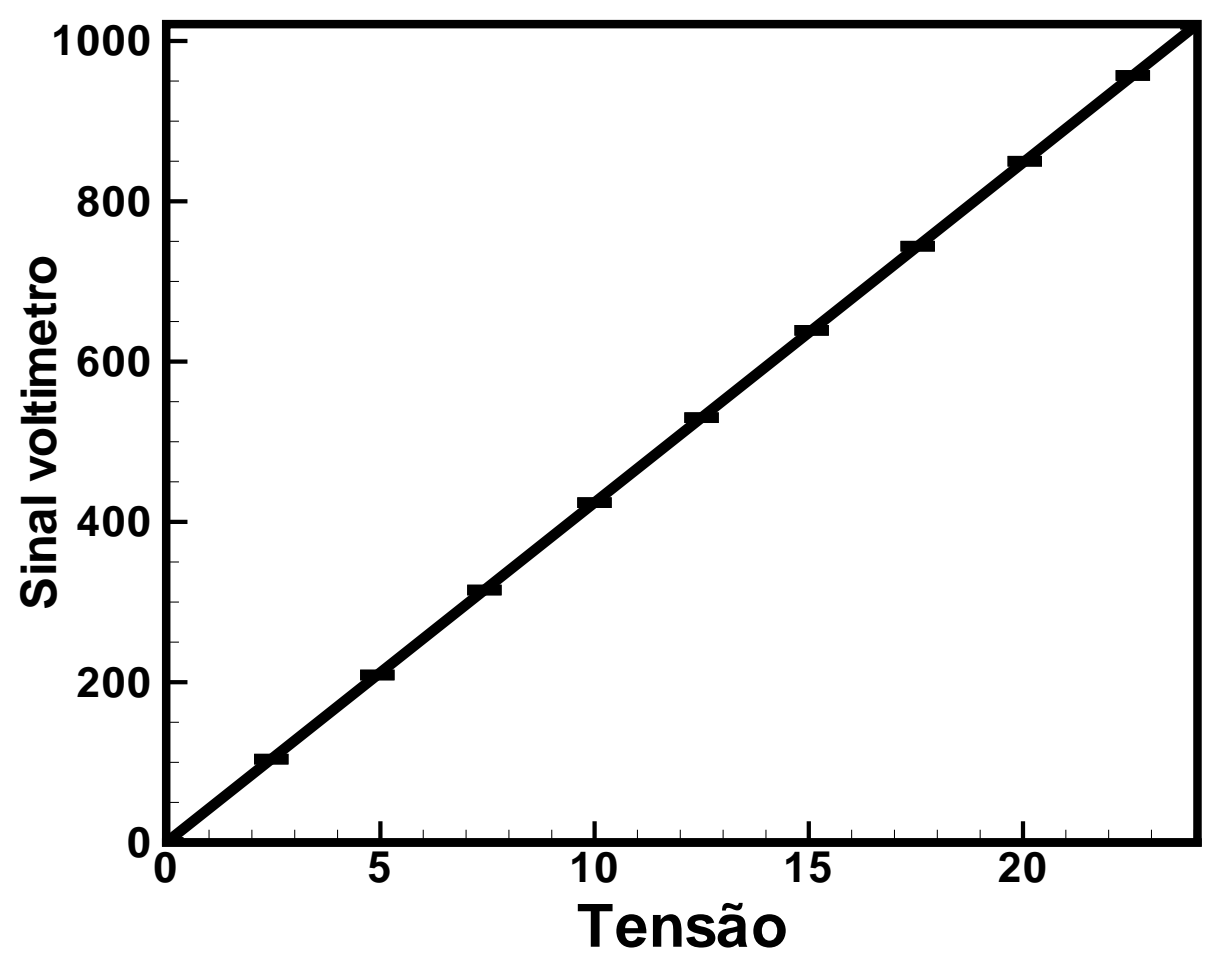

Figura 47 - Sensor de Tensão $y=0.0234 x+0.0654$

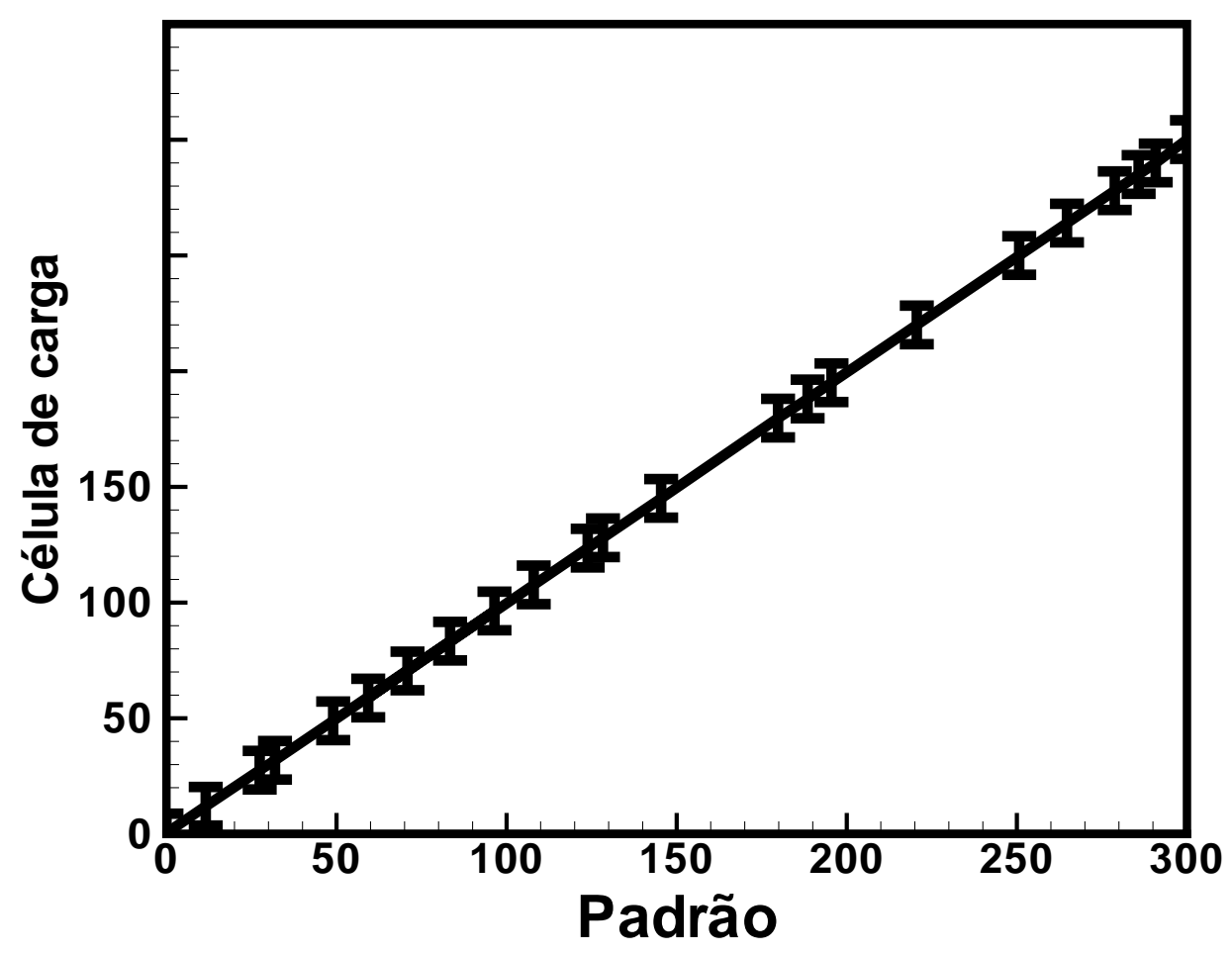

Figura 48 - Calibração da célula de carga $y=1.0026 x-0.0909$ 


\section{APÊNDICE C - Propagação de incertezas}

As incertezas desse trabalho são dadas pela soma das incertezas instrumental e aleatória. Nos sensores digitais, as incertezas instrumentais são determinadas pelo valor da menor escala medida pelo sensor e nos analógicos pela metade da menor escala. Já as incertezas aleatórias foram definidas como sendo igual ao desvio padrão calculado sobre um conjunto de ensaios realizados nas mesmas condições. Todas as incertezas dos ensaios podem ser escritas em função das incertezas dos seguintes sensores: célula de carga, sensor de velocidade, voltímetro e amperímetro:

$$
\begin{aligned}
V & =\bar{V} \pm \sigma V ; \\
I & =\bar{I} \pm \sigma I ; \\
\omega & =\bar{\omega} \pm \sigma \omega ; \\
F & =\bar{F} \pm \sigma F ;
\end{aligned}
$$

A medida to torque é proveniente da medida de força multiplicada por um braço de comprimento $x$, sendo que

$$
\sigma T=x F .
$$

Nos ensaios de calibração do gerador, tem-se que

$$
\begin{gathered}
\sigma P_{\text {mec }}=\omega T \sqrt{\left(\frac{\sigma \omega}{\omega}\right)^{2}+\left(\frac{\sigma T}{T}\right)^{2}} \\
\sigma P_{\text {ele }}=V I \sqrt{\left(\frac{\sigma V}{V}\right)^{2}+\left(\frac{\sigma I}{I}\right)^{2}} \\
\sigma \eta=\frac{V I}{\omega T} \sqrt{\left(\frac{V I \sqrt{\left(\frac{\sigma V}{V}\right)^{2}+\left(\frac{\sigma I}{I}\right)^{2}}}{V I}\right)^{2}+\left(\frac{\omega T \sqrt{\left(\frac{\sigma \omega}{\omega}\right)^{2}+\left(\frac{\sigma T}{T}\right)^{2}}}{\omega T}\right)^{2}} .
\end{gathered}
$$

No ensaio da turbina no túnel de vento, pretende-se obter a potência mecânica por meio da medida da potência elétrica e da utilização do valor de rendimento $\eta$ do ensaio do gerador, sendo

$$
P_{m e c}=\frac{P_{e l e}}{\eta},
$$

e o erro pode ser calculado como

$$
\sigma P_{\text {mec }}=\frac{P_{\text {ele }}}{\eta} \sqrt{\left(\frac{\sigma P_{\text {ele }}}{P_{\text {ele }}}\right)^{2}+\left(\frac{\sigma \eta}{\eta}\right)^{2}}
$$


sendo o $\sigma P_{\text {ele }}$ definido pela Equação C.7 e o $\sigma \eta$ pela Equação C.8.

Para o cálculo do $\sigma C p$ só foi levado em conta o erro $\sigma P_{m e c}$. Os demais erros, $\sigma \rho, \sigma U$ e $\sigma A$, não foram considerados, pois eles só foram medidos uma única vez, e por isso só apresentam erros instrumentais, sendo estes muito menores que os erros $\sigma P_{m e c}$.

$$
\sigma C p=\frac{\sigma P_{m e c}}{0,5 \bar{\rho} \bar{A} \bar{U}^{3}}
$$

